号

Design of a Synchrotron Radiation Detector for the Test Beam Lines at the Superconducting Super Collider Laboratory

Superconducting Super Collider Laboratory
SSCL-656

January 1994

Distribution Category: 414

R. D. Hutton

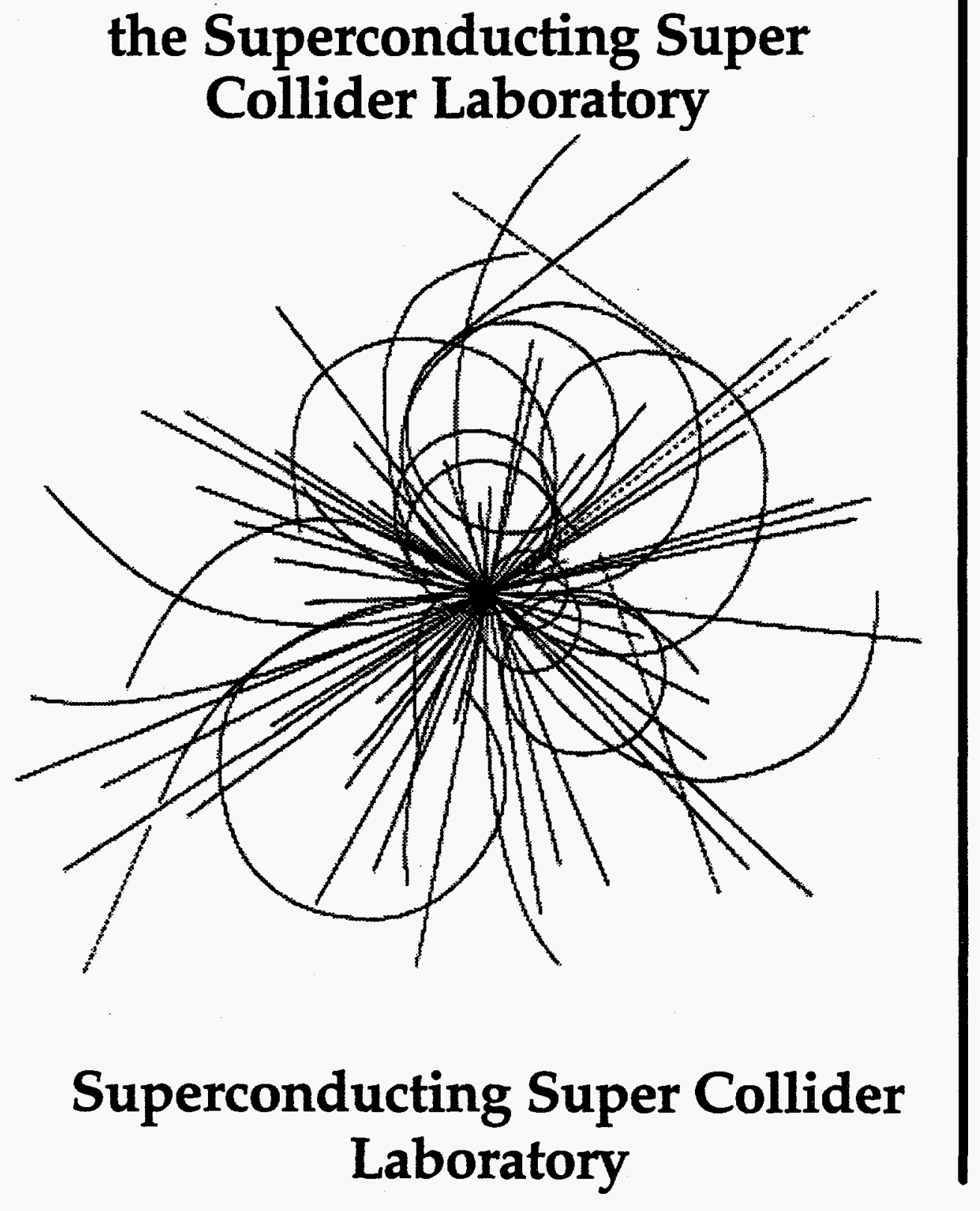

APPROVED FOR RELEASE OR

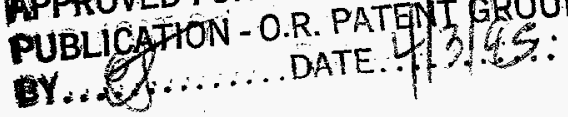




\section{Disclaimer Notice}

This report was prepared as an account of work eponsored by an agency of the United Stalas Govemment. Neither the United States Govemment or any agency thereof, nor any of their employeses, makes any warranty, expreas or impliad, or ascumes any legal tiability or responsibility for the accuracy, completencess, of usofulnese of any information, epparatus, product, of process disclosed, or represents that ths use would not intringe privately owned rights. Reference herein to eny specilic commercial product, process, or service by trade name, trademank, manutacturer, or cthenwise, does not necesesarily constitute or imply lis endoreement, recommendation, or favoring by the United States Govemment or any agency thereof. The views and opinions of authors expressed herein of not necessarily state or refiect those of the United Stales Govemment or any agency thereot.

Superconducting Super Collider Laboratory is an equal opportunity employer. 


\section{DISCLAIMER}

Portions of this document may be illegible in electronic image products. Images are produced from the best available original document. 
SSCL-656

\title{
Design of a Synchrotron Radiation Detector for the Test Beam Lines at the Superconducting Super Collider Laboratory
}

\author{
R. D. Hutton
}
Superconducting Super Collider Laboratory*
2550 Beckleymeade Ave.
Dallas, TX 75237

January 1994

\footnotetext{
* Operated by the Universities Research Association, Inc., for the U.S. Department of Energy under Contract
} No. DE-AC35-89ER40486. 


\subsection{INTRODUCTION}

As part of the particle- and momentum-tagging instrumentation required for the test beam lines of the Superconducting Super Collider (SSC), the synchrotron radiation detector (SRD) was designed to provide electron tagging at momentum above $75 \mathrm{GeV}$. In a parallel effort to the three test beam lines at the SSC, schedule demands required testing and calibration operations to be initiated at Fermilab. Synchrotron radiation detectors also were to be installed in the MP and MW beam lines at Fermilab before the test beam lines at the SSC would become operational.

The SRD is the last instrument in a series of three used in the SSC test beam lines. It follows a 20-m drift section of beam tube downstream of the last silicon strip detector. A bending dipole just in front of the last silicon strip detector produces the synchrotron radiation that is detected in a $50-\mathrm{mm}$-square cross section NaI crystal. A secondary scintillator made of Bicron BC-400 plastic is used to discriminate whether it is synchrotron radiation or a stray particle that causes the triggering of the Nal crystal's photomultiplier tube (PMT).

\subsection{DESIGN REQUIREMENTS}

When the test beam spill is commenced from the Medium Energy Booster during the beam line operation, the beam profile is oval in shape, and has four sigma measurements of a vertical minor axis of $40 \mathrm{~mm}$ and a horizontal major axis of $76 \mathrm{~mm}$. The bend angle of $7.6 \mathrm{mrad}$ produces a spray of synchrotron light to be detected $20 \mathrm{~m}$ downstream of the bend center, as illustrated in Figure 1. The SRD must provide a clear aperture for this radiation and for the beam particles, and must be "tune-able" from a remote location to optimize the output of the scintillators. The SSC beam profile presented a larger aperture requirement than did either of Fermilab's MW or MP lines such that it became the limiting sizing factor.

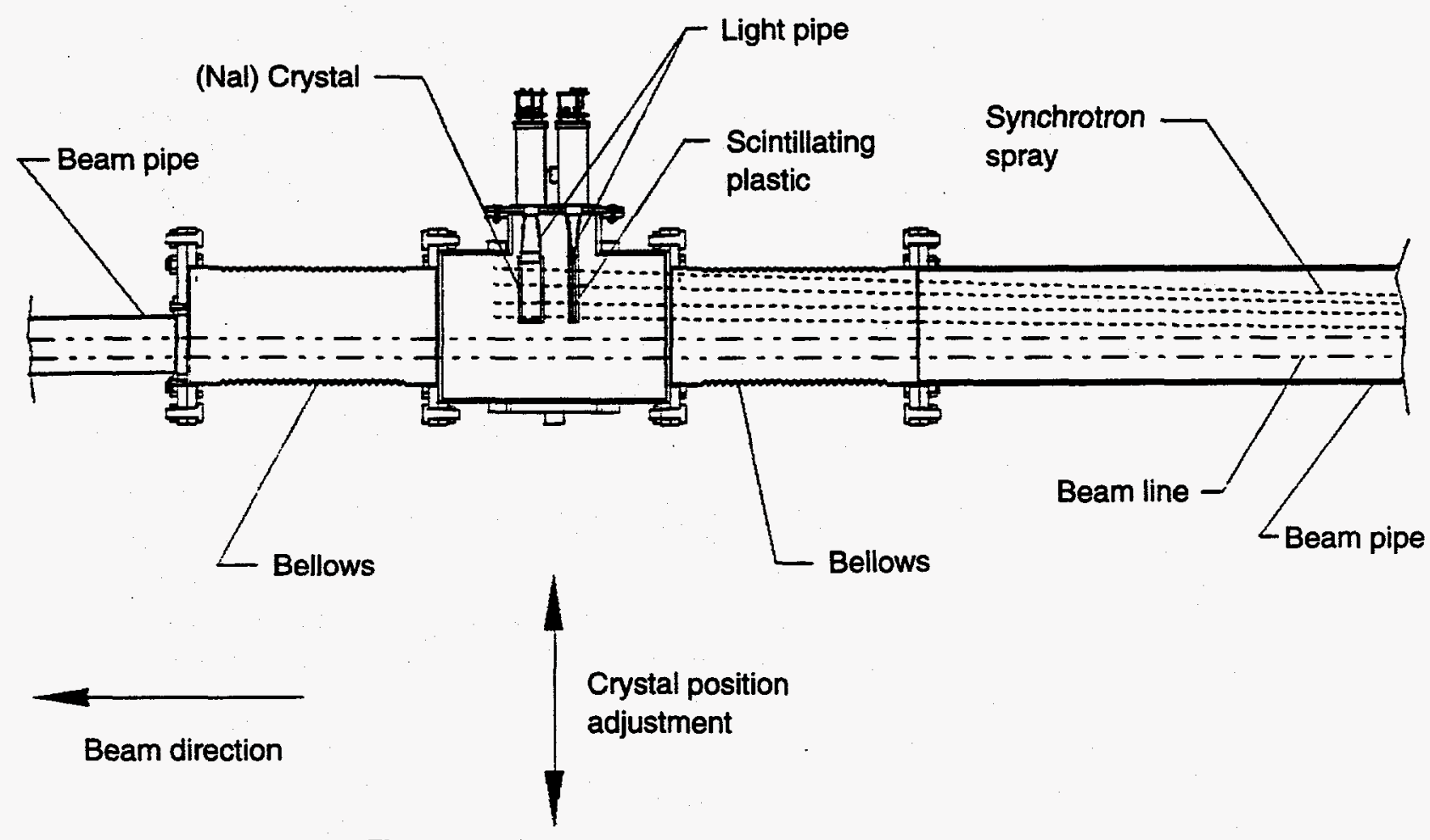

Figure 1. Synchrotron Radiation Detector (Side View). 
An automated motion requirement of $\pm 25-\mathrm{mm}$ travel in the horizontal direction perpendicular to the beam was specified. This was to be controllable through common computer equipment and standard communications interfaces. To minimize vessel size and to prevent heating and voltage breakdown problems, the PMTs and their electronics were to be located outside the beam line vacuum. To maximize photon transmission and, therefore, signal, scintillators were to be in the vacuum. This required a vacuum-tight seal that also transmitted the scintillation light. A circumferential O-ring seal on the light pipe had to be developed and tested to ensure its functionality in this application.

Radiation exposure to the device is minimal due to the slow spill beam extraction used in the test beam operation. Therefore, O-ring seals could be used at all vacuum interfaces, and the expected 25 -yr life of the device would not be adversely affected. A final requirement of the SRD was to have the design standardized so that it could be installed at either the SSC or Fermilab with little or no modification necessary.

\subsection{DESIGN SOLUTION AND SPECIFICATIONS}

\subsection{Mechanical}

The synchrotron radiation detector is shown in Figure 2, without its motion/alignment base and without a stand. The figure shows the enlarged beam pipe on the upstream side of the SRD, which allows clear aperture for the synchrotron radiation. The scintillators are shown in position, but their restraining clamps have been omitted for clarity. Two Phillips PMT bases (part number S563) are mounted on the T-section flange plate. The O-ring seal is at the point where the light pipe passes through the flange plate. Motion of the scintillators is effected by a global motion of the SRD body, which is mounted on linear bearings and is moved via a stepper motor-controlled lead screw. Compliance with the interfacing beam tubes is allowed by bellows on either end of the SRD body.

The body of the SRD was chosen to be 12-in., schedule 5S, 304 austenitic stainless steel pipe. This cross section yields a 316-mm internal diameter which, when allowing for tolerances and the motion requirements, leaves a clearance of approximately $15 \mathrm{~mm}$ per side from the beam and resulting synchrotron radiation. An 8-in., schedule 5S, 304 SS pipe is fit and welded to form the T-section. The cradle base of the SRD is welded to the main body and is also made from 304 stainless steel. Machining of thick interface pads on the bottom of the cradle base assures that the linear bearing blocks mate perpendicular to the centerline of the body and the T-flange, and are at the proper distance from centerline. Stainless steel was chosen for its weldability, cleanliness, resistance to corrosion, and cost savings due to its lack of required maintenance over its life requirement of $25+\mathrm{yr}$.

The two photomultiplier bases are mounted to the T-section flange plate using an adapter fiange. The adapter flange (dwg. no. R70-000013) has an M75 $\times 1.5$ thread on its outer diameter onto which the PMT base can be threaded. A neoprene gasket provides a light seal against the face of the flange and is a standard application in the use of the base. The opposite side of the adapter flange provides the lip profile, which crushes the O-ring seal down around the round cross section of the light pipe. This seal profile was fully examined by the SSC Physics Research Division Vacuum Support Group. Calculations and test results are attached to this report. The T-section flange plate is aligned to the mating flange on the SRD body using a diamond and a round pin. The alignment pins allow the flange plate to be removed for service, transportation, or any number of reasons, and they allow the flange plate to be reinstalled without necessitating any subsequent alignment or tuning of the SRD. 


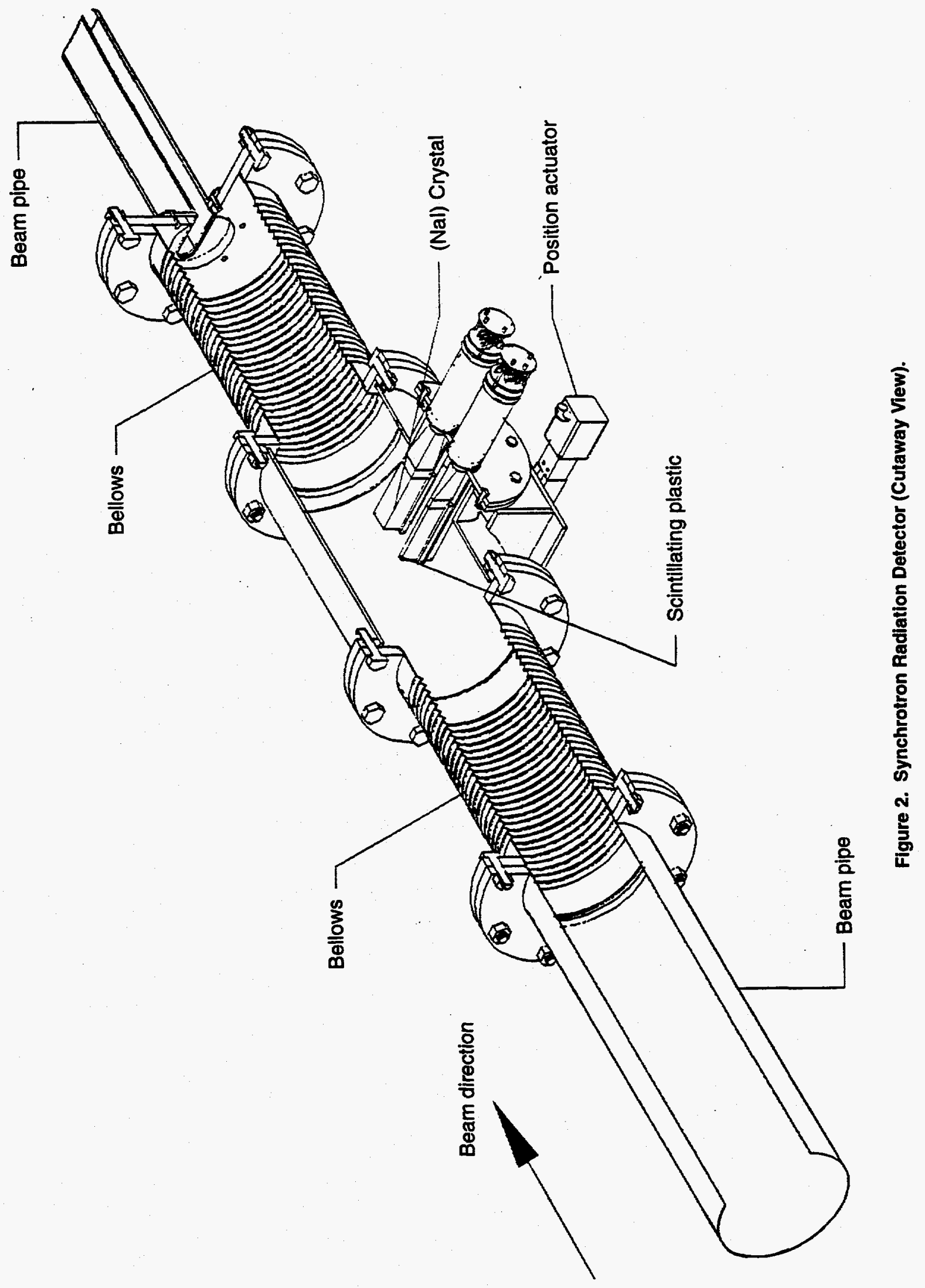


Registration of the scintillators is achieved through brackets attached to the T-section flange plate. Each aluminum bracket has a shallow groove machined down its length, just larger that the width of its scintillator. At the point where the bracket attaches to the flange plate is a ring clamp that secures the light pipe. When the assembly is made up, the light pipe is inserted through the hole in the plate, and the scintillator is positioned a calculated distance from the surface of the flange plate and is temporarily secured. An optical glue joint is made between the light pipe and scintillator, and the clamp is tightened. Once the glue has set, the entire clamp-scintillator-light pipe assembly can be wrapped with light shielding. The length of the circular cross section of the light pipe is not correct on the prints as shown. The required length will be determined by the PMT chosen.

The motion system consists of off-the-shelf components. The linear bearings are from the Thompson Industries, Inc., catalog. A double shaft system, 3/4-in. diameter, with super ball bushing bearing pillow blocks, was chosen (part number 1CB-12-HAO, 12-in. length). The linear actuator was chosen from Industrial Devices, Inc., which provides a turnkey system incorporating a Compumotor, Inc., stepper motor and controller with a lead screw actuator. The motor/actuator configuration, its mounting orientation, and the actuator end are specifiable from a number of options. The system chosen for the SRD is part number NH998A-2-MS6-FS2-PB-Q-ZH. This provides for a low profile actuator with an in-line motor with 2 in. of stroke on an 8 threads/in. acme screw that is mounted on its side with screws; it has a spherical joint rod end, a protective boot to keep contaminants out of the screw, and a quick-disconnect electrical connection, and it is equipped with an encoder and a home position sensor. The controller chosen was the H3951, which has encoder feedback capability and can communicate with a host computer through an RS232 serial interface. Appropriate pages from the vendor catalogs are attached.

The bellows were not bid, but design iterations were done with John Crane/Belfab, Inc. Primary design considerations were the minimization of axial beam line length used and minimization of the bellow's lateral spring rate to keep the load on the actuator within design limits. Two different size bellows are to be used, despite what is shown in Figure 2. Non-symmetrical vacuum loads are produced at the SRD because there is a large-diameter beam tube upstream and a small-diameter beam tube downstream. Rather than have facility people design load-carrying supports at each SRD installation, the SRD was designed to react to those loads itself and, therefore, to be innocuous to its interface connections. The flanges on the bellows are an ISO F-style (bolted) at the SRD connections, and an ISO K-style (clamped) at the beam tubes. This prevents difficulties with interface mismatch with hole locations in the tunnel installation. The drawings on the bellows and the SRD assembly drawing do not reflect the final design iterations. The final specifications on the bellows are listed in Table 1.

Table 1. Bellows for the SRD.

\begin{tabular}{|l|l|l|}
\hline Design Parameter & Upstream End & Downstream End \\
\hline Bellows type & Edge welded & Edge welded \\
\hline Material, stainless steel & $316 \mathrm{~L}$ & $316 \mathrm{~L}$ \\
\hline Internal diameter (in.) & 12.60 & 6.625 \\
\hline Outer diameter (in.) & 13.90 & 7.625 \\
\hline Material thickness (in.) & 0.005 & 0.006 \\
\hline Number of plies & 2 & 1 \\
\hline Number of convolutions & 50 & 70 \\
\hline Free length (in.) & 7.00 & 6.25 \\
\hline Lateral spring rate (ft lb/in.) & 75.6 & 40 \\
\hline Axial spring rate (ft lb/in.) & 14 & 18.6 \\
\hline Minimum lateral offset (in.) & \pm 1.0 & \pm 1.0 \\
\hline Minimum axial offset (in.) & \pm 0.125 & \pm 0.125 \\
\hline External pressure differential (psi) & 15 & 15 \\
\hline Minimum required cycles & 100 & 100 \\
\hline
\end{tabular}




\subsection{Vacuum Specifications}

The vacuum level at the SRD was to be in the $10 \mathrm{E}-03$ Torr range, resulting from the pumping of Roots blowers installed at WP 10 . Some back-streaming of pump oil was likely, but was not expected to be a significant problem downstream. The leak-tightness requirement of the vessel is that achieved with the standard application of O-ring seals at each of the locations in the design. Tighter sealing systems were not required.

The O-ring seal around the light pipe was designed to be a "crush" seal, providing an approximately 95\% fill of the gland volume. A Parker fluorocarbon compound, number V747-75, was chosen for its chemical inertness against Lexan polycarbonate and its lower permeability to helium compared to the other compounds tested against Lexan. The chemical inertness of the compound against acrylic light pipe material was tested, as was the ability to provide an acceptable seal. The seal design was successful for sealing vacuum, but there was some crazing of the light pipe from the O-ring compound. The test report is attached to this document.

Cleaning and leak check specifications were taken from Accelerator Division documents: Vacuum Leak Test, No. AMA-3210088, and Cleaning Vacuum Components, No. AMA-3210086. These process specifications were to be used in their entirety.

Two vacuum access ports are provided on the body of the SRD. These can be used for a variety of purposes. Vacuum pump-down in the lab during system check-out and vacuum monitoring in the tunnel installation were the main uses foreseen.

\subsection{Safety Specifications}

A major function of the SRD is containment of beam line vacuum. Due to the implosive nature of large vacuum volumes, safety codes exist to govern the design of vacuum vessels. Fermilab's codes were in place and were centered around the Compressed Gas Association's Standard for Insulated Cargo Tank Specification for Cryogenic Liquids, number CGA-341-1987. Within that standard is a section that covers the outer vacuum shell of a cargo tank; the SRD's physical parameters easily met those guidelines. Even with this standard satisfied, the Fermilab safety code number 5033 eliminated any special requirements other than sound engineering design, because the vessel volume was well below the $35-\mathrm{ft}^{3}$ threshold set forth in 5033. Copies of both of these items are attached.

The safety code for vacuum vessels at the SSC had not been developed at the time the SRD was designed and was to be produced. Meetings with Laboratory safety officers yielded the decision to design the vessel according to the practices of the ASME Boiler and Pressure Vessel Code, Section VIII, Division 1. Adherence to the code was to stop short of having ASME-approved inspectors witness and certify the fabrication of the vessel, but all other documentation was to be preserved. Code calculations performed by the Physics Research Division's Analysis Group are attached to this document.

\subsection{Electrical Specifications}

Electrical requirements were the least developed of all the design issues. PMT high-voltage and signal connections are very commonplace and did not need special attention. Standard high-voltage power supplies and data acquisition modules are required for the PMTs. Any vacuum-monitoring transducer connections would need to be provided for.

The stepper motor is the only other electrical device associated with the SRD. The motor controller is the point for power input, which is required to be 95-132 VAC @ 50/60 Hz; $5 \mathrm{~A} \max , 10 \mathrm{~A}$ peak. The controller connects directly to the motor and encoder via a quick disconnect cable approximately $12 \mathrm{ft}$ in length. The motor runs on direct current, and there are some maximum cable length considerations for it and the encoder. An RS232 serial communication line to the controller also needs to be provided. 


\subsection{Interface Specifications}

As noted in Section 3.2, the beam pipe connections require a standard ISO K-style flange attached to the existing ends. No clocking or bolt hole requirement exists for the flanges; only the ISO sizes need be correct. Axial beam line clearance has not been specified due to the uncertainty of the bellows manufacturer and, therefore, the ultimate bellows length. Electrical interfaces are discussed in Section 3.4.

Alignment of the SRD remains the final design issue. At the SSC, the alignment group preferred the use of spherically mounted targets as a standard equipment specification. Four spherical cups were to be mounted to the body of the SRD, two on either side body of the SRD at $45^{\circ}$ from vertical, with as much axial distance between them as possible. The drawings show an earlier concept with the cups mounted on the T-section flange plate, but the body location affords installation and alignment without the sensitive components needing to be in place.

The alignment plate had yet to be sent through the alignment group for approval, but the design is similar to another installation at the SSC. It uses bronze jack bolts at six locations, three of which are used to set height and tilt in two axes. The three screws are used exactly as any other three-point system would be, and the other three bolts are for added stiffness once the three primary bolts are secured. Slots in the jack bolt mounting plates allow for movement transversely to the beam line and also permit some rotation about the vertical axis. Adjustment in the axial direction, parallel to the beam line, was not considered critical, and initial survey placement of the device is sufficient. The stand design shown in drawing number R70000029 is generic and can differ in height depending on final installation requirements.

\section{ACKNOWLEDGMENTS}

The success of this device is due to the combined insight and experience of several persons. Howard Fenker provided the design requirements and project motivation. Ken Schlindwein provided hard knocks design applications experience and maintained the schedules. Kelley Bramble was responsible for the design details and drawings, and Sanyi Zheng for the vacuum calculations and testing. Electrical support was provided by Tom Regan, and vacuum test pieces were manufactured by the Physics Research Division shop personnel. 
ATTACHMENTS 
-

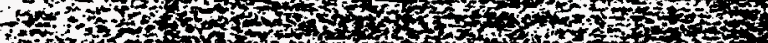

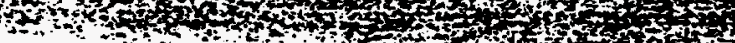

$$
\text { Pat }
$$

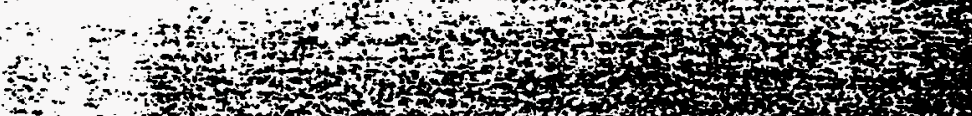

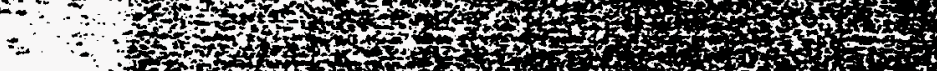

\section{-20 -}

-

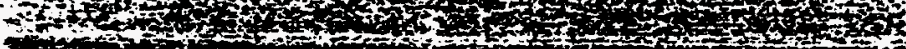

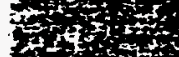

$$
\text { s. }
$$

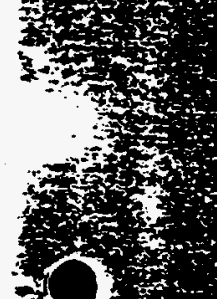

(1) $\frac{2}{2}$

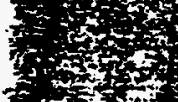

s.t.

(3)

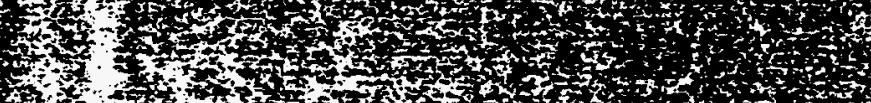

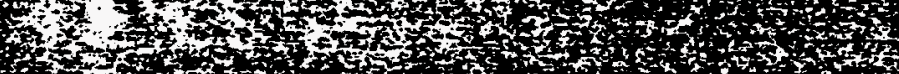

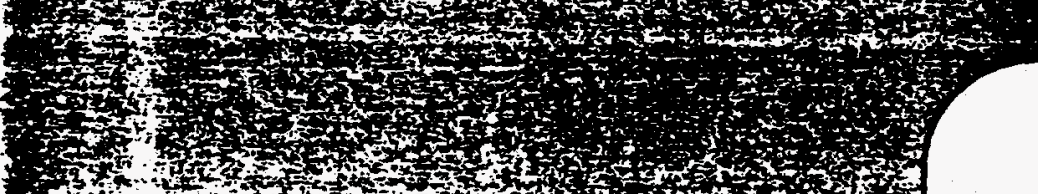

4 (3)

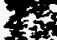

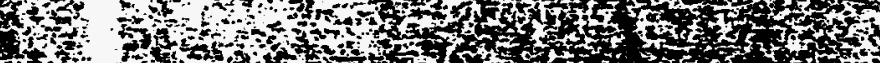

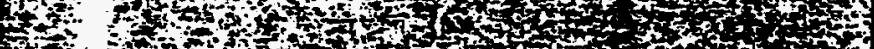

4.

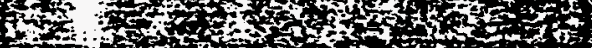

to $3 x+2$

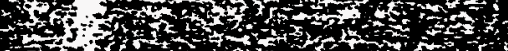

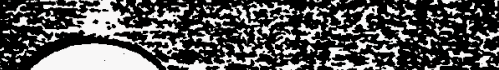

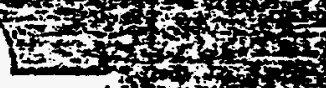

DEPT

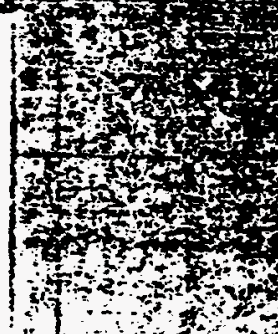

TP761

.065

C341

c.3

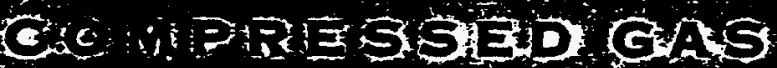

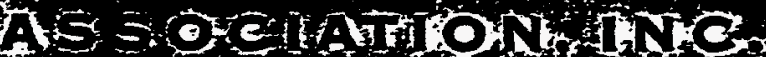

STANDARD FOR INSULATED CARGO TANK SPECIFICATION FOR CRYOGENIC LIQUIDS

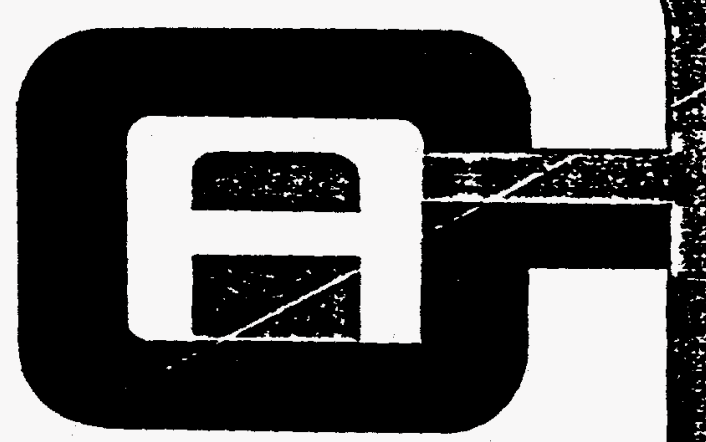

sisinges

\section{$-1987$}

.t.

3

1.

5

(1)

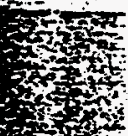

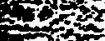

atso

par

Stot

intax

ons

s.

sit

t

f?

and

$+2$

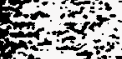

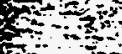

i.

㴗

$x=$

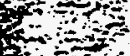

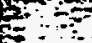

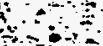

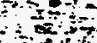

$+1$

$1+$

and

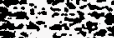

- -2

(x) . 烈 


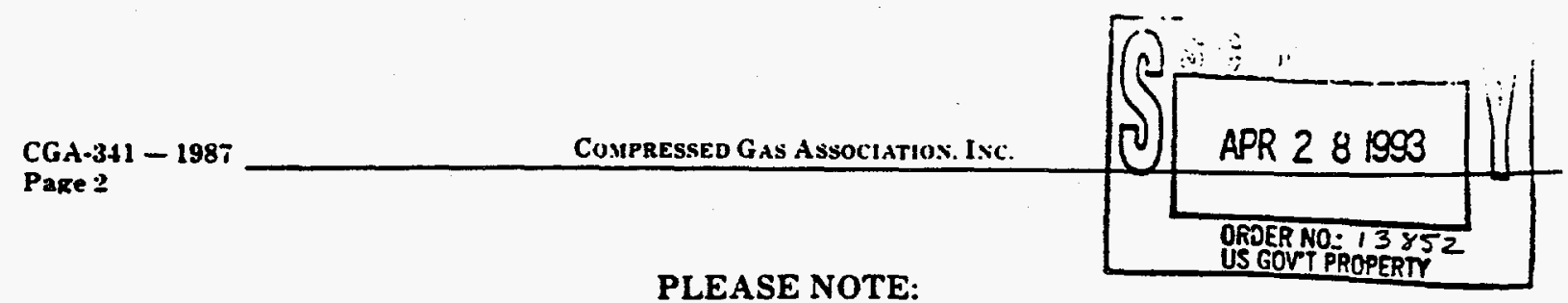

\section{PLEASE NOTE:}

The information contained in this document was obtained from sources believed to be reliable and is based on technical information and experience currently available from members of the Compressed Gas Association. Inc. and others. However, the Association or its members, jointly or severally, make no guarantee of the results and assume no liability or responsibility in connection with the information or suggestions herein contained. Moreover, it should not be assumed that every acceptable commodity grade, test or safety procedure or method, precaution, equipment or device is contained within, or that abnormal or unusual circumstances may not warrant or suggest further requirements or additional procedure.

This document is subject to periodic review and users are cautioned to obtain the latest edition. Comments and suggestions are invited from all users for consideration by the Association in connection with such review: any such comments or suggestions will be fully reviewed by the Association after giving the party, upon request. a reasonable opportunity to be heard.

This document should not be confused with federal, state, provincial, or municipal specifications or regulations. insurance requirements or national safety codes. While the Association recommends reference to or use of this document by government agencies and others, this document is purely voluntary and not binding.

THIRD EDITION: 1987

COPYRJGHT • 198Z BY THE COMPRESSED CAS ASSOCIATION. INC

I233 JEFFERSON DAVIS HIGHWAY. ARLINGTON, VA. 202

$$
\text { Printed in U.S.A. }
$$


1. INTRODUCTION

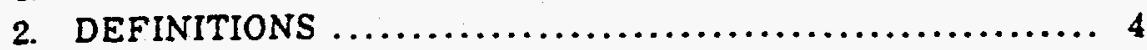

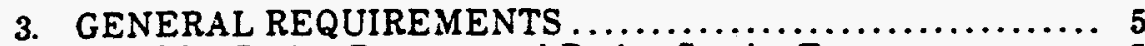

3.1 CGA Design Pressure and Design Service Temperature ...... 5

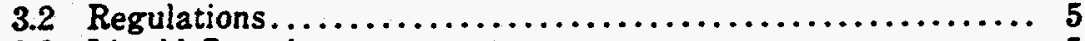

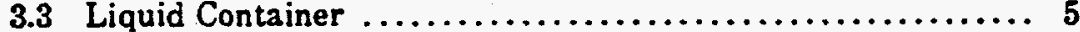

3.4 Inner Support System. $\ldots \ldots \ldots \ldots \ldots \ldots \ldots \ldots \ldots \ldots \ldots \ldots \ldots, 5$

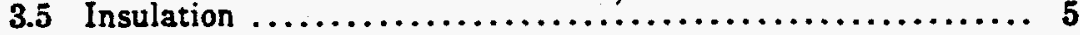

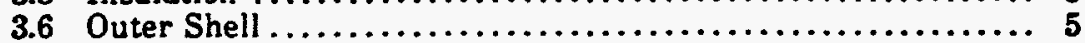

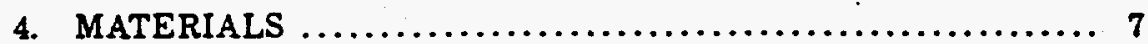

4.1 Liquid Container $\ldots \ldots \ldots \ldots \ldots \ldots \ldots \ldots \ldots \ldots \ldots \ldots \ldots, 7$

4.2 Other Components $. \ldots \ldots \ldots \ldots \ldots \ldots \ldots \ldots \ldots \ldots \ldots \ldots, 8$

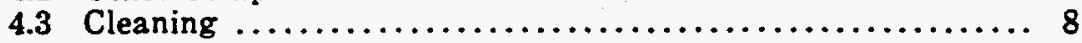

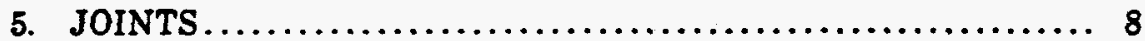

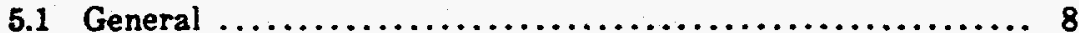

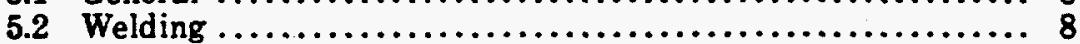

5.3 Location $. . \ldots \ldots, \ldots, \ldots, \ldots, \ldots, \ldots, \ldots, \ldots, \ldots, \ldots, 8,8$

5.4 Attachments..................................... 8

6. PIPING AND CONTROLS $\ldots \ldots \ldots \ldots \ldots \ldots \ldots \ldots \ldots \ldots \ldots \ldots, 8$

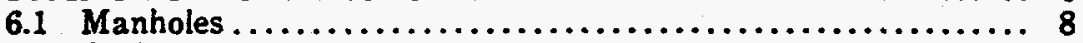

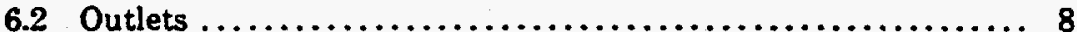

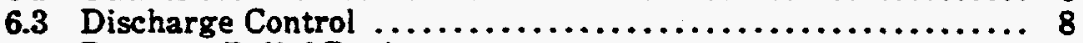

6.4 Pressure Relief Devices ............................. 8

6.5 Piping, Valves, and Fittings............................. 8

7. PROTECTION OF PIPING, VALVES, AND FITTINGS ........ 9

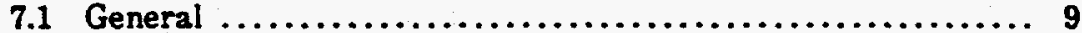

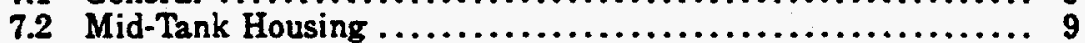

7.3 Protective Housing $. . \ldots \ldots \ldots \ldots \ldots \ldots \ldots \ldots \ldots \ldots \ldots \ldots, \mathbf{9}$

7.4 Rear Bumper ........................................... 9

8. SUPPORTS AND ANCHORING $\ldots \ldots \ldots \ldots \ldots \ldots \ldots \ldots \ldots \ldots, 9$

8.1 Cargo Tank with Frame.................................. 9

8.2 Frameless Cargo Tank ............................. 9

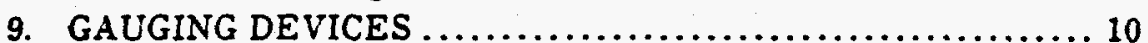

9.1 Level Gauging Devices ............................... 10

9.2 Pressure Gauges $\ldots \ldots \ldots \ldots \ldots \ldots \ldots \ldots \ldots \ldots \ldots \ldots \ldots \ldots \ldots$

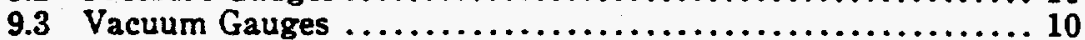

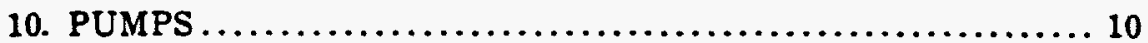

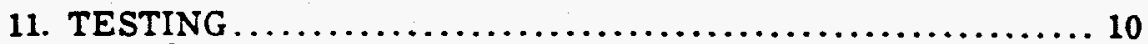

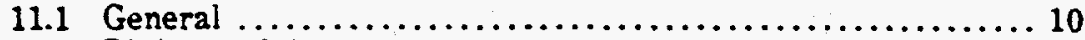

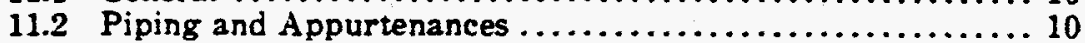

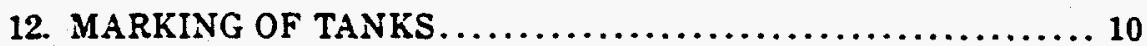

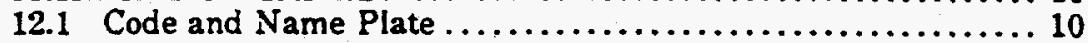

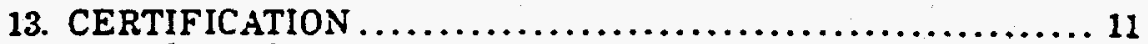

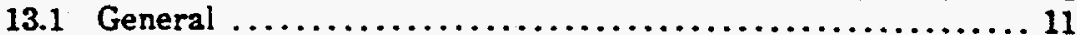

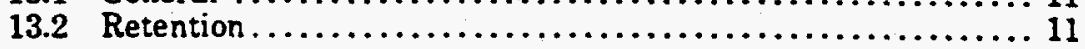

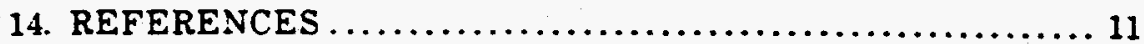

Tables

\section{LIST OF ILLUSTRATIONS}

1. Minimum Metal Thickness of Outer Shell.................. 5

2. Maximum Portion of Outer Shell to be Used in Computing Ring Section Modulus. 
CGA-3\$1 - 1987

CONPRESSED GAS ASSOCIATION. INC

Page 4

\section{COMPRESSED GAS ASSOCIATION SPECIFICATION CGA-341 INSULATED CARGO TANK FOR CRYOGENIC LIQUIDS}

\section{INTRODUCTION}

1.1 This cargo tank specification contains the suggested minimum guidelines for insulated cargo tanks intended for transportation of cryogenic liquids at pressures below 25.3 psig $(174.3 \mathrm{kPa})$ in the highway mode and, in the United States, not covered by Hazardous Materials Specification MC338 of the U.S. Department of Transportation (DOT) and other applicable sections of Title 49 of the U.S. Code of Federal Regulations. [1] ${ }^{1}$ In Canada. specification requirements for cargo tanks for refrigerated (cryogenic) liquids are promulgated by Transport Canada in the Transportation of Dangerous Goods Regulations. [2]

1.2 Specification CGA-341 provides a cargo tank with very efficient insulation and relatively low heat leak to the lading. It resembles an oversized thermos bottle in that the liquid container is supported in an approximately concentric manner within the outer shell, with insulation in the annular space. Thus, the outer shell is often the primary structural member anchored to the truck bed. or the tandem-fifth wheel of a cargo tank.

1.3 Specification CGA-341 cargo tanks are considered suitable for the transportation of liquid argon, helium, nitrogen, oxygen, and nonflammable cryogens.

\section{DEFINITIONS}

2.1 For the purpose of this standard the following terms are defined:

2.1.1 ASME Code. As used in this standard. AS.ME Code refers to the latest edition and addenda in effect at the date of manufacture of Section VIII. Division 1. "Pressure Vessels." of the AS.VEE Boiler and Pressure Vessel Code of the American Society of Mechanical Engineers. [3]

2.1.2 Cargo Tank. The assembled liquid container. insulation, support system and outer shell permanently mounted on or forming part of a road vehicle.

2.1.3 CGA Design Pressure. As used in this specification. CGA design pressure is identical to the term "maximum allowable working pressure" as used in the ASME Code. It is the maximum

NOTE: References in this document are indicated by bracketed numbers and are listed in the order of appearance. See Section 14. References. gauge pressure at the top of the liquid container in its operating position and should not be less than 25.3 psig $(174.3 \mathrm{kPa})$. To determine the minimum permissible thickness of the different parts of the liquid container. the static head of the lading shall be added to the CGA design pressure. If vacuum insulation is used, the liquid container must be designed for a pressure of $14.7 \mathrm{psia}(101.4 \mathrm{kPa})$ more than the CGA design pressure plus the static head of the lading.

2.1.4 Cryogenic Liquid. A liquefied gas having a boiling point colder than $-130^{\circ} \mathrm{F}\left(-90^{\circ} \mathrm{C}\right)$ at 14.7 psia $(101.4 \mathrm{kPa})$.

2.1.5 Design Service Temperature. This is identical to the minimum allowable temperature for which the liquid container is suitable as defined in paragraph UG-116 of the ASME Code. [3] The design service temperature must be $-320^{\circ} \mathrm{F}$ $\left(-196^{\circ} \mathrm{C}\right)$ : for liquid helium. the design service temperature must be $-452^{\circ} \mathrm{F}\left(-269^{\circ} \mathrm{C}\right)$.

2.1.6 Design Weight of Lading. The weight of the lading used in the design calculations for the liquid container, inner support system, outer shell. anchorage. etc. As a minimum, it must equal the actual weight of lading to be put in the cargo tank. but it may exceed this so that the cargo tank will be suitable for heavier ladings.

2.1.7 Insulation. A material of low thermal conductivity, surrounding the liquid container. which reduces the flow of heat to the liquid container. This insulation may or may not be evacuated.

2.1.8 Lading. The cryogenic liquid being transported in the liquid container.

2.1.9 Liquid Container. The inner tank (pressure vessel) which actually contacts and holds the lading.

2.1.10 Outer Shell. The outer metal housing around the insulation. This housing protects the insulation from moisture. It is often the primary structural member which serves as the frame of the cargo tank or is anchored to the frame of a truck.

2.1.11 Pressure Relief Device. A device intended to prevent rupture of a container. such as a liquid container or outer shell under certain conditions of exposure.

2.1.12 Ultimate Strength. The term ultimate strength has to do with the maximum stress a material can develop. This incorporates an account- 
ing of tensile, compressive, and torsional stress into one word. Ultimate strengths are usually stated in terms of the kind of stress producing the failure. Minimum ultimate means the minimum value of a range of ultimate strengths as determined by measurements.

\section{GENERAL REQUIREMENTS}

3.1 CGA Design Pressure and Design Service Temperature. See Section 2, Definitions.

\subsection{Regulations}

3.2.1 The cargo tank and its lading are subject to the following applicable regulations:

3.2.1.1 In the United States. Title 49 of the Code of Federal Regulations, (Transportation). [1]

3.2.1.2 In Canada, the Transportation of Dangerous Goods Regulations of Transport Canada as well as the Pressure Vessels Act and Regulations of the Provinces in which the cargo tank is used. [2]

\subsection{Liquid Container}

3.3.1 The liquid (pressure) container must be of welded construction and be designed. constructed. and stamped in accordance with and fulfill the requirements of the ASME Code. [3]

3.3.2 Local primary membrane stresses in the shell at the inner support system must be in accordance with UG-j4 of the ASME Code. Section VIII. Division 1. [3] The weight of the liquid container itself, the design weight of lading, and the articles supported by the liquid container must be considered using the forces as described in 3.4.1. The allowable stress value for the combined primary membrane stress and local primary membrane stress* shall not exceed 1.25 times the maximum allowable stress value as prescribed by the ASME Code. Section VIII. Division 1, at a temperature of $100^{\circ} \mathrm{F}\left(38^{\circ} \mathrm{C}\right)$. [3]

-NOTE: Refer to Appendix $t$ of the ASME Code. Section VIII. Division 2. for definitions.
3.3.3 Design details that permit the collection and retention of cleaning materials or contaminants should be avoided. Designs that permit the flushing of all surfaces by the normal sloshing of the cryogenic liquid are preferred.

\subsection{Inner Support System}

3.4.1 The liquid container must be supported within the outer shell by members designed to withstand minimum static loadings of:
(a) vertical downward of 2.0
(b) vertical upward of $\mathbf{1 . 5}$
(c) longitudinal of 1.5
(d) lateral of 1.5

times the weight of the liquid container and attachments when filled to the design weight of lading using a safety factor of not less than four (4) based on the room temperature minimum ultimate strength of the material used.

3.4.2 The design weight of lading used in determining the loadings in 3.3 .1 and 3.4 .1 must be shown on the markings required by 12.1 and on the report required by 13.1 .

3.5 Insulation. The surface of the liquid container must be insulated. Insulating material must not be subject to corrosive attack by the expected contents of the tank. Insulating material for cargo tanks for oxygen service must not sustain combustion when contacted with a glowing platinum wire in a 99.5 percent oxygen atmosphere at atmospheric pressure. Containers so insulated shall be marked with the words: INSULATION FOR OXYGEN, in accordance with Section 12, and all other containers marked with the words: INSULATION NOT FOR OXYGEN.

\subsection{Outer Shell}

3.6.1 The insulation must be completely covered with a metal shell constructed and sealed so that moisture cannot come in contact with the insula-

TABLE 1

MINIMUM METAL THICKNESS OF OLTER SHELL

\begin{tabular}{|c|c|c|c|c|}
\hline \multirow{2}{*}{$\begin{array}{l}\text { Metal } \\
\text { Carbon Steel }\end{array}$} & \multicolumn{2}{|c|}{ Evacuated } & \multicolumn{2}{|c|}{ Not Evacuated } \\
\hline & 0.0946 inch & $(2.40 \mathrm{~mm})$ & 0.0677 inch & $(1.72 \mathrm{~mm})$ \\
\hline Stainless Steel & 0.0428 inch & $(1.09 \mathrm{~mm})$ & 0.0269 inch & $(0.68 \mathrm{~mm})$ \\
\hline Aluminum & 0.125 inch & $(3.18 \mathrm{~mm})$ & 0.100 inch & $(2.54 \mathrm{~mm})$ \\
\hline
\end{tabular}


CGA.341- 1987

COMPRESSED GAS A SNIDCIATION. INC.

Page 6

tion. Minimum metal thicknesses are shown in Table 1.

3.6.2 If a vacuum is maintained in the insulation space. the outer shell must be designed for a minimum collapsing pressure of $30 \mathrm{psi}(206.8 \mathrm{kPa})$ differential. This is the equivalent of a 15 psi (103.4 $\mathrm{kPa}$ ) differential with a safety factor of 2 .

3.6.2.1 The cylindrical portion of the outer shell between stiffening rings must have a critical collapsing pressure of at least 30 psi $(206.8 \mathrm{kPa})$ as determined by the formula:

$$
P_{c}=2.6 E(t / D)^{2.5} /\left[(L / D)-.45(t / D)^{-3}\right]
$$

Where:

$$
\begin{aligned}
& P_{\mathrm{s}}=\text { Critical collapsing pressure, in psi; } \\
& E=\text { Modulus of elasticity of outer shell } \\
& \text { material, in psi; } \\
& t=\text { Thickness of outer shell material, in }
\end{aligned}
$$

3.6.2.2 If stiffening rings are used in designing the cylindrical portion of the outer shell for external pressure. each ring must be attached to the outer shell by fillet welds. Outside stiffening ring attachment welds must be continuous. Inside ring attachment welds may be intermittent.

Where intermittent welds are used. the total length of welds on each side of the ring must be at least one-third of the outer shell circumference or. if welded on one side. two-thirds of the outer shell circumference. The maximum spacing between intermittent welds attaching internal rings shall not exceed twelve times the thickness of the shell to which they are attached.

A portion of the outer shell may be included when calculating the moment of inertia of the ring. The effective width of outer shell plate. W. on each side of the attachment to the ring is given by the formula:

$$
\mathrm{W}=0.78(\mathrm{Rt})^{1 . .5}
$$

Where:

$$
\begin{aligned}
& \mathbf{R}=\begin{array}{l}
\text { Outside radius of the outer shell, in } \\
\text { inches. and }
\end{array} \\
& \mathbf{t}=\begin{array}{l}
\text { Thickness of the outer shell material } \\
\text { in inches }
\end{array}
\end{aligned}
$$

3.6.2.3 Where a stiffening ring consists of a closed section having two webs attached to the outer shell, the outer shell plate between the webs shall be included up to the limit of twice the value of $W$ as defined above. The flange of the section, if not a standard structural shape, is subject to the same limitation, with $W$ based on $R$ and $t$ of the outer shell. Where two separate members, such as two angles, are located less than $2 W$ apart, they shall be treated as a single stiffening ring (the maximum width of outer shell plate which shall be considered effective is $4 \mathrm{~W}$ ). The closed section between an external ring and the outer shell must be provided with a drain opening.

3.6.2.4 Each stiffening ring must have a minimum moment of inertia as determined by either of the following formulae:

or

$$
\mathrm{I}=1.05 \mathrm{D}^{3} \mathrm{~L} / \mathrm{E}
$$

Where:

$$
I^{\prime}=1.38 D^{3} \mathrm{~L} / \mathrm{E}
$$

$I$ = Required moment of inertia of the stiffener itself about a centroidal axis parallel to the outer shell axis, in inches to the fourth power:

$I^{\prime}=$ Required moment of inertia of the combined section of stiffener and effective width of outer shell plate about a centroidal axis parallel to the outer shell axis, in inches to the fourth power:

$D=$ Outside diameter of the outer shell, in inches:

$\mathrm{L}=$ One-half the distance from the centerline of the stiffening ring to the next line of support on one side. plus onehalf the distance from the centerline of the stiffening ring to the next line of support on the other side of the stiffening ring. both measured parallel to the axis of the outer shell, ${ }^{*}$ in inches;

-NOTE: A line of support is either a stiffening ring meeting the requirements of this paragraph or a circumferential line on a head at one-third the depth of the head from the tangent line.

$E=$ Modulus of elasticity of the stiffener material in psi.

3.6.2.5 The outer shell heads on vacuum-insulated cargo tanks must be sufficiently thick to sustain a critical collapsing pressure of at least 
$30 \mathrm{psi}(206.8 \mathrm{kPa})$ as determined by the following formula:

$$
P_{c}=0.25 E(t / R)^{2}
$$

Where:

$$
\begin{aligned}
& P_{\mathrm{v}}= \text { Critical collapsing pressure, in psi ( } 30 \\
& \text { psi minimum): } \\
& E= \text { Modulus of elasticity of head material. } \\
& \text { in psi; }
\end{aligned}
$$

$R=$ Inside dish radius of head, in inches. For ellipsoidal heads. $R=K_{i} D_{0,}$, where $\mathrm{K}_{1}$ is established from Table UG-37 in the ASME Code [3], and $D_{0}$ is the outside diameter of head.

3.6.3 When used as the primary structural member, a nonevacuated outer shell must have circumferential reinforcement as prescribed below:

3.6.3.1 Ring stiffeners, heads, and bulkheads must be located in such a manner that the maximum unreinforced portion of the outer shell is not more than 60 inches $(152.4 \mathrm{~cm})$.

3.6.3.2 Ring stiffeners, when used to comply with this section. must be continuous around the circumference of the outer shell, and must have a section modulus about the neutral axis of the ring section parallel to the outer shell at least equal to that determined by the following formula:

$$
\begin{array}{ll}
\frac{I}{C}(\mathrm{Min})=0.00027 \mathrm{DL} & \text { for Steel } \\
\frac{1}{C}(\mathrm{Min})=0.000467 \mathrm{DL} & \text { for Aluminum Alloy }
\end{array}
$$

Where:

$$
\begin{aligned}
& \frac{I}{C}= \text { Section modulus. in (inches) } \\
& \mathbf{D}= \\
& \mathrm{L}= \text { Outer shell diameter. in inches } \\
& \text { mum distance from the midpoint of } \\
& \text { the unsupported outer shell on one side } \\
& \text { of the ring stiffener to the midpoint of } \\
& \text { the unsupported outer shell on the } \\
& \text { opposite side of the ring stiffener. }
\end{aligned}
$$

\begin{tabular}{|c|c|c|}
\hline $\begin{array}{c}\text { Circumferential } \\
\text { ring stiffener } \\
\text { to outer shell } \\
\text { welds } \\
\text { (No. of sides) }\end{array}$ & $\begin{array}{l}\text { Distance between } \\
\text { parallel } \\
\text { circumferential ring } \\
\text { stiffener to outer } \\
\text { shell welds }\end{array}$ & $\begin{array}{l}\text { Outer shell } \\
\text { section credit }\end{array}$ \\
\hline $\begin{array}{l}1 \\
2 \\
2\end{array}$ & $\begin{array}{c}\text { Less than } 20 t \\
20 t \text { or more }\end{array}$ & $\begin{array}{c}20 t \\
20 t+L_{1} \\
40 t\end{array}$ \\
\hline
\end{tabular}

If a ring stiffener is welded to the outer shell (with each circumferential weld not less than $50 \%$ of the total circumference of the vessel and the maximum unwelded space on this joint not exceeding 40 times the shell thickness), a portion of the outer shell shall be considered as part of the ring section for purposes of computing the ring section modulus. The maximum portion of the outer shell to be used in these calculations is shown in Table 2:
TABLE 2

MAXIMUM PORTION OF

OUTER SHELL TO BE USED IN COMPUTING RING SECTION MODULUS

Where:

$t=$ Outer shell thickness

$\mathrm{L}_{1}=$ Distance between parallel circumferential ring stiffener to outer shell welds.

If the configuration of the internal or external ring stiffener encloses an air space, this air space must be arranged for venting and be equipped with drainage facilities which must be kept operative at all times.

3.6.4 When load rings in the outer shell are used for supporting the liquid container, they must be designed to carry the liquid container plus its design weight of lading at the static loadings specified in 3.4. Where loads are applied to the outer shell stiffening rings from the support system used to support the inner container within the outer shell, additional stiffening rings. or an increased moment of inertia of the stiffening rings designed for the external pressure. must be provided to carry the support loads. Loads applied directly to the outer shell or outer head must be analyzed in accordance with Appendix G of the ASME Code. [3]

3.6.5 If the outer shell constitutes in whole or in part a stress member used in lieu of a frame, it must conform to the requirements of 8.2 .

\section{MATERIALS}

4.1 Liquid Container. All materials used for the construction of the liquid container and its appurtenances that shall come in contact with the lading must be suitable for use with the lading to be transported. All materials used for the liquid container pressure parts must conform with requirements of the ASME Code in all respects. [3] 
CGA-341 - 1987

CIMPRESSED Gas ASSOCiATION. INC.

Page 8

4.2 Other Components. All tie rods, mountings and other appurtenances with in the outer shell and all piping, fittings. and valves must be of materials suitable for use at the lowest temperature to be encountered.

4.3 Cleaning. Surfaces of the liquid container, associated valves, pumps, piping, etc., which will contact the lading to be transported must be suitably cleaned of contaminants for the service intended. Tanks constructed for oxygen service must be cleaned and inspected for cleanliness emploving appropriate methods described in CGA G-4.1. Cleaning Eyuipment for Oxygen Service. [4]

\section{JOINTS}

5.1 General. All joints for the liquid container must be as required by the ASME Code. [3]

5.2 Welding. For the liquid container, the welding procedure specification. procedure qualification records, and welder qualification tests, including qualification renewals, shall be in accordance with the most cur rent edition of Section IX of the AS.ME Boiler and Pressure Vessel Code. [5]

5.3 Location. All longitudinal welds in liquid containers and a load-bearing outer shell must be so located as not to intersect supports other than load rings and stiffening rings.

5.4 Attachments. Substructures must be properly fitted before attachment. and the welding sequence must be such as to minimize stresses due to the shrinkage of the weld.

\section{PIPING AND CONTROLS}

6.1 Manholes. Manholes are optional.

6.2 Outlets. With the exception of gauging devices. pressure relief devices, manual vents, and pressure control valves or devices, each opening in the liquid container must be closed with a plug. cap. bolted flange or plate, or provided with a valve conforming to the requirements of 6.5 .

\subsection{Discharge Control}

6.3.1 Shut-Off Valves. Each liquid filling and liquid discharge line must be provided with a manually operable shut-off valve located as close to the tank as is practicable.

\subsection{Pressure Relief Devices}

\subsubsection{Liquid Container. Pressure relief devices}

shall be provided for the liquid container in accordance with requirements of the most current edition of CGA S-1.2. Pressure Relief Device StandardsPart 2-Cargo and Portable Tanks for Compressed Gases. [6] In addition. the following requirements shall apply:

6.4.1:1 Pressure relief devices must be installed to have direct communication with the vapor space of the liquid container near the midpoint of the top centerline, and be so installed and located that the cooling effect of the contents will not prevent effective operation of the device.

6.4.1.2 Connections to pressure relief devices. including entrance and exit piping, must be of sufficient size to provide the required rate of discharge through the pressure relief devices.

6.4.2 Outer Shell. The outer shell must be protected by a suitable pressure relief device to release internal pressure. The discharge area of this device must be at least 0.00024 square inches per pound $\left(0.34 \mathrm{~mm}^{2} / \mathrm{kg}\right)$ of the water capacity of the liquid container. This relief device must function at a pressure not exceeding the internal design pressure of the outer shell, calculated in accordance with the ASME Code, or 25 psig $(172 \mathrm{kPa})$, whichever is less. [3]

\subsection{Piping, Valves, and Fittings}

6.5.1 Welded pipe joints must be used wherever possible. Where copper tubing is permitted. joints must be brazed or made with equally strong metal unions. Metal unions must not decrease the strength of the tubing. as by cutting threads or grooves. The melting point of brazing material must be no lower than $1000^{\circ} \mathrm{F}\left(538^{\circ} \mathrm{C}\right)$. The materials used in valves and fittings must be suitable for use at the temperature of the lading.

6.5.2 The bursting strength of all pipe. fittings. and hose must be at least four times the CGA design pressure of the liquid container and not less than four times the pressure to which they shall be subjected in service by the action of a pump or other device. the action of which shall subject portions of the piping to pressures greater than the liquid container's CGA design pressure.

6.5.3 Each valve must be designed and constructed for a rated pressure not less than the liquid container's CGA design pressure at the coldest temperature expected to be encountered.

6.5.4 Valve parts or fitting parts made of aluminum which are subject to internal rubbing or abrasion in normal service shall not be used with oxygen. 
6.5.5 Suitable provisions must be made to prevent damage to piping due to thermal expansion and contraction, jarring, and vibration.

6.5.6 All pipe, valves, and fittings must be proven free from leaks at not less than their design pressure.

6.5.7 Piping must be grouped and protected from damage as required by Section 7 .

6.5.8 Each portion of liquid piping which can be closed at both ends must be provided with a pressure relief valve without an intervening shut-off valve.

6.5.9 Wherever a pressure building coil is used on a cargo tank, the vapor connection to the coil must be provided with a valve or check valve. The liquid connection to the coil must be provided with a shut-off valve. All such valves must be as close to the tank as practicable to prevent loss of lading in case of damage during transportation.

6.5.10 All loading, unloading, and hose connections shall conform to CGA V-6, Standard Cryogenic Liquid Transfer.Connections. [7]

\section{PROTECTION OF PIPING, VALVES, AND FITTINGS}

7.1 General. All pressure relief devices and their inlet piping. and all valves, fittings, and other accessories which are in communication with the liquid container without intervening shut-off valves or check valves, must be installed within the motor vehicle framework or within a suitable collision resistant guard or housing, and appropriate ventilation must be provided. Pressure relief devices must be protected so that in the event of the upset of the vehicle onto a hard surface, their opening will not be prevented and their discharge will not be restricted. Every part of the loaded cargo tank and any associated value or pipe. enclosure. or protective device or structure (exclusive of the wheel assemblies) must be at least 14 inches $(360 \mathrm{~mm})$ above level ground.

7.2 Mid-Tank Piping. Piping and valves subject to liquid container pressure during transportation that are not located at the rear of and within the protection of the cargo tank's circumference and the vehicle frame, or which do not have intervening shut-off valves or check valves which are located within the motor vehicle framework. must be protected by a protective device or housing which meets the requirements of 7.3 .

7.3 Protective Housing. The protective devices or housings and their attachments to the cargo tank structure must be designed to withstand static loading in any direction in which they will be loaded. The static loading shall be equal to twice the weight of the cargo tank and attachments when the cargo tank is filled with the lading. The strength of these devices or housings and their attachment to the vehicle structure must be based on a stress no higher than the minimum ultimate stength of the material.

7.4 Rear Bumper. Each tank motor vehicle must be provided with at least one rear bumper designed to protect the outer vessel and piping in the event of a rear end collision. The bumper design must transmit the force of the collision directly to the chassis of the vehicle. The rear bumper and its attachments to the chassis must be designed to withstand a load equal to twice the weight of the loaded cargo tank and attachments, based on a safety factor of four on the minimum ultimate strength of the material used with such load being applied horizontally and parallel to the major axis of the cargo tank.

The rear bumper dimensions must meet the requirements of 49 CFR 393.86 of the U.S. Motor Carrier Safety Regulations. and the bottom edge of the rear bumper must be no higher than 30 inches (760 $\mathrm{mm}$ ) from the ground. [8] The bumper, or a vertical post attached to the bumper, must extend vertically to a height adequate to protect all valves and fittings forward of the bumper if damage could cause loss of lading.

\section{SUPPORTS AND ANCHORING}

8.1 Cargo Tank with Frame. Each cargo tank with a frame not made integral with the outer shell as by welding. must be provided with positive restraining devices for drawing the cargo tank down tight on the frame without introducing undue concentrations of stresses. In addition. suitable stops or anchors must be attached either to the frame or to the outer shell to prevent relative motion between them from occurring as a result of starting. stopping, and turning of the vehicle. The stops and anchors must be so installed as to be readily accessible for inspection and maintenance. The stops and anchors and their attachments to the frame and outer shell must be capable of withstanding the minimum static loadings required by 8.2 .

8.2 Frameless Cargo Tank. A cargo tank constructed so that the outer shell constitutes, in whole or in part, the structural members used in place of a structural frame must have the cargo tank supported by external cradles or other suitable supporting devices such as load rings. Cradles used 
CGA-3\$1 - 1987

CUMPRESSED Gas A SSOCIATION. INC.

Page 10

without other stiffening means must subtend at least 120 degrees of the circumference to which they are attached. The supports and their attachments to the cargo tank must be designed to withstand minimum static loadings of:

(a) vertically downward of 2

(b) vertically upward of 2

(c) longitudinal of 2

(d) lateral of 2

times the weight of the cargo tank and its attachments when filled to the design weight of lading. The stresses induced into the supports, their attachments. and the outer shell shall not exceed 25 percent of the room temperature minimum ultimate strength of the materials used. The effects of fatigue must be considered in the calculation. All attachments of supports to inner vessels and to loadbearing outer shells must be by means of pads of material similar to that of the inner vessel or outer shell, respectively, by load rings, or by bosses so designed or gussetted as to distribute the load.

\section{GAUGING DEVICES}

\subsection{Level Gauging Devices}

9.1.1 Each cargo tank, except cargo tanks filled by weight. must be equipped with one or more gauging devices to indicate the maximum permitted liquid level. Permitted gauging devices shall be a fixed length dip tube or differential pressure liquid level gauge.

9.1.2 The volume setting of a fixed length dip tube must be indicated in a visible location at or adjacent to the valve.

9.1.3 The design pressure of each liquid level gauging device must be no lower than that of the liquid container.

9.1.4 A liquid level gauging device used as a primary control for filling must be designed and installed to indicate the maximum filling level with the cargo tank parked on a level surface.

9.2 Pressure Gauges. All cargo tanks must be provided with a pressure gauge located in the operating compartment. A shut-off valve must be installed between the gauge and the cargo tank.

9.3 Vacuum Gauges. Each vacuum-insulated cargo tank must be provided with a connection for a vacuum gauge to the insulation space.

\section{PLMPS}

Liquid pumps. if used, must be of a suitable design. Parts made of aluminum which are subject to internal rubbing or abrasion in normal service must not be used with liquid oxygen ladings. Pumps may be driven by motor vehicular power take-off or other mechanical, electrical. or hydraulic means. The downstream piping must be protected from overpressurization.

\section{TESTING}

11.1 General. Inspection of materials of construction of the liquid container and its appurtenances, excluding the outer shell, must be as required by the ASME Code. The liquid container must be subjected to either a hydrostatic or a pneumatic test in accordance with the ASME Code. [3]

11.2 Piping and Appurtenances. Piping and appurtenances must be tested to at least $110 \%$ line operating pressure.

\section{MARKING OF TANKS}

12.1 Code and Name Plate. A code plate with the markings required by the ASME Code under which the liquid container was constructed, and a corrosion resistant metal nameplate, must be permanently affixed by brazing, welding, or riveting to the outer shell in a readily visible location. The nameplate must be plainly marked by stamping. embossing. or other means and form characters not less than $3 / 16$ inch $(5 \mathrm{~mm})$ high into the metal of the plate. The plate must be marked with the following information and shall include the use of the parenthetical abbreviations. Cargo tanks for use in Canada shall be marked in metric units.

(1) CGA Specification Number (CGA-341).

(2) Tank Manufacturer (Tank Mfr.).

(3) Manufacturer's serial number ( $\mathrm{S} / \mathrm{N}$ ).

(4) Date of manufacture as month and year (Date of Mfr.).

(5) Design weight of lading (Design Wgt. of Lading _ lbs:__ kg).

(6) Water capacity (W. Cap lbs: kg). Water capacity shall be based on a density of water (8.32828 lbs/U.S. gallon $(0.9980 \mathrm{~kg} /$ liter $)$ ) with the liquid container at its design service temperature after deduction for the volume above the inlet of the pressure relief or pressure control valve.

(7) Design service temperature (Design Service Temp. $\left.{ }^{\circ} \mathrm{F}\right)\left({ }^{\circ} \mathrm{C}\right)$.

(8) Original test date (Orig. Test Date).

(9) Insulation Description: (INSULATION FOR OXYGEN) or (INSULATION NOT FOR OXYGEN). 
(10) In Canada, the Canadian Registration Number of the pressure vessel design as provided by the Province of principal use and others in which the design has been registered.

\section{CERTIFICATION}

13.1 General. For each cargo tank, the cargo tank vehicle manufacturer must supply, and the owner must obtain. the following:

13.1.1 In the United States, the liquid container manufacturer's report required by the ASME Code.

13.1.2 The certificate stating that the mounted cargo tank is in complete compliance with Specification CGA-341 and the applicable codes noted in 13.1. The certificate shall be signed by a responsible employee of the cargo tank vehicle manufacturer. The certificate must state whether or not it includes certification that all valves, piping, and protective devices comply with the requirements of the specification.

13.1.2.1 In the case of a cargo tank manufactured in two or more stages, each manufacturer that performs a manufacturing operation on the incomplete vehicle or portion thereof, shall furnish to the succeeding manufacturer at or before the time of delivery, a certificate covering the particular operation performed by that manufacturer. The certificates must include sufficient information such as sketches, drawings, or other clear descriptions of the particular work performed by that manufacturer. Each certificate must be signed by an of ficial of the manufacturing firm responsible for the portion of the completed cargo tank vehicle represented thereby, such as basic cargo tank fabrication, insulation. jacketing. or piping.

13.1.3 A photograph, pencil rub, or other facsimile of the plates required in Section 12 of this specification.

13.2 Retention. The owner shall retain a copy of the data report and certificates and related papers in a file throughout the ownership of the cargo tank and for at least one year thereafter. In the event of change in ownership, retention by the prior owner of non-fading, photographically reproduced copies will be deemed to satisfy this requirement. Each motor carrier using the cargo tank. if not the owner thereof, shall obtain a copy of the data report and certificate and retain them in their files during the time they use the cargo tank and for at least one year theréafter.

\section{REFERENCES}

[1] Code of Federal Regulations, Title 49 CFR Parts 100-179(Transportation). U.S. Department of Transportation. Superintendent of Documents, Government Printing Office. Washington, DC 20402.

[2] Transportation of Dangerous Goods Regulations, Supply and Services Canada, Canadian Publications Centre, Ottawa, Ontario KIA OS9.

[3] ASME Boiler and Pressure Vessel Code. (Section VIII). American Society of Mechanical Engineers. 345 East 47th Street. New York. NY 10017.

[4] CGA G-4.1. Cleaning Equipment for Oxygen Serice. Compressed Gas Association, Inc., 1235 Jefferson Davis Highway, Arlington, VA 22202.

[5] ASME Boiler and Pressure Vessel Code. (Section IX), American Society of Mechanical Engineers, 345 East 47th Street, New York, NY 10017.

[6] CGA S-1.2. Pressure Relief Device StandardsPart 2-Cargo and Portable Tanks for Compressed Gases, Compressed Gas Association, Inc., 1235 Jefferson Davis Highway. Arlington, VA 22202.

[7] CGA V-6.Standard Cryogenic Liquid Transfer Connections. Compressed Gas Association. Inc.. 1235 Jefferson Davis Highway. Arlington. VA 22202.

[8] Code of Federal Regulations, Title 49 CFR Parts 390-397 (Transportation). U.S. Department of Transportation. Superintendent of Documents. Government Printing Office, Washington. DC 20402. 



\section{EIGHT STEPS TO ORDERING A COMPLETE NH SYSTEM}

The following steps will guide you to a complete NH Series svstem for your application.

For help:

- Complete the Application Data Form on pages 180 and 181

- Revierv the NH Series specifications page 71

- Refer to the Engineering section for selection assistance.

- Consult your local Industrial Devices distributor, or cal the factory.

\section{BASE MODEL Number}

Select the $\mathrm{NH}$ model $\mathrm{w}$ hich provides sufficient thrust and speed for the application. with a comfortable margin of saferv. Available thrust will be consumed by acceleration, friction. pushing'pulling against an external force. and is the case of a vertical application. supporting the load against gravity. Refer to the NH Speed vs. Thrust curves in this section. When making this selection. be sure to consider duty cycle. side loading. back driving, and the other design considerations from the IDC Application Data Form.

\section{STROKE LENGTH}

Seven stanclard travel lengths are available from 2 to 24 inches. Custom lengths are also available. Consult your IDC distributor or the factory for details.

To maximize cylinder life, the thrust tube should not impact eirher physical end of stroke during normal operation. Extra travel length is needed to decelerate the load to a stop when an end-of-travel limit switch is encountered. This extra travel distance depends on load and speed. Consult the Engineering Section.

\section{MOTOR MOUNTING (PARALLEL UNITS ONLY)}

$\mathrm{NH}$ crlinders with gear or timing belt drive reductions have the motor mounted parallel to the lead screw. (With in-line units, the motor is always coupled directly to the screw shaft, with no reduction.)

Though most customers use the standard parallel configuration. NH Series parallel models offer two motor mounting options for optimum integration into your machine. See pages 78 to 83 for full dimensional drawings.
(1)

BAse MODEL
Rod-Type
Cylinder

In-Line Nodels ХTO92B- NH995A NH995B- [NH998A-
(2)

(3)

PARALlel

STROKE MOTOR

LENGTH MOUNTING
(4)

CYLINDER ROD MOUNTING END

(5)
(6)

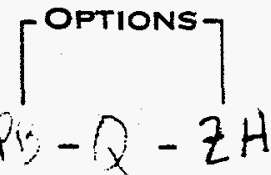

2
2
6
8
12
18
24

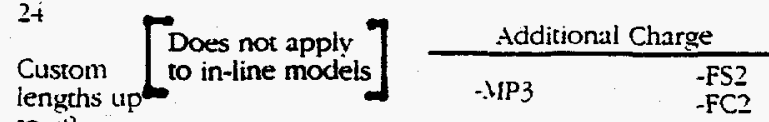

lengths up

to 48

inches blank (standard)

-RU ( reverse parallel)

Does not apply
to in-line models

(
No Charge

\begin{tabular}{|c|c|c|}
\hline 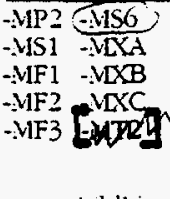 & $\begin{array}{l}\text {-FT1 } \\
\text {-ITI1 } \\
\text {-FE2 }\end{array}$ & $\begin{array}{l}-B S \\
-D B \\
-E M \\
-F\end{array}$ \\
\hline
\end{tabular}

- $\mathrm{Z}$ or $-\mathrm{ZH}$ required for cylinders controlled by H3851. H3951 or $\mathrm{H} 3952$ controls.

$-\mathrm{H}$
$-\mathrm{L}$
$-\mathrm{W}$
$-\mathrm{Q}$
$-\mathrm{PB}$
$-\mathrm{Z}$
$-\mathrm{Z} \mathrm{H}^{*}$
$\mathrm{H}$
for
d by
3951




\section{NH SERIES CYLINDERS}

\section{CYLINDER MOUNTING}

ipecify any one of these cylinder mounting options. See pages $78-83$ for limensional dratwings.

(ilinder base mount options

-IIP2. -LIP3, -LIF2. -WF3, -LLXB. -.LLYC iannot be ordered uith in-line models

.HF1. 2. 3 Rectangular Flanges
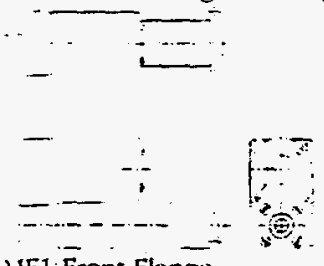

U.JF1 Front Flange

IIF 2 Rear Flange

VIF3 Both Flanges
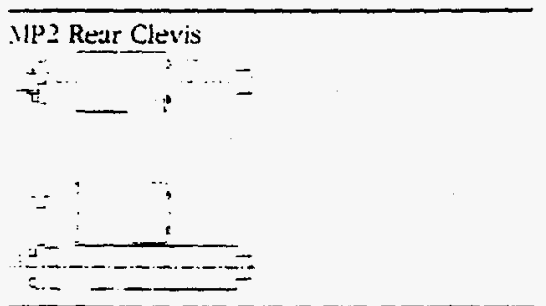

US1 Side End Angles

- - ; - I

- $-:-\pi$

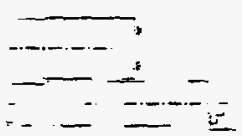

ILA. B. C Extended Tie Rods
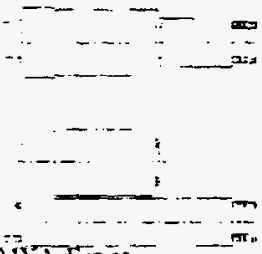

ivent

inB Rear

IIS Both

YS6 Side Tapped Holes
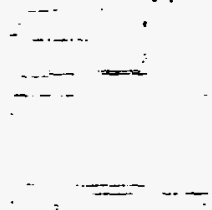

ST2 Trunnion (In-Line Mockels Onlv')

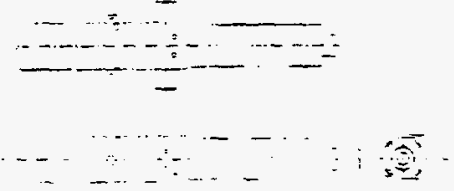

\section{ROD ENDS}

IDC offers 5 rod end options for $\mathrm{NH}$ Series cylinders. Caretully consider the best method of attaching the load to provide optimum perfomance and long life. by preventing excessive backlash. side load monents. rod end rotation. and misalignment. To determine overall cylinder length. be sure to include the rod end dimensions. see page 78 .

-FT1 Female thread

-MT1 Wale thread

-FE? Female exe

-FS2 Spherical joint (includes -FT1)

-FC2 Clevis (includes -iTI)

\section{OPTIONS}

Industrial Devices offers several $\mathrm{NH}$ Series cylinder options to satisfy unique application requirements.

See the Options and Accessories section for complete specifications of these options.

\section{-BS Holding Brake}

20 in-lb holding brake mounted on the rear lead screw shaft extension. Not available on in-line models or with cylinder base mount options (-LIF2. -WIF3. -LIS1. -WP2. -IIP3. $-V X B-W C X C)$

-DB Dual Road End Berring Dual rod-end bearings increase side moment load rating to -5 in-lbs. This option reduces actucal stroke length by 1.5 inches.

-EM Encoder

500 line incremental encoder mounted on the rear shift of the motor. Order $-\mathrm{Z}$ or $-\mathrm{ZH}$ instead of Ell when using crlinders with H3852. H3951 or H3951 controls.

-F Sub-Freezing Enrironment Increased internal clearances allow thermal expansion and contraction for operation to $-20^{\circ} \mathrm{F}$. Increases sistem backlash to 0.025 inches imax:

-H High Temperature Increases maximum crlinder operating temperarure to $180^{\circ} \mathrm{F}$ by changing internal materials and lubricants.

Vote: $-\mathrm{F}$ : lnd $-\mathrm{H}$ are not compatible

-I Linear Pestentienser Outpu Linear porentis mmelet mounted insicte the $\mathrm{XH}$ cylincles
-PB Protective Boot

Protects the thrust tube from solid contaminants and prevents liquids from entering the crlinder through the rod end bearing. This option increases overall cyllinder length.

Q Motor Quick Disconnect Wale quick clisconnect receptable instailed in the back of the cylinder drive housing, including a $12 \mathrm{ft}$. moror cable with molded quick disconnect piug. Inline models bute the disconnect receptable installed in the motor

-W Water Resistant Option provides protection from light moisture contact with cylinder

$-Z$ and $-Z H$ Encoder and Home? Position Sensor

Required for. WH cylinders controlled by H3851. H3951 and H3952.

$-Z$ Combines - EM encoder with one RPS-1 normally open reed switch. tested at factory as a system. $-\mathrm{ZH}$ combines -EM with one RP1. normally open Hall effect switch.

\section{ACCESSORIES}

Accessories are ordered as separate items. with separate model number. Details can te found in the Options and Accessories section.

Magnetic Position Sensors

Position sensors are wailable for stopping position indication. for changing direction or speed. and more using the $\mathrm{H} 3301$ Control

All $\mathrm{H}$ Series controls use normally closed switches (RP2 or RPS-2) for end-of-travel limit sensing. To maximize cyliuder life, IDC recommends the use of end-oftravel limit switches with all cylinders.

RP'1 Womally open Hall-effect witch

[RP2 Normally closed Hall-effect switch]

RPS-1 Comally open reed conact sn-itch

RPS-2 Normally closed reed contact siritch

\section{H3OOO SERIES CONTROLS}

To complete the system. IDC offers controls which are optimized to run IH Series cylinders.

Details of the Hanou Series controls begin on page (x). 
INDIVIDUAL MODEL SPECIFICATIONS-BALL SCREW MODELS

$\begin{array}{lcccccccc} & \text { NH102B } & \text { NH105B } & \text { NH152B } & \text { NH155B } & \text { NH205B } & \text { NH355B } & \text { NH992B NH995B } \\ \text { Timing } & \text { Timing } & \text { Timing } & \text { Timing } & \text { Timing } & \text { Helical } & \text { In-line } \\ \text { Drive Type } & \text { Belt } & \text { Beit } & \text { Belt } & \text { Belt } & \text { Belt } & \text { Gear } & \text { Direct Flex Coupled } \\ \begin{array}{l}\text { Drive Ratio } \\ \text { (motor:Screw) }\end{array} & 1: 1 & 1: 1 & 1.5: 1 & 1.5: 1 & 2: 1 & 3.5: 1 & 1: 1 & 1: 1 \\ \begin{array}{c}\text { Screw Pitch } \\ \text { (rev/inch) }\end{array} & 2 & 5 & 2 & 5 & 5 & 5 & 2 & 5 \\ \begin{array}{l}\text { Load Before } \\ \text { Back Driving (lbs) }\end{array} & 10 & 20 & 10 & 20 & 20 & 20 & 10 & 20\end{array}$

\section{SYSTEM PERformance USING H3OOO SERIES CONTROKS}

Maximum Acceleration

\begin{tabular}{|c|c|c|c|c|c|c|c|c|c|}
\hline (ips' at no & $\begin{array}{l}\text { load) } \\
\text { Stroke }\end{array}$ & 200 & 110 & 140 & 90 & 70 & 40 & 200 & 110 \\
\hline Maximum & $2-18$ in & 30 & 12 & 16 & 8 & 6 & 3.2 & 30 & 12 \\
\hline Speed & $24 \mathrm{in}$ & 18 & 10 & 16 & 8 & 6 & 3.2 & 18 & 10 \\
\hline
\end{tabular}

(ips at no load)

When applying NH cylinders with greater than 18 inch stroke, maximum speed may be limited by critical screw speed. as shown bere in bold. The individual model performance curves shown on the following pages bave been qualified (borizontal black lines) for critical speed limitations in 24 inch lengtbs.

$\begin{array}{lllllllll}\text { Maximum } & 135 & 350 & 200 & 550 & 700 & 800 & 135 & 350\end{array}$

Thrust (lbs)

Repeatability (inches) Repeatability values achievable with $\mathrm{H} 3951$ control.

$$
\pm 0.003 \quad \pm 0.001 \quad \pm 0.003 \quad \pm 0.001 \quad \pm 0.001 \quad \pm 0.001 \quad \pm 0.003 \quad \pm 0.001
$$

\section{A COMPARISON OF SPEED VS THRUST PERFORMANCE}

For duty cycle limitations. see the individual model performance curves on page 74 .

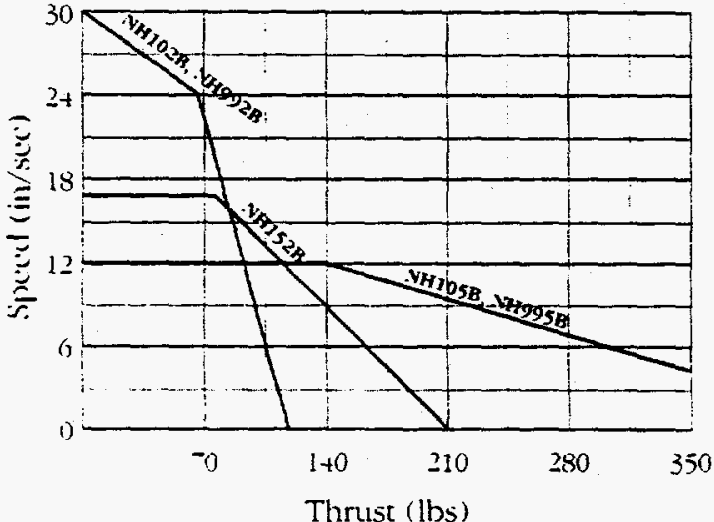

HIGHER SPEED MODELS

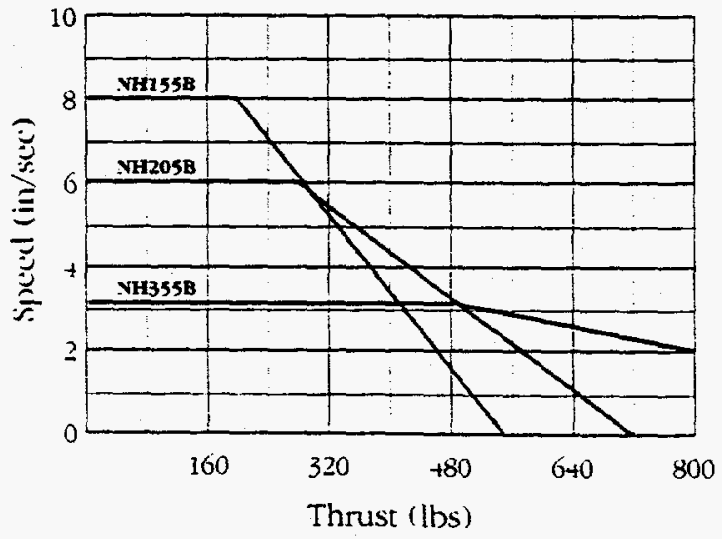

HIGHER THRUST MODELS 


\section{NH SERIES CYLINDERS}

INDIVIDUAL MODEL SPECIFICATIONS-ACME SCREW MODELS

\begin{tabular}{|c|c|c|c|c|c|c|c|c|}
\hline $\mathrm{NH} 105 \mathrm{~A}$ & NH155A & $\mathrm{NH} 158 \mathrm{~A}$ & $\mathrm{NH} 205 \mathrm{~A}$ & $\mathrm{NH} 208 \mathrm{~A}$ & $\mathrm{NH} 355 \mathrm{~A}$ & $\mathrm{NH} 358 \mathrm{~A}$ & NH995. & \\
\hline$\underset{\text { Belt }}{\text { Timing }}$ & $\begin{array}{c}\text { Timing } \\
\text { Beit }\end{array}$ & $\begin{array}{c}\text { Timing } \\
\text { Belt }\end{array}$ & $\begin{array}{c}\text { Timing } \\
\text { Belt }\end{array}$ & $\begin{array}{l}\text { Timing } \\
\text { Beit }\end{array}$ & $\begin{array}{c}\text { Helical } \\
\text { Gear }\end{array}$ & $\begin{array}{c}\text { Helical } \\
\text { Gear }\end{array}$ & \multicolumn{2}{|c|}{$\begin{array}{c}\text { In-Line } \\
\text { Flex Coupled }\end{array}$} \\
\hline $1: 1$ & $1.5: 1$ & $1.5: 1$ & $2: 1$ & $2: 1$ & $3.5: 1$ & $3.5: 1$ & $1: 1$ & 1:1 \\
\hline 5 & 5 & 8 & 5 & 8 & 5 & 8 & 5 & 8 \\
\hline 400 & 400 & 800 & 400 & 800 & 400 & 800 & 400 & \\
\hline
\end{tabular}

\section{SYSTEM PERFORMANCE USING H3OOO SERIES CONTROLS}

$\begin{array}{lllllllll}110 & 90 & 50 & 70 & 45 & 40 & 25 & 110 & 60 \\ 12 & 8 & 5 & 6 & 3.8 & 3.4 & 2 & 12 & 7.5 \\ 10 & 8 & 5 & 6 & 3.8 & 3.4 & 2 & 10 & 7.5\end{array}$

When applying $\mathrm{AH}$ cylinders uith greater than 18 incb stroke. maximum speed may be limited bl critical screu' specd. as shou'n bere in bold. The indizidual model performance curves sboun on the follouing pages baie been qualified (borizontal black lines) for critical speed limitations in 24 inch lengtbs.

150

220

360

290

475

500

800

150

[230]

Repeatability (inches) Repeatability values achievable with $\mathrm{H} 3951$ control.

$$
\pm 0.001 \quad \pm 0.001 \quad \pm 0.001 \quad \pm 0.001 \quad \pm 0.001 \quad \pm 0.001 \quad \pm 0.001 \quad \pm 0.001 \quad \text { [0.001] }
$$

\section{A COMPARISON OF SPEED VS THRUST PERFORMANCE}

For duty cycle limitations, see the individual model performance curves on page 75 .

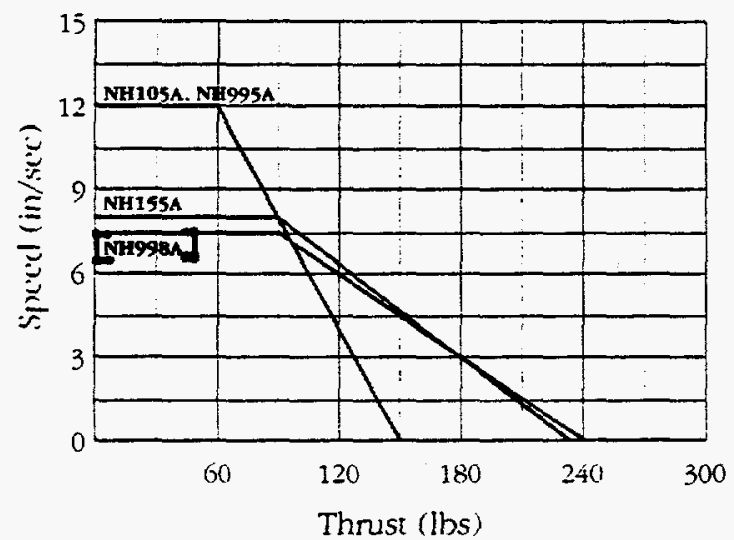

HIGHER SPEED MODELS

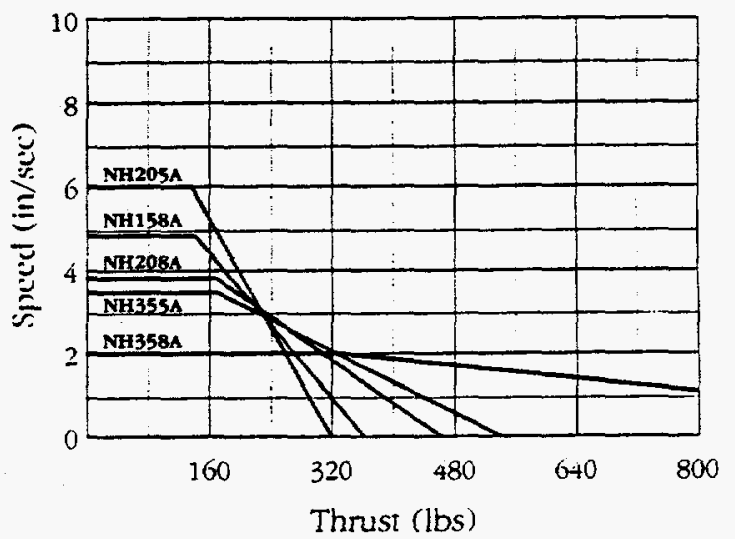

HIGHER THRUST MODELS 
THRUST VS. SPEED PERFORMANCE ACME SCREW MODELS

Performance using $\mathrm{H} 3000$ Controls.

Duty crcle percentage of "on time" is shown on each performance curve. For operation in the $60 \%$ or $30 \%$ region. motor temperature rise due to load. speed. number of acceleration/decelerations. and ambient temperature require consideration. Refer to the Engineering section.
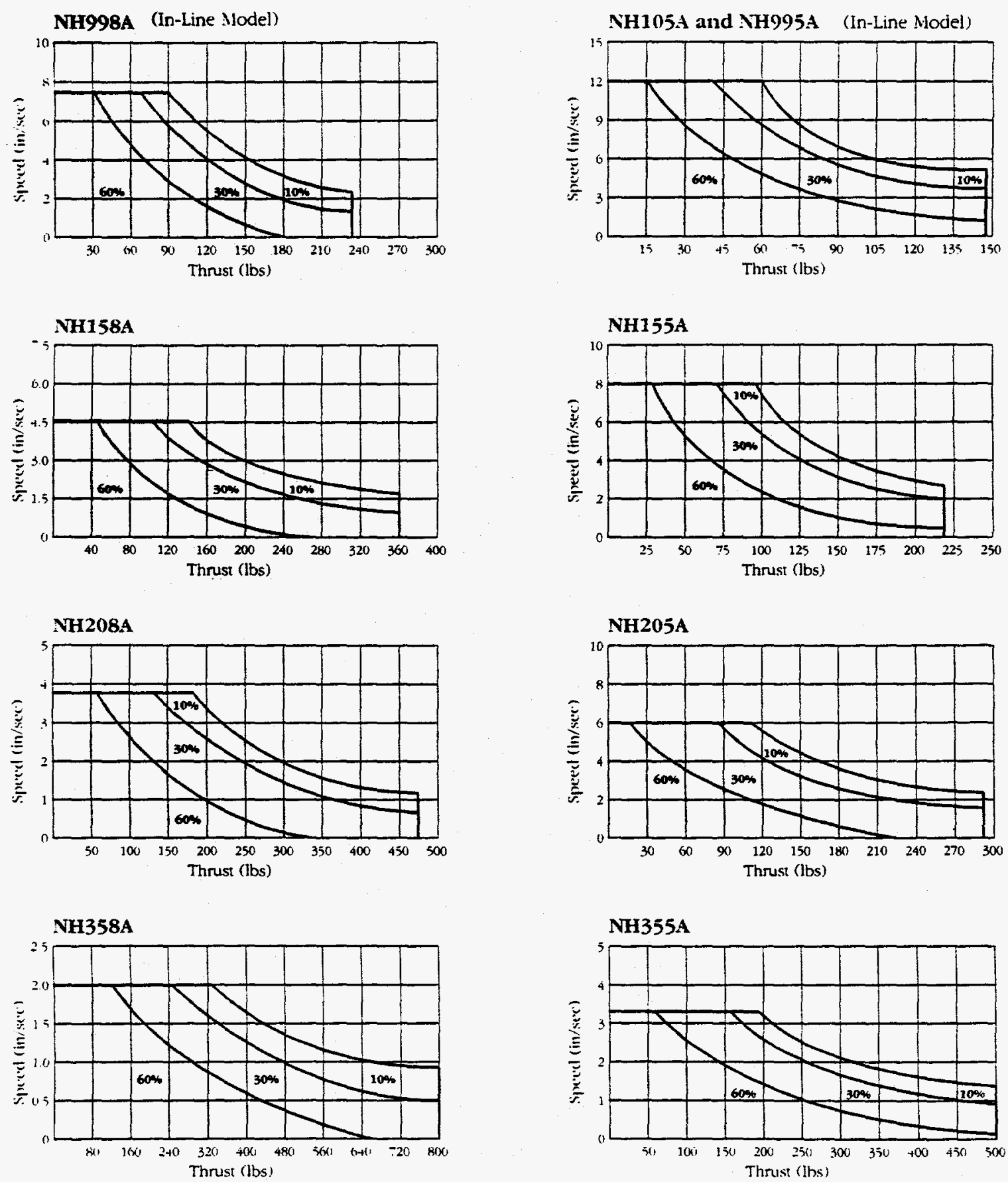
MSG SIDE TAPPED MOUNTING

NLINE

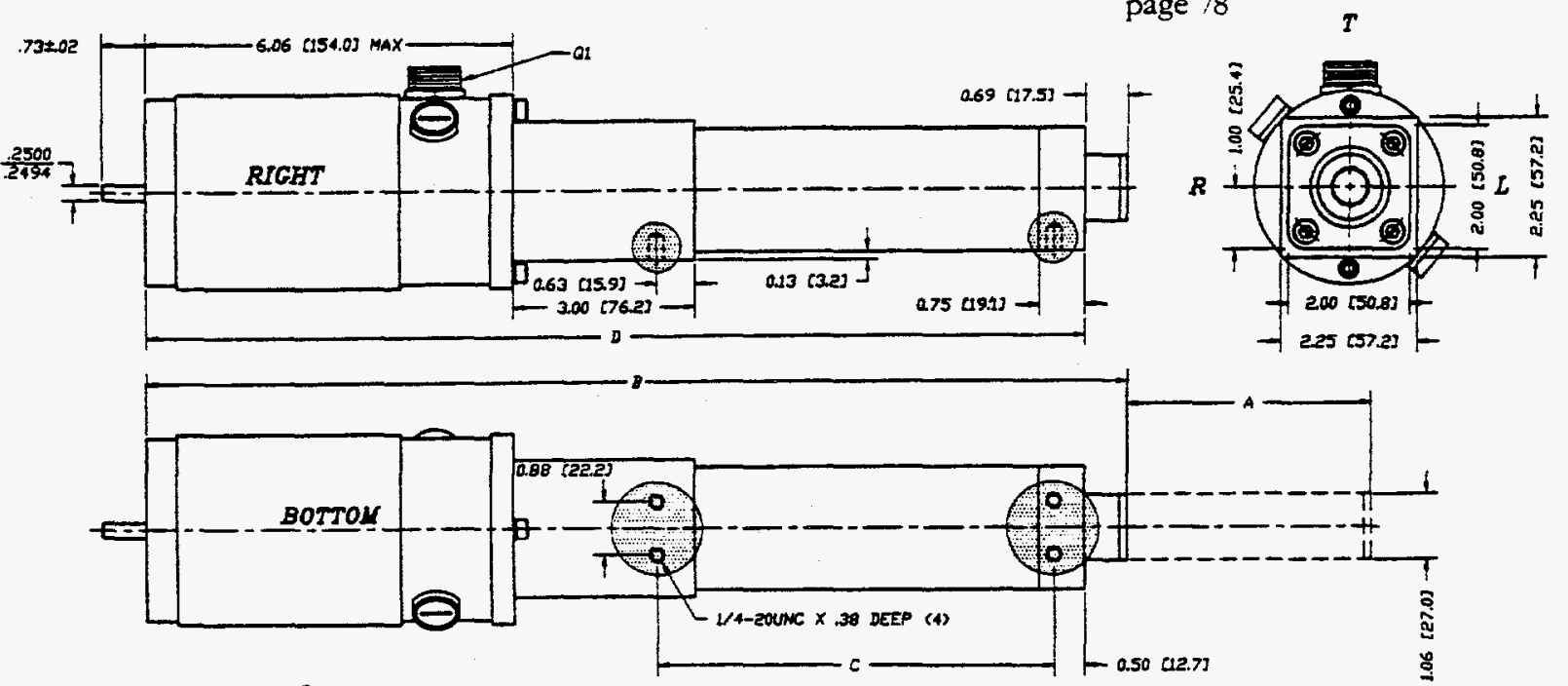

A Stroke imes (Merric)

$\begin{array}{lllllllll}\text { B Retract } & 13.15 & (334.0) & 15.15 & (384.8) & 17.15 & (435.6) & 19.15 & (486.4)\end{array}$

C Mounting $4.56(115.8) \quad 6.56(166.6) \quad 8.56 \quad(217.4) \quad 10.56 \quad$ (268.2)

$\begin{array}{lllllllll}\text { D Overall } & 12.47 & (316.7) & 14.47 & (367.5) & 16.47 & \text { (418.3) } & 18.47 & \text { (469.1) }\end{array}$
- CAD drawings are available on diskerte

- Include rod end dimensions. see page 78

$12.00 \quad(304.8) \quad 18.00 \quad(457.2) \quad 24.00(609.6)$

$\begin{array}{llllll}23.15 & (588.0) & 29.15 & (740.4) & 35.15 & (892.8)\end{array}$

$\begin{array}{llllll}14.56 & (369.8) & 20.56 & (522.2) & 26.56(674.6)\end{array}$

$22.47 \quad(570.1) \quad 28.47 \quad(723.1) \quad 34.47(875.5)$

\section{MT2 TRUNNION MOUNTING}

INLINE
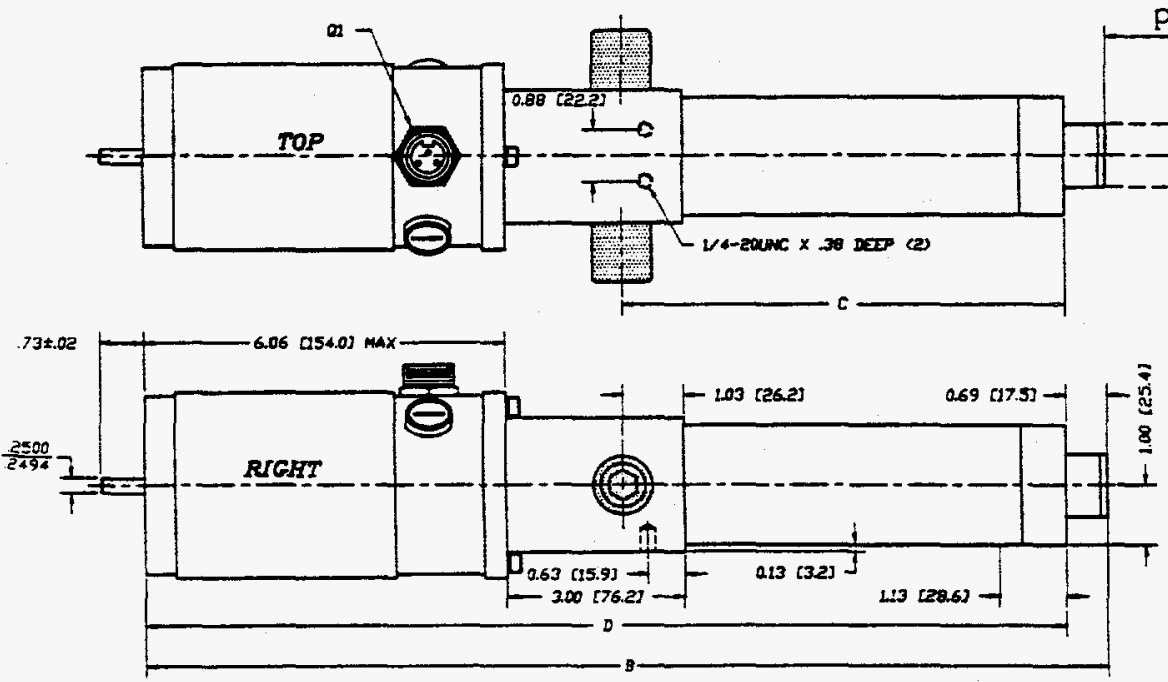

- CAD drawings are available on diskette

- Include rod end dimensions, see page 78

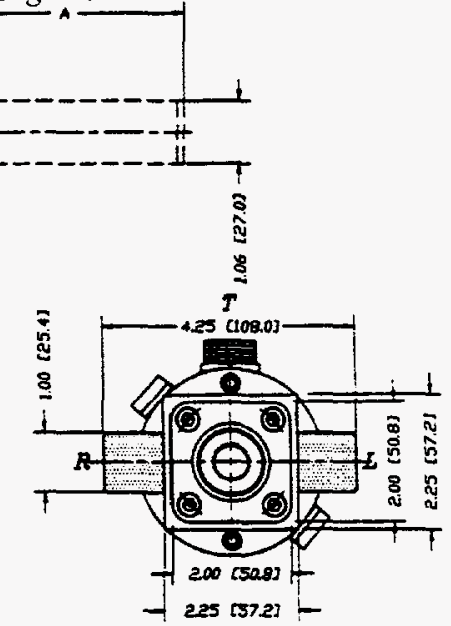

)

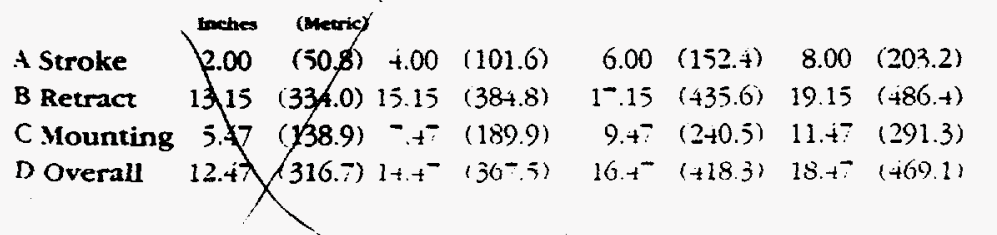



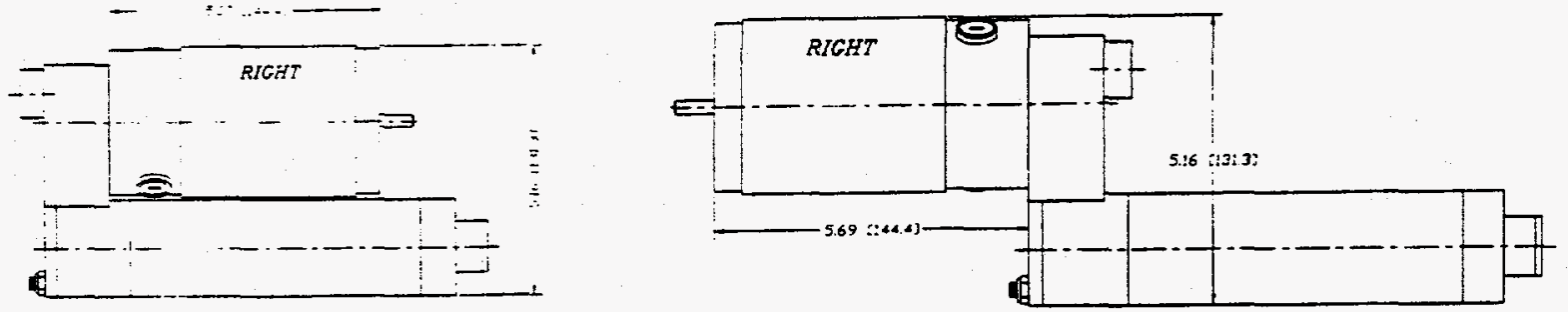

FT1

ROD ENDS
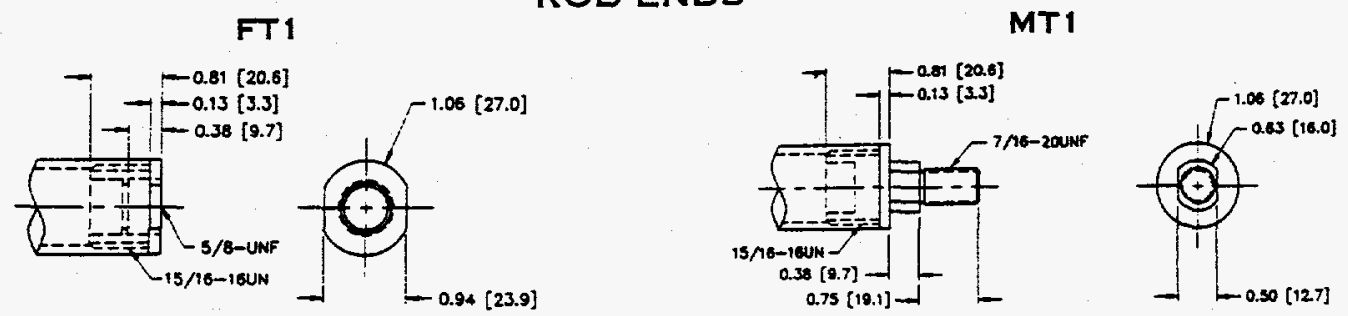

FC2

FE2

FS2
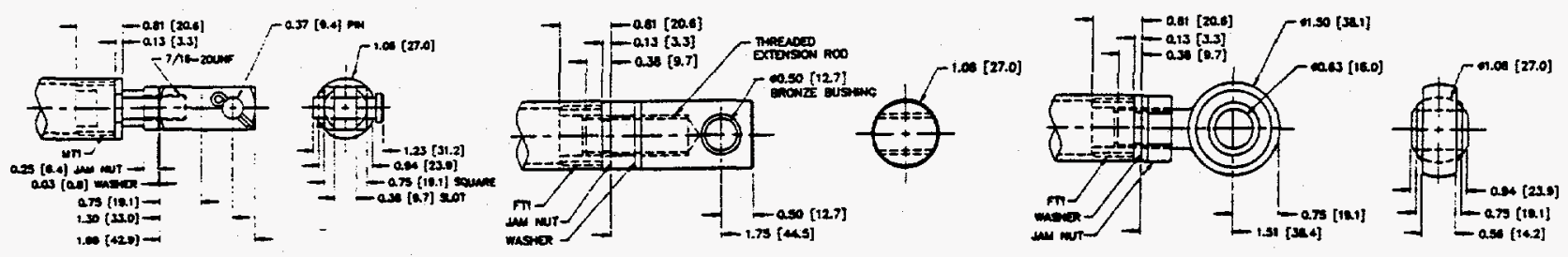

\section{MF 1 HEAD RECTANGULAR FLANGe MOUNTING}

PARAllel

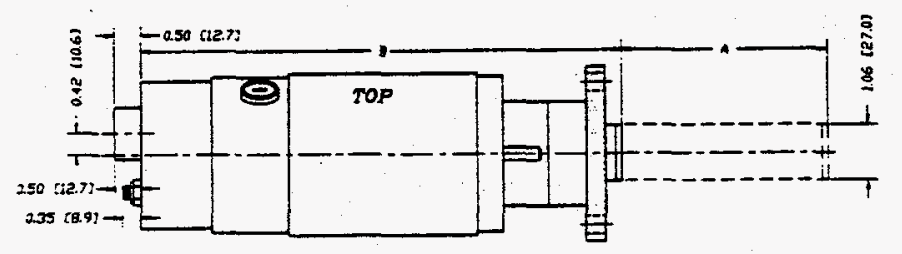

- CAD dranings available on diskette

- Include rod end dimensions. see above

- Opcional reverse paralle! configuration (-RM) dimensions. see above

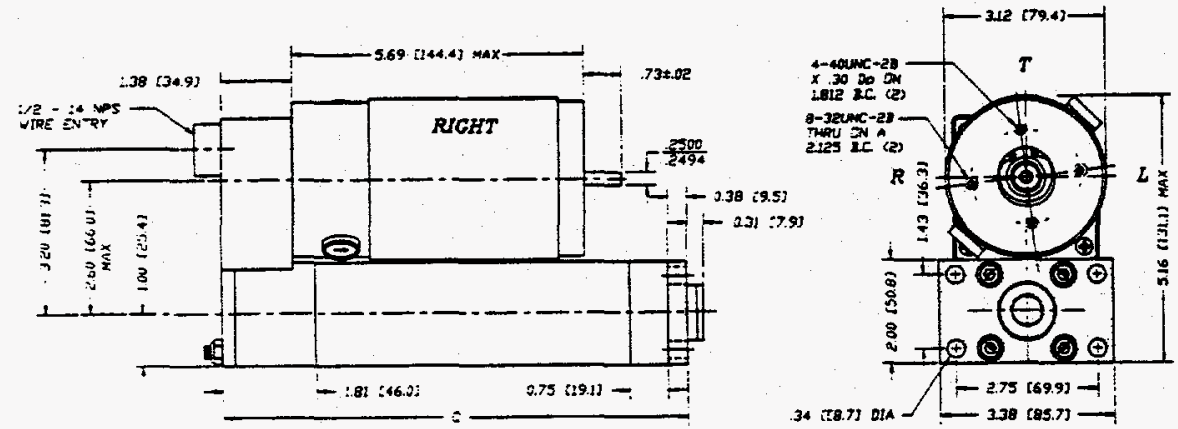
A Stroke
Inches (Merric)
B Retract
$2.00 \quad(50.8)+.00 \quad(101.6)$
$\begin{array}{llll}-.3- & (18 \% .2) & 9.3^{-} & 1238.0)\end{array}$
$\begin{array}{llll}6.00 & (152.4) & 8.00 \quad(203.2)\end{array}$
$\begin{array}{lllll}11.37 & (288.8) & 13.37 & (339.6)\end{array}$
$12.00 \quad(304.8) \quad 18.00 \quad(457.2) \quad 24.00(609.6)$
C Mounting
$\begin{array}{llll}-.06 & (179.3) & 9.06 & (230.1)\end{array}$
$\begin{array}{llll}11.06 & (280.9) & 13.06 \quad(331.7)\end{array}$
$\begin{array}{lllllll}17.37 & (441.2) & 23.37 & (593.6) & 29.37 & (746.0)\end{array}$
$\begin{array}{lllll}17.06 & (433.3) \quad 23.06 & (585 .-) & 29.06 & (738.1)\end{array}$ 


\section{CONTROLS}

The H3851 and H3951 controls are both microprocessor-based. closed loop servo positioning systems which use incremental encoder feedback $(0)$ provide accurate positioning control of $\mathrm{NH}$ and $\mathrm{RH}$ Series cylinders.

\section{Programming}

Both units use an advanced motion control language accessed by a builtin keypad/LCD display or by RS232C Serial Communication to create up to 98 programs containing move profiles and functional operations.

\section{INTERFACE}

Each has twelve inputs and ten outputs which offer a variety of $\mathrm{L} / \mathrm{O}$ configurations-allowing the units to stand alone or be easily interfaced with external devices such as computers, PLCs, or simple pushbutton operator stations.

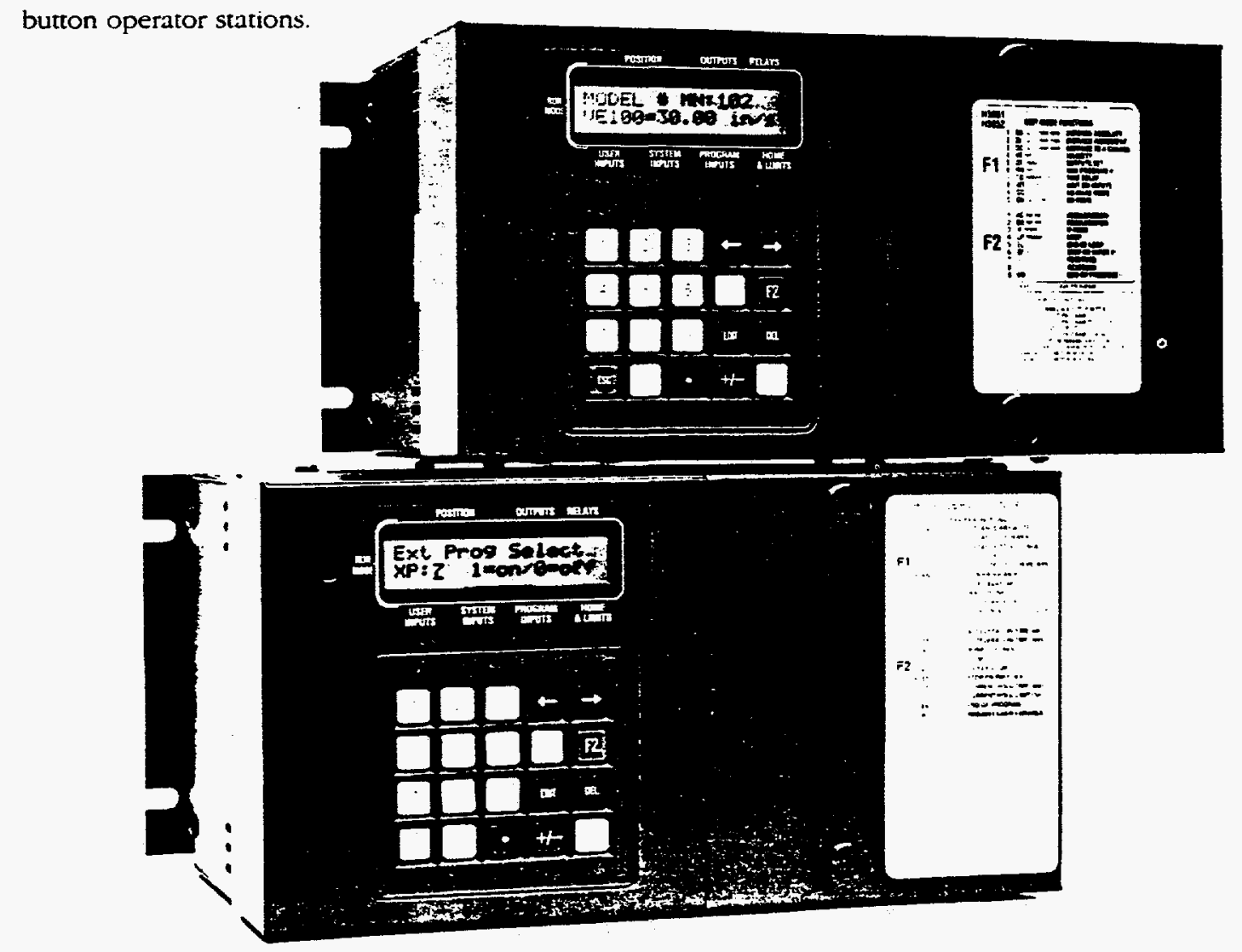

\section{H3851}

The Hixil executes a pre-defined moxe by doning a velociry loop to provide smoth and reliable speed regulation. As is nears the end of a move. the unit introduces il "speed reduction" to al fixed kom speed velociry at a user defined. set distance from the end point called the FIXIL MOVE to achieve a high degree of positioning repeatalbility.

\section{BASIC H3851/3951 SYSTEM}

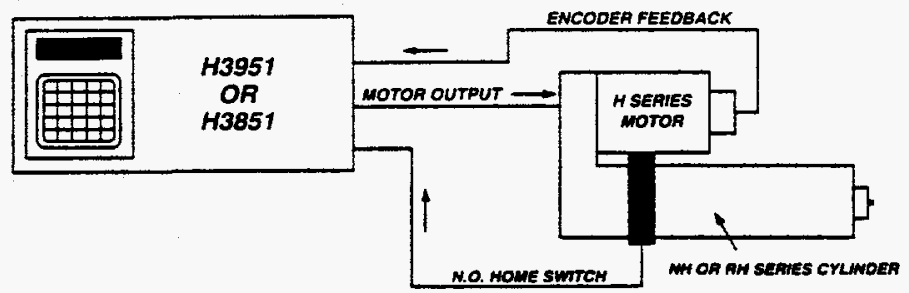

\section{[H3951]}

The H3951 uses an advanced move algorithm to reduce move cycle time. substantially increasing system throughput. The move algorithm closes a velocity servo loop to provide smooth and reliable speed regulation and closes a position servo loop to obtain accurate positioning (nithout a final move) couple with the ability to hold position before and atter moves. Both servo loops can be optimized by adjusting PID tuning parameters accessibte to users. 


\section{SYSTEM COMPONENTS}

The Control and Cylinder System

1 1. $1 \mathrm{H} 3851$ or H3951 Control

2. $1 \mathrm{NH}$ or $\mathrm{RH}$ Series Electric Cylinder (with a mounted H Motor)

3. 1 Encoder-500 line (2000PPR) mounted to the $\mathrm{H}$ Motor

f. 1 Home Switch

Normally Open Magnetic Position Sensors

RPS-1: Reed Switch (Mechanical Contact)

RP1: Hall Effect Switch (Solid State)

5. Two End-of-Travel "Extend and Retract" Limit Switches

Normally Closed Magnetic

Position Sensors

RPS-2: Reed Switch (Mechanical Contact)

RP2: Hall Effect Switch (Solid

State)

Extend and Retract End-of-

Travel Limit Switches are Not

Required for System Oper-

ation but are RECOMMIENDED

for Overtravel Protection.

\section{H3851/H3951 SERIES}

\section{REMOTE KEYPAD}

The model H3952 control offers all the features of the H3951 with the addition of a Remote Keypad and LCD Display for panel mounting or remote stand alone operation.

When restrictions such as panel mounting, operator interface considerations, or environmental requirements require control off-site, the $\mathrm{H} 3952$ is the correction solution.

The H3952 comes standard with' 6 feet of remote ribbon cable, shielded wire cable of lengths 10 feet and 20 feet are also available.

Options: CS10 10 feet of shielded wire cable CS20 20 feet of shielded wire cable

\section{Z OPTION FOR NH AND RH SERIES CYLINDERS}

All NH and RH Cylinders controlled by an $\mathrm{H} 3851$ or $\mathrm{H} 3951$ must include an encoder for feedback and a Home Limit Switch (for start up reference position). To simplify the ordering and installation process, the $Z$ Option containing an encoder pre-wired to the control and a home limit switch, is available for $\mathrm{NH}$ and $\mathrm{RH}$ Series cylinders.

\section{Z OPTION}

- RPS-1 Normally Open Home Switch (Reed Type)

- Encoder (Prewired to Control)

\section{ZH OPTION}

- RP1 Normally Open Home Switch (Hall Effect Type)

- Encoder (Prewired to Control)

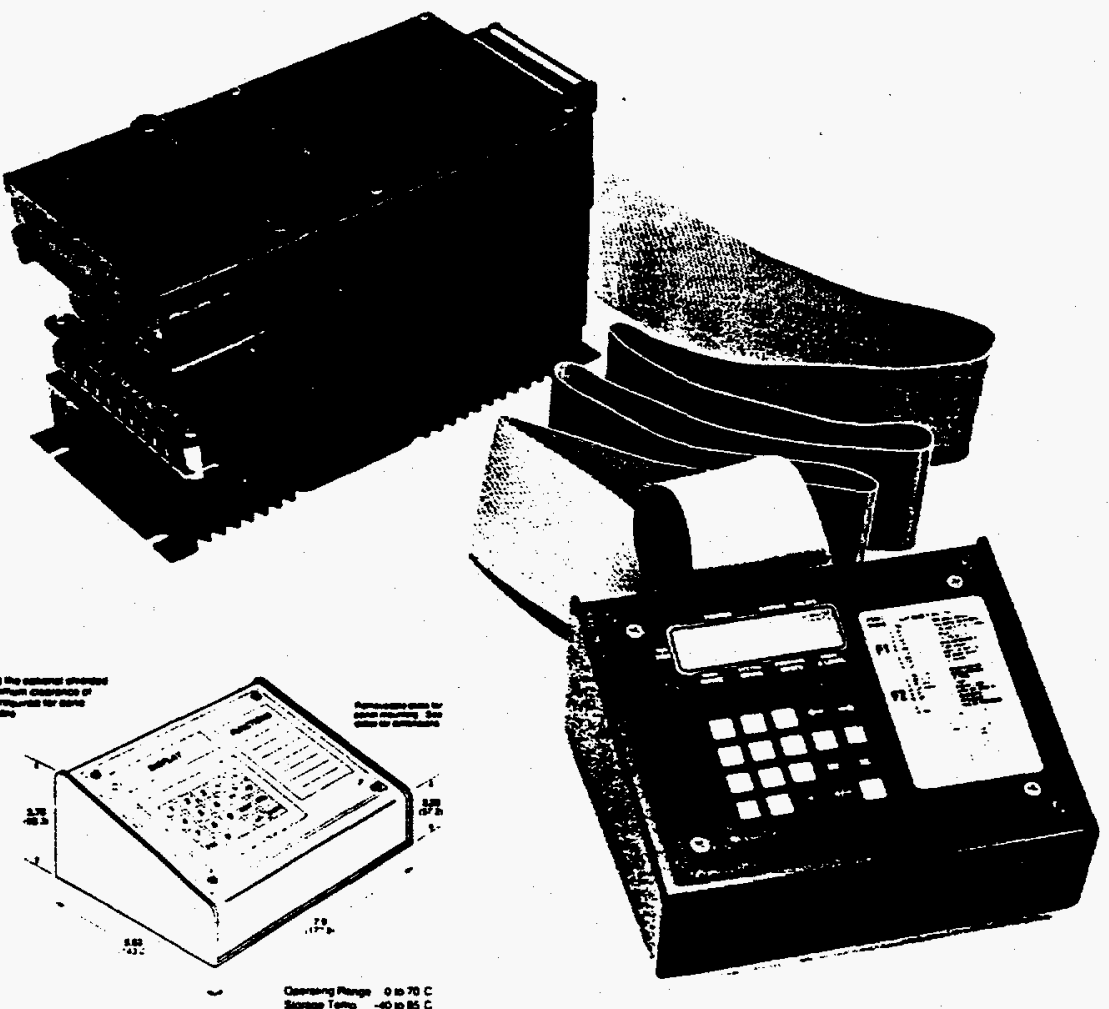


ENVIRONMENTAL SPECIFICATIONS

\section{OPERATING}

Temperature

$32^{\circ} \mathrm{F}$ to $130^{\circ} \mathrm{F}\left(0\right.$ to $55^{\circ} \mathrm{C}$ ) Note: An internal thermostat will shut don'n the drive if the intemal air temperature exceeds $160^{\circ} \mathrm{F}\left(? 1^{\circ} \mathrm{C}\right)$

Heat Sink Temperature

Storage Temperature

$\mathrm{H}$ Motor

ENCODER

Operational

Potrer Requirement

Pulses Per Rev:

Interface

Cabling

MOTOR

Operational

Voltage

Current

Torque

No Load Speed

Windings

- Resistance

Inductance

Cabling

Brushlife

\section{DIMENSIONS}

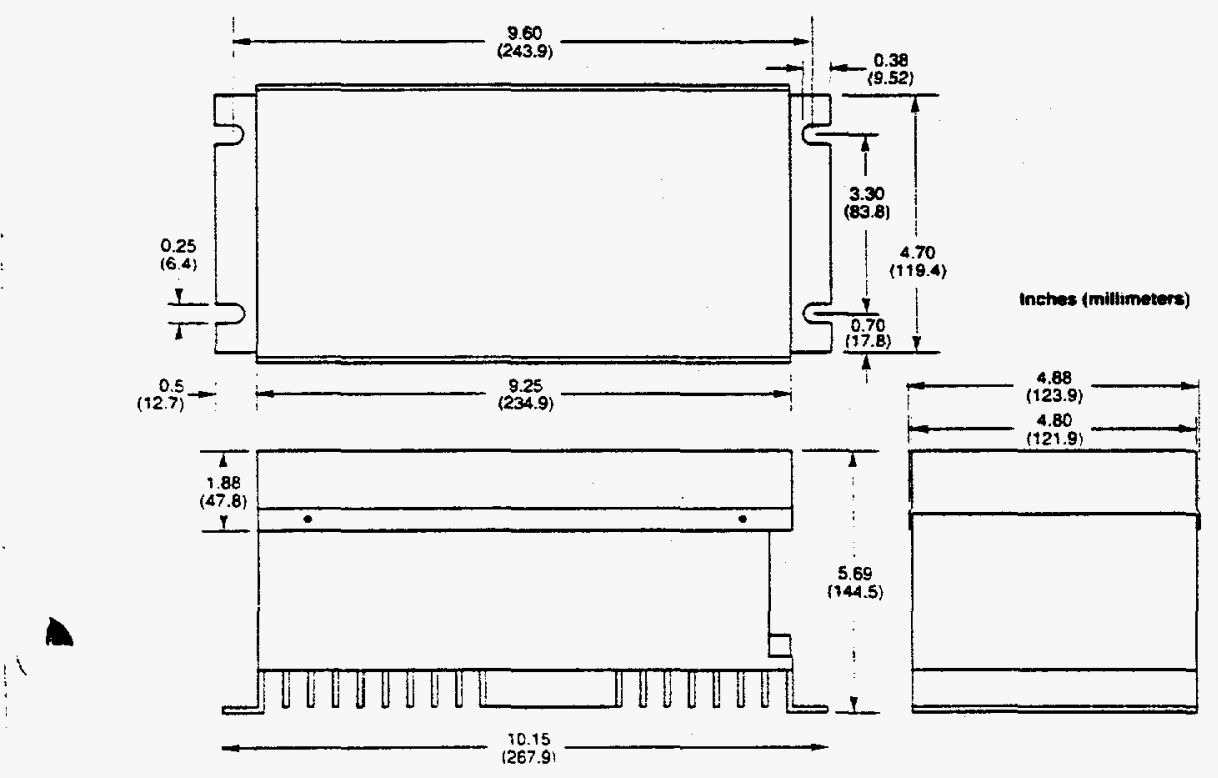

$212^{\circ} \mathrm{F}\left(100^{\circ} \mathrm{C}\right)$

$-40^{\circ}$ to $185^{\circ} \mathrm{F}\left(-40\right.$ to $\left.85^{\circ} \mathrm{C}\right)$

$180^{\circ} \mathrm{F}\left(82^{\circ} \mathrm{C}\right)$ (max. case temp.):

Dual Channel TTL Level Feedback

5 IDC at $90 \mathrm{ma}$

500 lines with quadrature (2000PPR)

Line Driver

8 Wire Shielded Cable W/Twisted Pair

Maximum length $200 \mathrm{ft}$. (22AWG)

Pernanent Magnet 2 Pole DC Motor. 2 lead

Rated 160 VDC. 180 VDC max

2 amps continuous. 6 amp peak

108 oz-in

3600 RPM

6.4 ohms

$21 \mathrm{mh}$

Less than 50f (16AWG).

50-100f (14AWG), 100-200ft (10AWG)

5 Million Cycles, 5000 Hours 


\section{SPECIFICATIONS}

\section{MOTOR/POWER}

Input Porver

Motor Output

Output Type

Capacitor

\section{OPERATIONAL}

Velocity Range

Accel/Decel Range

Position Range

Coordinate System

Linear Positioning

Repeatability

\section{LOGIC POWER}

Rating

\section{INPUTS}

High Level Inputs

Operational

Power Requirement

Low Level Inputs

Operational

Rating

\section{OUTPUTS}

Relay Outputs

Operational

Contact Ratings

Low Level Outputs

Operational

Ratings

\section{COMMUNICATIONS}

Operational

RS232C Setup
95 to $132 \mathrm{VAC}$ - $50 / 60 \mathrm{~Hz}$ : 5 amps max. 10 amps peak

160 VDC 22 amps continuous; 4.5 amps peak

PWM; MOSFET, bipolar H-bridge; switching $20 \mathrm{kHz}$

680uf (4700uf $\max$ ), 200 VDC, Polarized

$1-100 \%$ (linear speeds are cylinder dependent)

$0.05-15 \mathrm{sec}$

(士) 0-999.999 inches

Absolute or Incremental

0.001 inches ( $\mathrm{NH}$ and $\mathrm{RH}$ cylinders $\mathrm{w} / 5 \mathrm{~B}, 5 \mathrm{~A}, \& 8 \mathrm{~A}$ screw types)

0.003 inches ( $\mathrm{NH}$ and $\mathrm{RH}$ cylinders $\mathrm{w} / 2 \mathrm{~B}$ )

12 VDC unregulated at $500 \mathrm{ma}$

$250 \mathrm{ma}$ available to power external devices

$[\mathrm{H} 3951( \pm) \mathrm{SI} 1,( \pm) \mathrm{SI} 2,( \pm) \mathrm{SI} 3,( \pm) \mathrm{SI} 4]$

H3851 ( \pm IN $3,( \pm) I N 4,( \pm)$ SI1, ( \pm )SI2

Optically isolared Sinking or Sourcing Inputs Jumper Selectable AC or DC Voltage Activation

VDC 10 to $30 \mathrm{VDC}$ at 44 ma max

VAC 95 to $130 \mathrm{VAC}$ at 14 ma max

HOME, EEOT, REOT, PRG1, PRG2, PRG3, IN1, IN2

Optically isolated, sinking inputs

Draws $20 \mathrm{ma} 12 \mathrm{VDC}$ (10-16 VDC isolated voltage range)

All Inputs must be stable for a minimum of $10 \mathrm{~ms}$ to be recognized

(COM2, NC2. NC1) \& (COM1, NC1, NO1)

SPDT normally open normally closed contacts

2 amps at $30 \mathrm{VDC}$ resistive

2 amps at $125 \mathrm{VAC}$ resistive

OUT1, OUT2. OUT3, SO1, SO2, HOUT, LOUT, MCOM

Optically Isolated NPN Open Collector Sinking Outputs

ON Sinking to ground, $250 \mathrm{ma} 1.5 \mathrm{VDC}$

OFF Open circuit high. $2 \mathrm{ma}$ 12VDC

Serial RS232 Communication

9600 baud. 8 data bits, no parity, 1 stop bit

Three twire implementation (no handshaking).

\section{SOFTWARE/PROGRAMMING}

\section{Liemory}

Programs
H3851

$2 \mathrm{~K}$ Non-Volatile EEPROM (1.jK available for programming)

Lp to 98 Motion Programs

Lp to 256 Characters per program (not to exceed the $1.5 \mathrm{~K}$ of total available program memon:)

Command Format 2 character upper-calse ASCII

Progr:am Entr. Keypad or RS232 Serial Interface

\section{H3951}

8K Non-Volatile EEPROM (7.5K available for programming)

Lip to 98 Motion Programs

Up to 1000 Characters per program (not to exceed tho

$7.5 \mathrm{~K}$ of total available program memory)

2 character upper-case ASCII

Keypad or RS232 Serial Interface

Keypad, RS232, or External I/O Interface 


\section{OPERATIONAL FLOWCHART}

\section{Run Mode}

Poner Lp . Mode and Vain Mode of Operation Allows the user to perform the following

Allows immediate OPERATIONAL \& FLNCTIONAL CONTROL through the keypad using the Run Hode "Function" Command Set

Allow's the user to MONITOR Cylinder Position. I/O Status. and/or Function Status from the LCD Screen Allows ACCESS to all other Modes of Operation

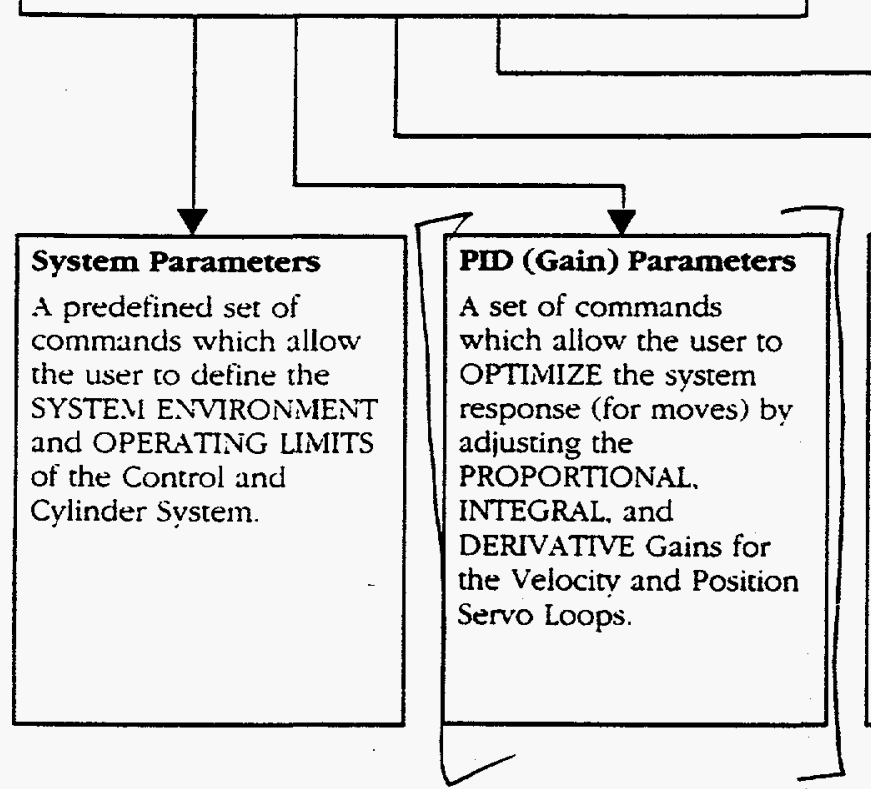

\section{RS232}

Allows user to communicate with the $\mathrm{H} 3951 / \mathrm{H} 3851$ ria ASCII Characters over the RS232 Port from a remote host device such as a computer or PLC to perform the following;

- LPLOAD \& DOW:NLOAD program strings and

$C$ parameter values

- EXECLTE Programs and Functional Operations

- MONITOR Position and L/O Status

The RS232 Por will operate ONLY in the Run Mode.

\section{SIMPLE KEYPAD PROGRAMMING}

The keypad rith an integral LCD display allon's the user to easily enter new programs, vien status messages and edit programs stored in the nonvolatile memon: Each of the 20 pushbuttons on the kerpad have been assigned to a specific role in developing or running a program.

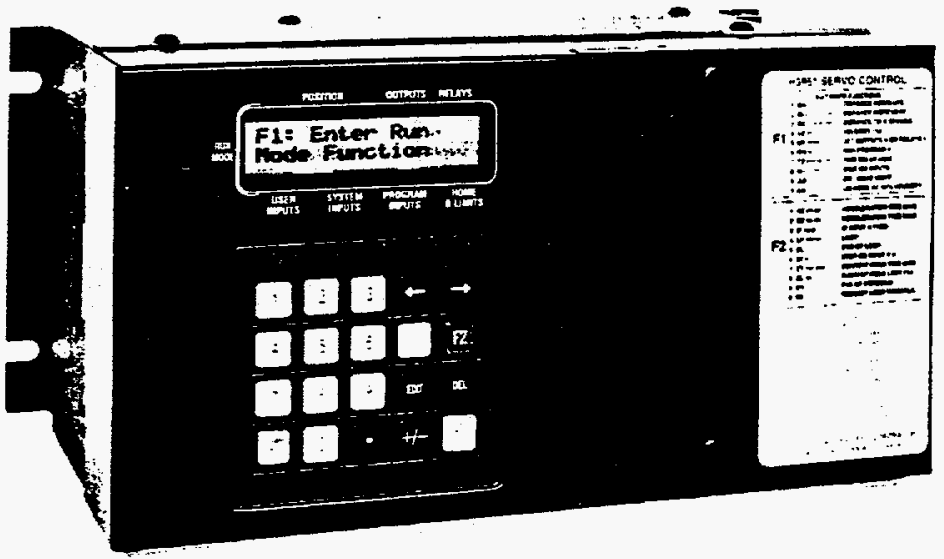

\section{Edit Mode}

The Edit Mode allows the user to access the Edic Mode Command List to CREATE new programs or EDIT existing programs for execution in the Run Mode.

A PROGRAM consists of a series of Edit Mode Commands denoted a Move Profile andior a Functional Operation.

\section{Learn Mode}

The Learn Mode allows the user to MANLALLY TEACH POSITIONS tO the Control by manually jogging the cylinder to desired positions and loading them into a specified program. 

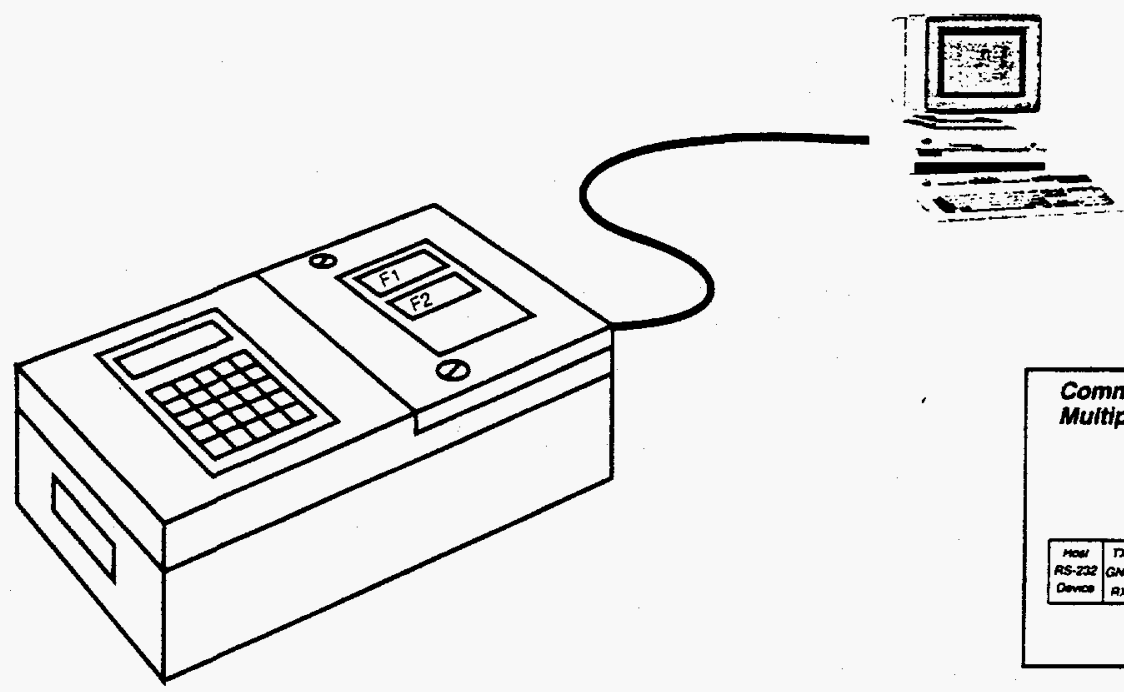

\section{RS-232C PROGRAMMING}

The RS-232C port allows the $\mathrm{H} 3851$ and H3951 Controls to communicate to a host device (such as a Computer or $P(C)$ via a 3 wire Serial Interface to LPLOAD and DOWNLOAD programs $\&$ parameters and to allow remote functional control.

PROGRAM EXECUTTON from the RS-232C port is available on the H3951 ONLY

\section{RS-232C COMMAND SYNTAX $<$ i $>$ ASCII} [device address] [command]

\section{RS-232C COMMAND SET}

\section{Operational Command Set}

Used to Upload \& Download programs and initiate software control functions.

System Parameter Commands

Used to Configure Svstem Functions

PID Parameter Commands] Used to Configure PID Gains

Edit Mode Commands

Used to Create Programs

(See Command Summary on page 113.)

RS-232C COMMAN
$<$ id
[device address]
$<\mathrm{a}>\quad$ device address
ASCII command
$\mathrm{nnn}$ paramerers
$<\mathrm{p}>$ delimiter




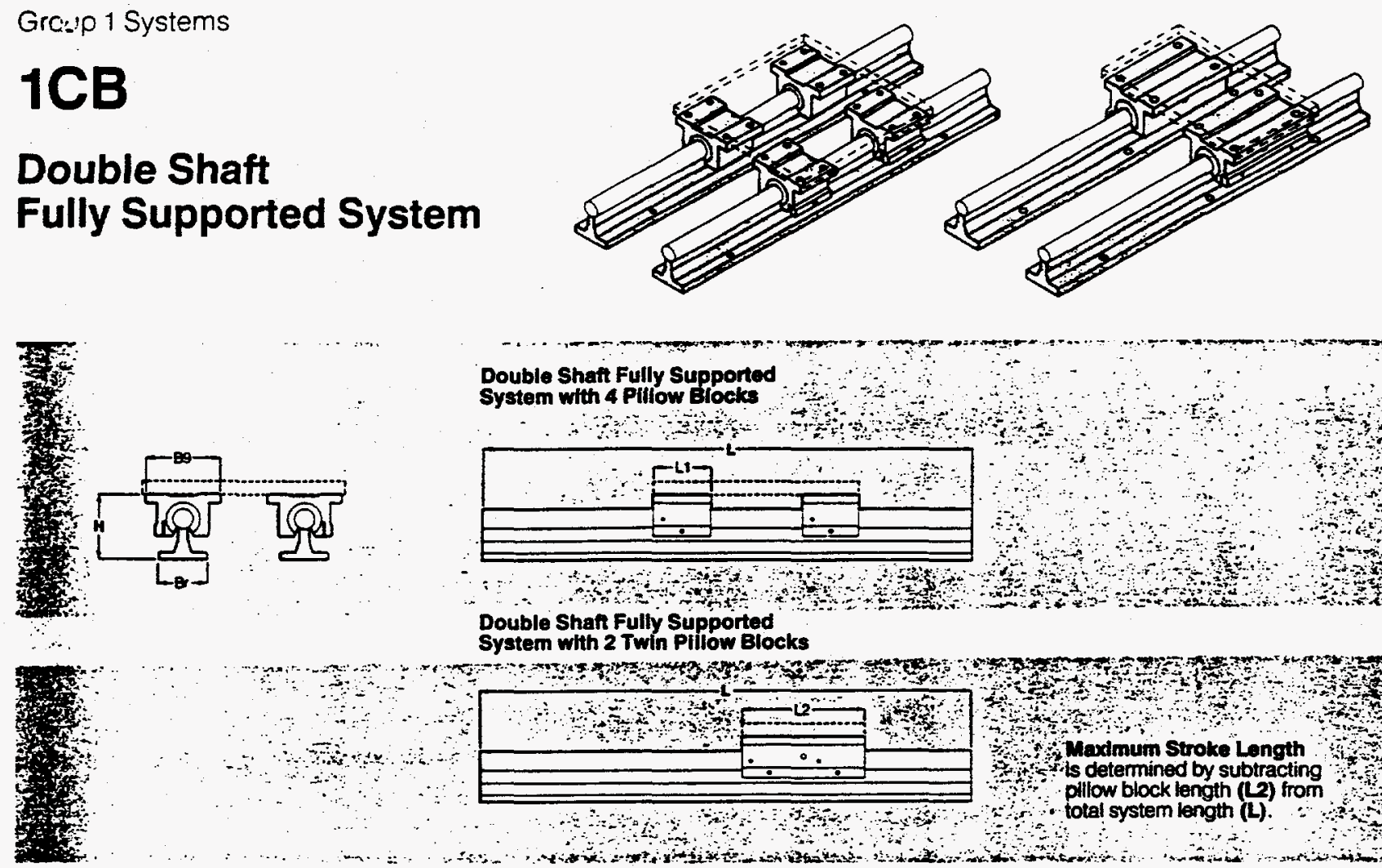

\section{Double Shatt Fully Supported \\ System with 4 Pillow Blocks}

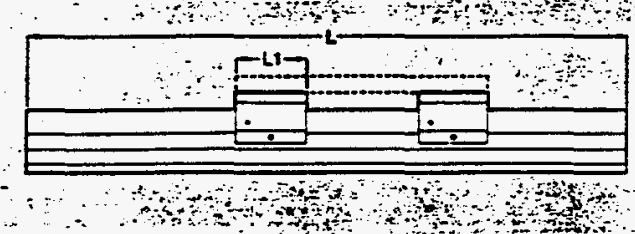

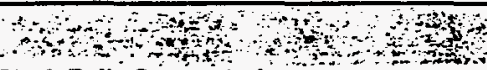

Double Shat Fully Supported

System whth 2 Twin Plilow Blocks

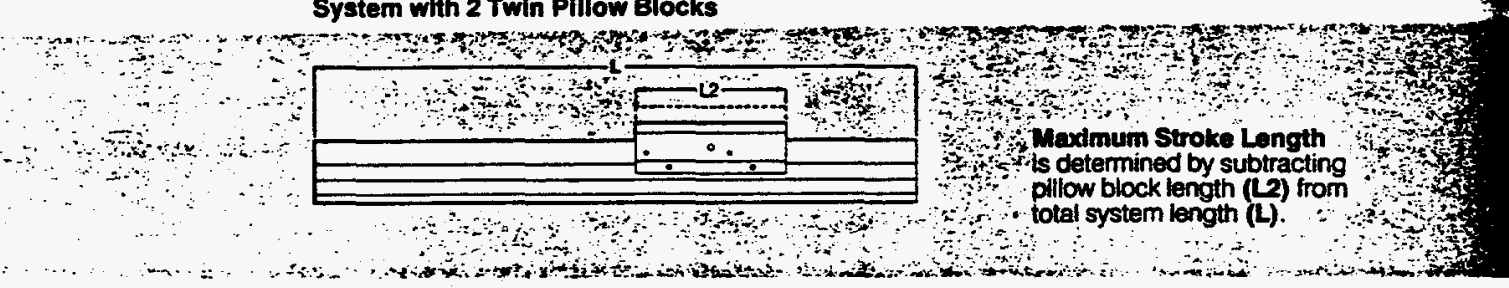

\begin{tabular}{|c|c|c|c|c|c|c|c|c|c|}
\hline \multirow{2}{*}{$\begin{array}{l}\text { Part } \\
\text { No. }\end{array}$} & \multirow{2}{*}{$\begin{array}{l}\text { Nom. } \\
\text { Shatt } \\
\text { Dia. }\end{array}$} & \multicolumn{2}{|c|}{ Load (bf)* } & \multicolumn{4}{|c|}{ Dimension (in.) } & \multirow{2}{*}{$\begin{array}{l}\text { Pillow } \\
\text { Block }\end{array}$} & \multirow{2}{*}{$\begin{array}{l}\text { Rail } \\
\text { Assembly }\end{array}$} \\
\hline & & $\begin{array}{l}\text { Max. } \\
\text { On } \\
\text { System }\end{array}$ & $\begin{array}{l}\text { Max. } \\
\text { On Any } \\
\text { Bearing }\end{array}$ & LI & $\begin{array}{l}H \\
\pm 0.001\end{array}$ & $\overline{B r}$ & $\mathrm{B9}$ & & \\
\hline 1CB-OB-FAO & $1 / 2$ & 720 & 180 & 1.50 & 1.812 & 1.50 & 2.00 & SPB-8-OPN-XS & SRA-8-XS \\
\hline 1CB-12-FAO & $3 / 4$ & 1880 & 470 & 1.88 & 2.437 & 1.75 & 2.75 & SPB-12-OPN-XS & SRA-12-XS \\
\hline 1CB-16-FAO & 1 & 3120 & 780 & 2.63 & 2.937 & 2.13 & 3.25 & SPB-16-OPN-XS & SRA-16-XS \\
\hline 1CB-24-FAO & $11 / 2$ & 6240 & 1560 & 3.75 & 4.250 & 3.00 & 4.75 & SPB-24-OPN-XS & SRA-24-XS \\
\hline
\end{tabular}

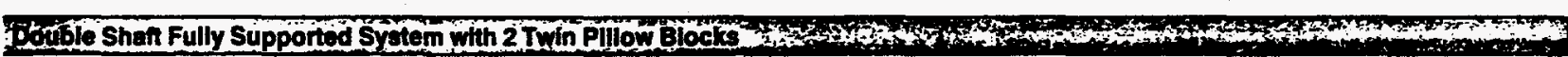

\begin{tabular}{|c|c|c|c|c|c|c|c|c|c|c|}
\hline \multirow{2}{*}{$\begin{array}{l}\text { Part } \\
\text { No. }\end{array}$} & \multirow{2}{*}{$\begin{array}{l}\text { Nom. } \\
\text { Shatt } \\
\text { Dia. }\end{array}$} & \multicolumn{2}{|c|}{ Load $(\mathrm{lb})^{*}$} & \multicolumn{4}{|c|}{ Dimension (in.) } & \multirow{2}{*}{$\begin{array}{l}\text { Maximum } \\
\text { Stroke } \\
\text { Length } \\
\text { (in.) }\end{array}$} & \multirow{2}{*}{$\begin{array}{l}\text { Pillow } \\
\text { Block }\end{array}$} & \multirow{2}{*}{$\begin{array}{l}\text { Rail } \\
\text { Assembly }\end{array}$} \\
\hline & & $\begin{array}{l}\text { Max. } \\
\text { On } \\
\text { System }\end{array}$ & $\begin{array}{l}\text { Max. } \\
\text { On Any } \\
\text { Bearing }\end{array}$ & $\overline{\mathrm{L} 2}$ & $\begin{array}{l}H \\
\pm 0.001\end{array}$ & $\mathrm{Br}$ & B9 & & & \\
\hline 1 CB-08-HAO & $1 / 2$ & 720 & 180 & 3.50 & 1.812 & 1.50 & 2.00 & $L-(3.50)$ & TWN-8-OPN-XS & SRA-8-XS \\
\hline 1CB-12-HAO & $3 / 4$ & 1880 & 470 & 4.50 & 2.437 & 1.75 & 2.75 & $L-(4.50)$ & TWN-12-OPN-XS & SRA-12-XS \\
\hline $1 \mathrm{CB}-16-\mathrm{HAO}$ & 1 & 3120 & 780 & 6.00 & 2.937 & 2.13 & 3.25 & $L-(6.00)$ & TWN-16-OPN-XS & SRA-16-XS \\
\hline 1CB-24-HAO & $11 / 2$ & 6240 & 1560 & 9.00 & 4.250 & 3.00 & 4.75 & $L-(9.00)$ & TWN-24-OPN-XS & SRA-24-XS \\
\hline
\end{tabular}

*Based on a travel life of 2 million inches.

\begin{tabular}{|c|c|c|c|c|c|c|c|c|c|c|c|c|c|c|}
\hline System & $8^{\prime \prime}$ & 12 & $16^{\prime \prime}$ & $18^{\prime \prime}$ & $20^{\circ}$ & $24^{\prime \prime}$ & $28^{\prime \prime}$ & $30^{\prime \prime}$ & $32^{\prime}$ & $36^{\prime \prime}$ & $40^{\circ}$ & $42^{\circ}$ & $44^{\prime \prime}$ & $48^{\prime \prime}$ \\
\hline $1 C \mathrm{CB}-08$ & 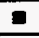 & E & 0 & & E & 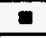 & $\mathbf{E}$ & & 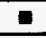 & 1 & 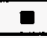 & & e & e \\
\hline $1 \mathrm{CB}-12$ & & a & & - & & - & & $\bar{\square}$ & & $\bar{E}$ & & $\square$ & & 口 \\
\hline $1 \mathrm{CB}-16$ & & a & & $\square$ & & 口 & & 口 & & - & & a & & $\square$ \\
\hline 1CB-24 & & & - & & & $\square$ & & & 口 & & $\square$ & & & n \\
\hline
\end{tabular}

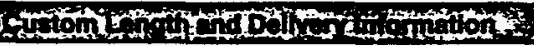

Systems ordered in standard lengths are typically shipped in one week. Custom length systems are available and require two to three weeks for delivery. Lengths exceeding 156.00 ins. require butt joints and will need four to six weeks for delivery. For special requirements, please contact the Thomson requirements, please contact the Thornson
Systems application engineering department. 
Svstem 1CB Benefits:

$\because$ Allowis for custom table applications.

- Fully supported shatts increase rigidity.

- Double shaft configuration resists torque.

- Allows for unlimited system length.
System 1CB Components:

- 4 Super Open Ball Bushing Bearing Pillow Blocks or 2 Super Twin Open

Ball Bushing Bearing Pillow Blocks

- 260 Case Inner Races

- Aluminum Shaft Support Rails
Spectying a Thomaon Syatem:

1 Determine the proper snatt diameter for your load and iffe requirements 2 . Select ine pan number that corresponas to the snat diameter. 3. Add ine tetter " $L$ " foliowed by the overali length in inches, as a suttix to the Dat number lcnoosing a stancard length will reduce cosis and speed deliveryl 4. Place your order with you tocal authorized Thomson distrioutor.

Part Numbering System

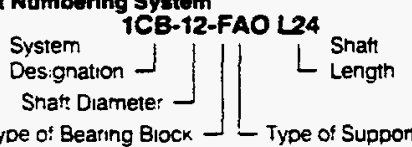

Type SPB-OPN Super

Ball Bushing Eearing

Plllow Bloek
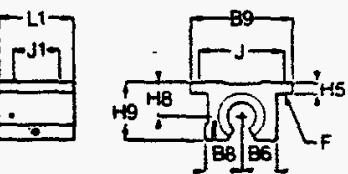

Type TWN-OPN

Twin Open Plllow Block

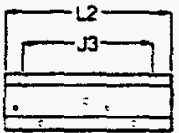

\section{Type SRA Aluminum Shan} Support Rall Aseambly
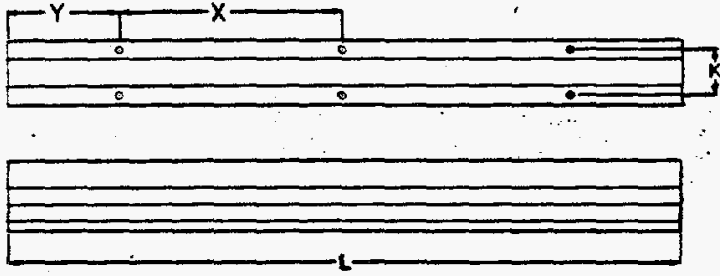

$\underbrace{+}_{-B x} \int_{2}^{G}$

\begin{tabular}{|c|c|c|c|c|c|c|c|c|c|c|c|c|c|c|c|c|c|c|}
\hline \multirow{2}{*}{$\begin{array}{l}\text { Part } \\
\text { No. }\end{array}$} & \multicolumn{13}{|c|}{ Nom. Dimension (in.) } & \multirow{2}{*}{$\begin{array}{l}\text { Part } \\
\text { No. }\end{array}$} & \multirow{2}{*}{$\begin{array}{l}\text { Nom. } \\
\text { Shatt } \\
\text { Dia. }\end{array}$} & \multicolumn{3}{|c|}{ Dimension (in.) } \\
\hline & $\begin{array}{l}\text { Shaft } \\
\text { Dia. }\end{array}$ & $\overline{\mathrm{L1}}$ & H9 & $\begin{array}{l}\mathrm{H} 8 \\
\pm 0.00\end{array}$ & ${ }_{1} \mathrm{HS}$ & B9 & 88 & B6 & $\mathrm{J}$ & J1 & $\frac{F}{B o l t}$ & Hole & $\begin{array}{l}\text { Wh. } \\
\text { (lb.) }\end{array}$ & & & $\overline{2}$ & $\sqrt{3}$ & $\begin{array}{l}\mathrm{m} . \\
\text { (ib.) }\end{array}$ \\
\hline SPB-8-OPN-XS & $1 / 2$ & 1.50 & 1.12 & 0.687 & 0.25 & 2.00 & 0.75 & 0.69 & 1.69 & 1.00 & $\# 6$ & 0.16 & 0.20 & TWN-8-OPN-XS & $1 / 2$ & 3.50 & 2.50 & 0.40 \\
\hline SPB-12-OPN-XS & $3 / 4$ & 7.88 & 1.56 & 0.937 & 0.31 & 2.75 & 1.00 & 0.94 & 2.38 & 1.25 & $\# 6$ & 0.19 & 0.50 & TWN-12-OPN-XS & $83 / 4$ & 4.50 & 3.50 & 1.00 \\
\hline SPB-16-OPN-XS & & 2.63 & 2.00 & 1.187 & 0.38 & 3.25 & 1.25 & 1.19 & 2.88 & 1.75 & $\# 10$ & 0.22 & 1.00 & TWN-16-OPN-XS & & 6.00 & 4.50 & 2.00 \\
\hline SPB-24-OPN-XS & $11 / 2$ & 3.75 & 2.94 & 1.750 & 0.50 & 4.75 & 1.88 & 1.75 & 4.12 & 2.50 & $1 / 4^{\prime \prime}$ & 0.28 & 3.20 & TWN-24-OPN-XS & $511 / 2$ & 9.00 & 6.50 & 6.70 \\
\hline
\end{tabular}

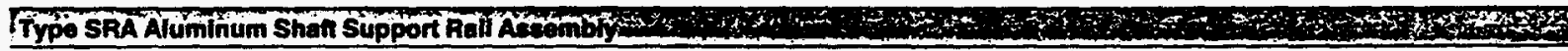

\begin{tabular}{|c|c|c|c|c|c|c|c|c|c|c|}
\hline \multirow{3}{*}{$\begin{array}{l}\text { Part } \\
\text { No. }\end{array}$} & \multirow{3}{*}{$\begin{array}{l}\text { Nom. } \\
\text { Shat } \\
\text { Dia. }\end{array}$} & \multicolumn{9}{|c|}{ Dimension (in.) } \\
\hline & & \multirow{2}{*}{$\begin{array}{l}\mathrm{H} 1 \\
=0.001\end{array}$} & \multirow[t]{2}{*}{$\mathrm{H} 7$} & \multirow[t]{2}{*}{$\mathrm{Br}$} & \multirow[t]{2}{*}{$\mathrm{K}$} & \multirow[t]{2}{*}{$\bar{x}$} & \multirow[t]{2}{*}{$\bar{Y}$} & \multicolumn{2}{|l|}{ G } & \multirow{2}{*}{$\begin{array}{l}\text { Weight } \\
\text { (ib.) }\end{array}$} \\
\hline & & & & & & & & Bolt & Hole & \\
\hline SRA-8-XS & $1 / 2$ & 1.125 & 0.19 & 1.50 & 1.00 & 4.00 & 2.00 & $\# 6$ & 0.17 & 1.26 \\
\hline SRA-12-XS & $3 / 4$ & 1.500 & 0.25 & 1.75 & 1.25 & 6.00 & 3.00 & $\# 10$ & 0.22 & 2.50 \\
\hline SAA-16-XS & 1 & 1.750 & 0.25 & 2.13 & 1.50 & 6.00 & 3.00 & $1 / 4^{n}$ & 0.28 & 4.06 \\
\hline $5 R A-24-\times S$ & $11 / 2$ & 2.500 & 0.38 & 3.00 & 2.25 & 8.00 & 4.00 & $5 / 16^{\prime \prime}$ & 0.34 & 8.60 \\
\hline
\end{tabular}

Support rail material: Aluminum Alloy Black Anodized Base mounting holes are within $\pm 0.010^{\prime \prime}$. Noncumulative

Maximum length of Aluminum Shatt Support Rails is $24^{\prime \prime}$. It longer continuous one-piece Shaft Support Rails are required, contact the Thomson Systems application engineering department. 
David M. Russell

(214) $708+410$

Superconducting Super Collider Laboratory

Physics Research Department.

2550 Beckjeymende Avenue. MS 2004

Dallas. Texas 75237-3997

FAX: (214) 708-5111

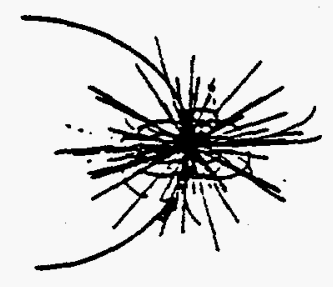

\section{Svnchrotron Radiation Detector}

June, 14- 1993

\section{ASMIE Boiler and Pressure Vessel Code Section 8 Division I}

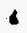

- This document logs the procedure for verifying the Synchrotron Radiation Detector, SRD, against the ASME Boiler and Pressure Vessel, BPV, Code. The goal is to have the SRD pass the ASME BPV Code.

U-1(c) - The following classes of vessels are not considered to be within the scope of this Division:

(8) - vessels having an internal or external operating pressure not exceeding 15 psi with no limitarions on size.

U-1(k) - Any pressure vessel which meets all of the requirements of this Division, including those for inspection. may be stamped with the Code U Symbol even though exempted from such stamping.

Interp. - The external operaing pressure is $14.7 \mathrm{psi}$ and therefore the SRD is exempt from the ASME, BPV, Code. But if the SRD meets the ASME BPV Code it can be stamped with the Code $U$ symbol.

U28-(f) - Vessels intended for service under extemal working pressure of 15 psi or less. which are to be stamped with the Code symbol denoting compliance with the rules for external pressure, shall be designed for a maximum allowable working pressure of 15 psi or $25 \%$ more than the maximum possible external pressure. whichever is smaller.

Interp. - Design the SRD for an external pressure of $15 \mathrm{psi}(103.42 \mathrm{kPa})$. 
UG-16(b) - The minimum thickness of shells and heads is $1 / 16$ in. (1.5875 mm).

(Summary)

Table UHA-23 - Seamless Pipe. 304L Stainless Steel (SA-312).

Specified Min. Yield $25 \mathrm{ksi}$

Specified Min. Tinsile $70 \mathrm{ksi}$

Maximum Allowable Stress $16.7 \mathrm{ksi}$

Note: Due to the relatively low yield strength of these materials, these higher stess values were established at temperatures where the shor time tinsile properties govern to permit the use of these alloys where slightly greater deformation is

- acceptable. These higher stress values exceed $2 / 3$ bur do not exceed $90 \%$ of the yield strength at temperature. Use of these stress values may result in dimensional changes due to permanent strain. These stress values are not recommended for flanges of gaskered joints or other applications where slight amounts of distorion can cause leakage or malfuncrion.

Intrp. - Use conservarive maximum allowable suess of $12 \mathrm{ksi}$, (82.7 MPa).

UG-23(b) - The maximum allowable longizudinal compressive suess is the smaller of:

(1) - The maximum allowable tensile stress from Table UHA-23. (16.7 ksi).

(2) - The computed value of B from FIG. 5-UHA-28.3.

$$
A=\frac{0.125}{R_{1} / t}
$$

Where. $R_{r}=6.375$ in. $t=0.134$ in. and $E=28 \times 10^{6}$ psi. Therefore. $A=0.00263$ and from FIG. 5 -UHA-28.3, B=11.0 ksi.

Intrp. - Use maximum allowable longirudinal compressive stress of $11.0 \mathrm{ksi}$. (75.8 $\mathrm{MPa}$ ).

UG-28 - Thickness of shells and tubes under external pressure.

$$
\begin{array}{lr}
L=15.82 \text { in }(401.8 \mathrm{~mm}) & D_{0}=12.75 \mathrm{in} . \\
L / D_{0}=1.24 & D_{O} / t=95.15 \\
A=0.0012 & \text { (From FIG. 5-UGO-28.0) } \\
B=9 \mathrm{ksi} & \text { (From FIG. 5-UHA-28.3) } \\
E=28 \times 10^{6} \mathrm{psi} & \text { Modulus of Elasticity } \\
P=15 \mathrm{psi} & \text { Design Pressure }
\end{array}
$$


Determine the external working pressure using,

$$
P_{a}=\frac{4 B}{3 D_{0} / t}
$$

For $i=0.18$ in. the working pressure, $P_{2}$, is 126 psi.

If $t=1 / 16 \mathrm{in}$, the working pressure. $P_{2}$, is $68 \mathrm{psi}$.

Intrp. - The current design thickness is more than sufficient. (Assuming the stresses are less than the allowable sress.)

UG-34 - The minimum thickness of flatheads and covers is defined by,

$$
t=d \sqrt{C P / S E+1.9 W h_{c} / S E d^{3}}
$$

- Where,

$\begin{array}{ll}d=9.12 \mathrm{in} . & \text { Diameter as indicated in Fig. UG-34 } \\ C=0.30 & \text { Attachment Factor } \\ \mathrm{P}=15 \mathrm{psi} & \text { Design Pressure } \\ \mathrm{S}=12 \mathrm{ksi} & \text { Allowable Stress } \\ E=1.0 & \text { Joint Efficiency of Welds. } \\ W=7800 & \text { Tom Bolt Load } \\ \text { hG }=0.56 \mathrm{in} . & \text { Dimension as indicated in Fig. UG-34 Assumed }\end{array}$
then, the minimum thickness is .327 in $(8.3 \mathrm{~mm})$. The minimum thickness of the coverplate in the gasket region is given by,

$$
t=d \sqrt{1.9 W h_{c} / S d^{3}}
$$

which yieids a minimum thickness of .275 in $(7.0 \mathrm{~mm})$.

Intrp. - The minimum thickness of the head is .327 in $(8.3 \mathrm{~mm})$ and the minimum thickness in the gasket region is .275 in $(7.0 \mathrm{~mm})$.

UG-36(b)(1) - Rules UG-36 through UG-43 and supplemental rules 1-7 apply to openings in vessels 60 in. in diameter and less, exceeding one-half the vessel diameter. but not exceeding 20 in. (Summary)

UG-36(c)(3)(a) - Openings in vessels not subject to rapid fluctuations in pressure do not require reinforcement if not larger than $31 / 2$ in. in vessel shells or heads $3 / 8$ in. or less in thickness or $23 / 8$ in. diameter in vessel shells or heads over $3 / 8$ in. in thickness. 
Intrp. - The large hole may need reinforcing but the small holes in the head and the shell are exempt.

UG-37(d)(1) - The reinforcement required for openings in single-walled vessels subject to exremal pressure need be oniy $50 \%$ of.

$$
A=d t_{r} F+2 t_{n} t_{r} F\left(1-f_{r 1}\right)
$$

where,

$$
\begin{array}{ll}
d=7.891 \text { in. } & \text { Diameter of Circular Opening } \\
t_{r}=1 / 16 \text { in. } & \text { Require Thickness of Shell Assumes Stress is } O K \\
F=1.0 & \text { Correction Factor } \\
t_{n}=0.109 \text { in. } & \text { Nominal Thickness of Nozzle Wall } \\
f_{r 1}=1.0 & \text { Nozzle Attachment Factor }
\end{array}
$$

- yields a required reinforcing area of .2466 in $^{2}$. The area available in the shell for reinforcement is compured to be .5642 in 2 . The current design also complies with rules UG-36 through UG-43 and the supplemental rules in 1-7.

Intrp. - The thickness of the shell is sufficient to provide the required reinforcement to the opening. Therefore no addirional material is required.

UG-54(b) - Appendix G contains suggested rules for the design of supports.

UG-101 - Proof tests to establish maximum allowable working pressure.

G-6 - Horizontal vessels may be supported by means of saddles or equivalent leg supports. For other than very small vessels. the bearing afforded by the saddles shall extend over at least one-third of the circumference of the shell.

Stress - From Roark's Formulas for Stress \& Strain;

$$
\begin{array}{ll}
\sigma_{1}=P / t & \text { Longindinal Stress } \\
\sigma_{z}=q R / t & \text { Circumferencial Stress }
\end{array}
$$

Where, $P$ is the end load and $q$ is the uniform pressure. The values of these are far below the allowable suress. $\sigma_{1}=524 \mathrm{psi}$. This doesn't account for loads other than the extemal pressure. but indicates that the stresses in the vessel will be far below the allowable stress. 
ANSYS - The SRD was modeled using STIF63 shell elements, with conservarive force estimates applied. The resulting maximum stress was $11.6 \mathrm{ksi}$, which is less than the $12 \mathrm{ksi}$ allowable stress. The resulting maximum longitudinal compressive stress was $9.58 \mathrm{ksi}$. which is less than the allowable of $11 \mathrm{ksi}$. The resulting maximum von Misis suess was $12.85 \mathrm{ksi}$, which is slightly above the allowabie stress, but, this is at a stress concentration (the edge of the support). The other maximums are also at the same stress concentration. If this node is not considered then the maximum von Misis stress is $6.86 \mathrm{ksi}$. (This is an allowable practice according to the code.) These are the values at either the top or bortom of the shells. The maximum von Misis stress at the middle of the shells is $5.20 \mathrm{ksi}$, which is all that is required by the code. If the von Misis stress is less than the allowable stress than all of the stress components will be less than the allowable - stress.

Intrp. - The stresses in the SRD are less than half of the allowable stress and therefore the SRD can receive the code stamp.

Conclusion - The SRD easily passes all the criteria of the ASME Boiler and Pressure Vessel Code and can be stamped with the Code U symbol. 


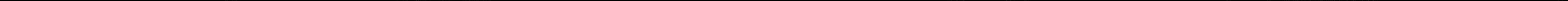


Fiq. Co-34

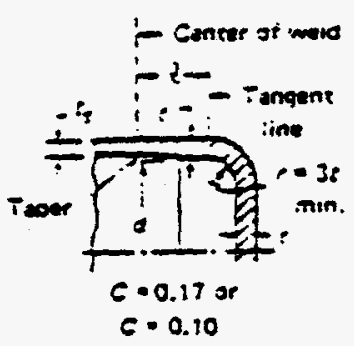

(a)

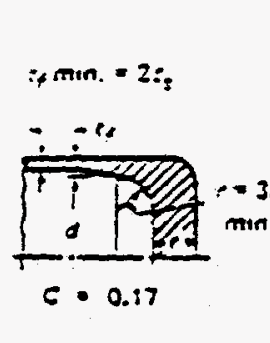

(b-1)

1989 SECTON VTII - DIVISION 1

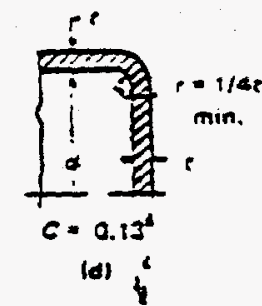

(d) is

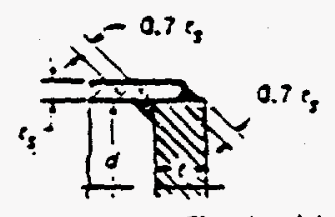

skarenes (e), (l), and (g) eireular covors, $6=2.33 \mathrm{~m}$, $6 \mathrm{~min}$. $=0.20$

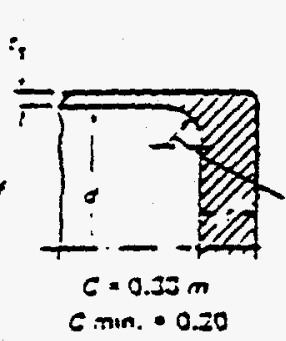

$(b-2)$

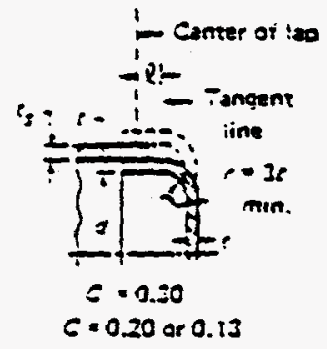

(e)

$t_{w} \cdot 2 t_{p}$ min. nor less tan $1.25 \mathrm{r}_{5}$ but newa not se greater inan $b$

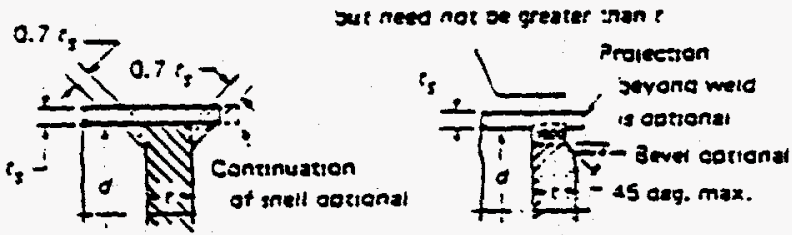

Proresten

mun 2.275 in.

rmun. $0.25 \mathrm{c}_{3}$ tor

$t_{8}>1-1 / 2$ in.

jut nesd not se greater man 314 in.

S. Fig. UW-13.2 akerentes (a) rotg)." incturne. for cowals of weted jotne 6 not lea $\operatorname{than} 1.25 e_{\text {; }}$

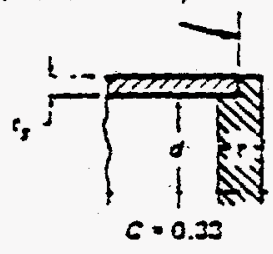

(h) (e)

(1)

(a)

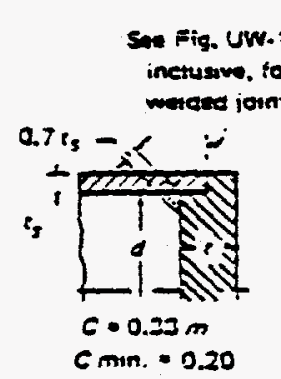

(i)

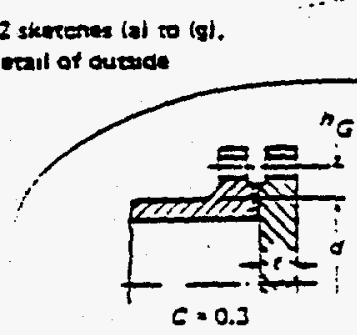

(U) है. (2) or (5))

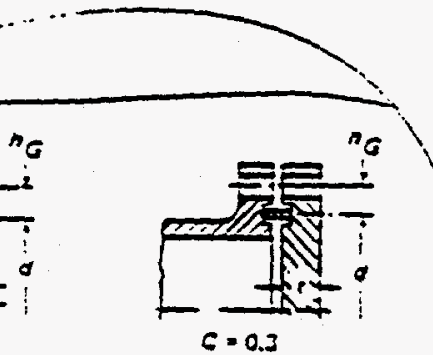

[Use E. (2) or (5)]

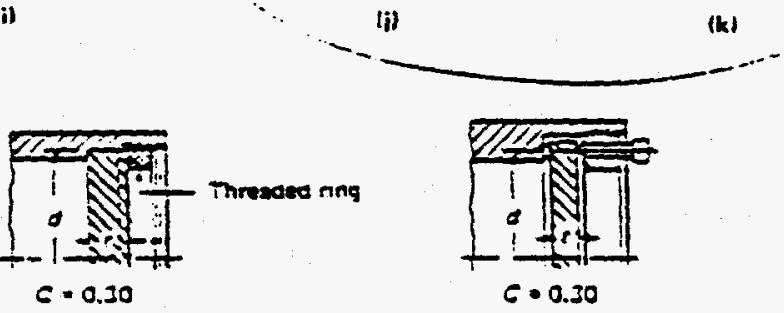

(n)

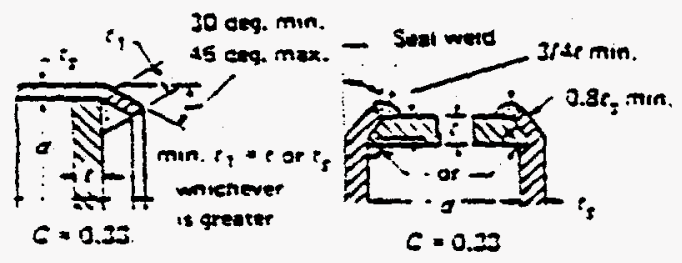

(r)

ist

FIG. UG-3A SOME ACERTABLE TYPES OF UNSTAYED FLAT HEADS AND COVEES The Above Dlustrations Are Diagrammatic Onry. Other Designs That Meet the Requiremens of UG-34 Are Aceeseade. 
TABLE UHA-23 (CONT'D)

MAXIMUM ALLOWABLE STRESS VALUES IN IENSION FOR HIGH ALLOY STEEL (CAUTION: See UW-12 lor vessels consinucied under Pan UW)

ILLOY STEEL

IW)

\begin{tabular}{|c|c|c|c|c|c|c|c|c|c|c|c|c|}
\hline $\begin{array}{c}\text { Mominal } \\
\text { Composillon }\end{array}$ & $\begin{array}{l}\text { UNS } \\
\text { Mo. }\end{array}$ & P. & $\begin{array}{c}\text { Group } \\
\text { No. }\end{array}$ & $\begin{array}{l}\text { Produce } \\
\text { Form }\end{array}$ & $\begin{array}{l}\text { Spec. } \\
\text { No. }\end{array}$ & Grade & Motes & $\begin{array}{l}\text { Specified } \\
\text { Miln. } \\
\text { Yield. } \\
\text { ksl }\end{array}$ & $\begin{array}{l}\text { Specifled } \\
\text { Mln. } \\
\text { Tensile. } \\
\text { kal }\end{array}$ & $\frac{111}{-2010}$ & $\begin{array}{l}\text { Spec. } \\
\text { No. }\end{array}$ & $\begin{array}{c}\text { Ext. Press. } \\
\text { Chart } \\
\text { Fly. Ho. }\end{array}$ \\
\hline $\begin{array}{l}C r_{r} \\
C r_{r}-\pi I\end{array}$ & $\begin{array}{l}5+3000 \\
543035\end{array}$ & 1 & 2 & $\begin{array}{l}\text { Bar } \\
\text { Bar }\end{array}$ & $\begin{array}{l}5 A-179 \\
5 A-479\end{array}$ & $\begin{array}{l}430 \\
\times M .6\end{array}$ & $\begin{array}{l}(2)(111) \\
(2)(11)\end{array}$ & $1-40$ & 70 & 17.5 & $\begin{array}{l}5 A-479 \\
5 A-479\end{array}$ & 3-UIIA-28.2 \\
\hline
\end{tabular}

$17 \mathrm{Cr}_{\mathrm{C}}-\mathrm{NL}-6 \mathrm{Mn}_{\mathrm{n}}$

$17 C_{r}-4 N I-6 M n$
$17 C r-4 N I-6 M n$

520100 - 5 Plate $5 A-412 \quad 201$

520100
520100
520100

Plate $5 A-240 \quad 201+1$

... 45

99

23.8

SA-412

d
$d$

520100

Plale $\quad 5 A-240$ 201.

(i) 30

95

... 45

90

$\left.\begin{array}{ll}22.5 & \text { SA-240 } \\ 22.5 & \text { SA-240 }\end{array}\right]$

$\left.\begin{array}{ll}22.5 & S A-240 \\ 22.5 & S A-240 \\ 23.0 & S A-240\end{array}\right]-3-U C 5.26 .2$

IBCr-QNI .

SA-34) CaJCu-1

(6)(16) $\quad 140$

150

20.0

SA-747 S-UCS-28.2

$\mid \mathrm{ACr}-6 \mathrm{NH}$

$|\mathrm{ICC}-\mathrm{BN}|$
IBCr-ONI

|BCr-8N|

JeCr-8NI

IBCr-8NI

$18 \mathrm{Cr}-\mathbf{A N I}$

IACr-BNI

IBCr-ANI

$1 \mathrm{CC}-\mathrm{ant}$

IOCr-ANI

IaCr-8NI

IBCr-8III

|aCr-8N|

|ACr-BN!

IOCr-GN!

IOCt-6NI

IBCr-8NI

IOCT-GNI

IBCr-ONI

530403 - 1 Farg. SA-182 F304L.

$\begin{array}{lllll}530403 & \text { Plale } & \text { SA.240 } & 304 L \\ 530403 & 1 & \text { Smls. Tt. } 5 A-213 & \text { IP304L }\end{array}$

530403 I Smls. Tb. SA-233 IP304L

$\begin{array}{lllll}530403 & \text { I } & \text { Sinls. PD. } & \text { SA.312 } & \text { TP304L } \\ 530403 & \text { I } & \text { Bar } & \text { SA-479 } & 304 L\end{array}$

$530403-1$ fittings SA-403 304L WPS

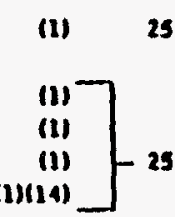

(1) 25

… 25

… 25

$\cdots \quad 25$

… 25

(14) 25

530403

530403

530403

530403

530403
530403

530403

530403
530403

530403

530403

530403

$\$ 92500$

Plate SA-240 304L

Simls. Pp. SA-312 IP304L

Forg. SA-182 F304L

Gar SA-479 304

Wid. Tb. SA-249 TP3OAL

Whe Po. SA-112 TP304L

Wid. Tb. SA-680 TP3O4L

(III) 7

(III)

Flitings SA-403 J04L CR

Fillings. SA-403 J04L WP-W

Fillings SA-403

304L. WP-WX

(111(1)

(1)(4)

Wid. Ib. SA-249 TP30AL

Wid. Pp. . SA-312 TPJOAL

Cast. SA-Jst CF3

(1)(6) 30
65

16.3

SA-182 S-U11A-28.3

WId. Tb. SA-68B. IP3OAL

$\left[\begin{array}{c}(19) \\ (4) \\ -(1 i\end{array}\right]-25$

\begin{tabular}{|c|c|c|}
\hline l & SA-240 & \\
\hline 16.7 & $\begin{array}{l}S A-213 \\
5 A-312\end{array}$ & $\mid-5-U[1 A-2 \theta]$. \\
\hline & SA-419 & \\
\hline
\end{tabular}

65

$15.7 \quad 5 A-403 \quad N A$

$\left.\begin{array}{l}70 \\ 70 \\ 70 \\ 65 \\ 65 \\ 70\end{array}\right]$

$\left.\begin{array}{l}\text { SA-240 } \\ \text { SA-213 } \\ \text { SA-312 } \\ \text { SA-182 } \\ \text { SA-316 } \\ \text { SA-479 }\end{array}\right]-5 \cdot$ UIIA-28.3

$5 A-249$

\begin{tabular}{l|l} 
SA. & -112 \\
SA. & -5. UIIA-28.3
\end{tabular}

SA-680

SA-403 HA

SA-2197

$\left.\begin{array}{l}\text { SA-312 } \\ \text { SA-688 }\end{array}\right]-3$. U11A-26.3

SA-351 5-UIIA-28.J 

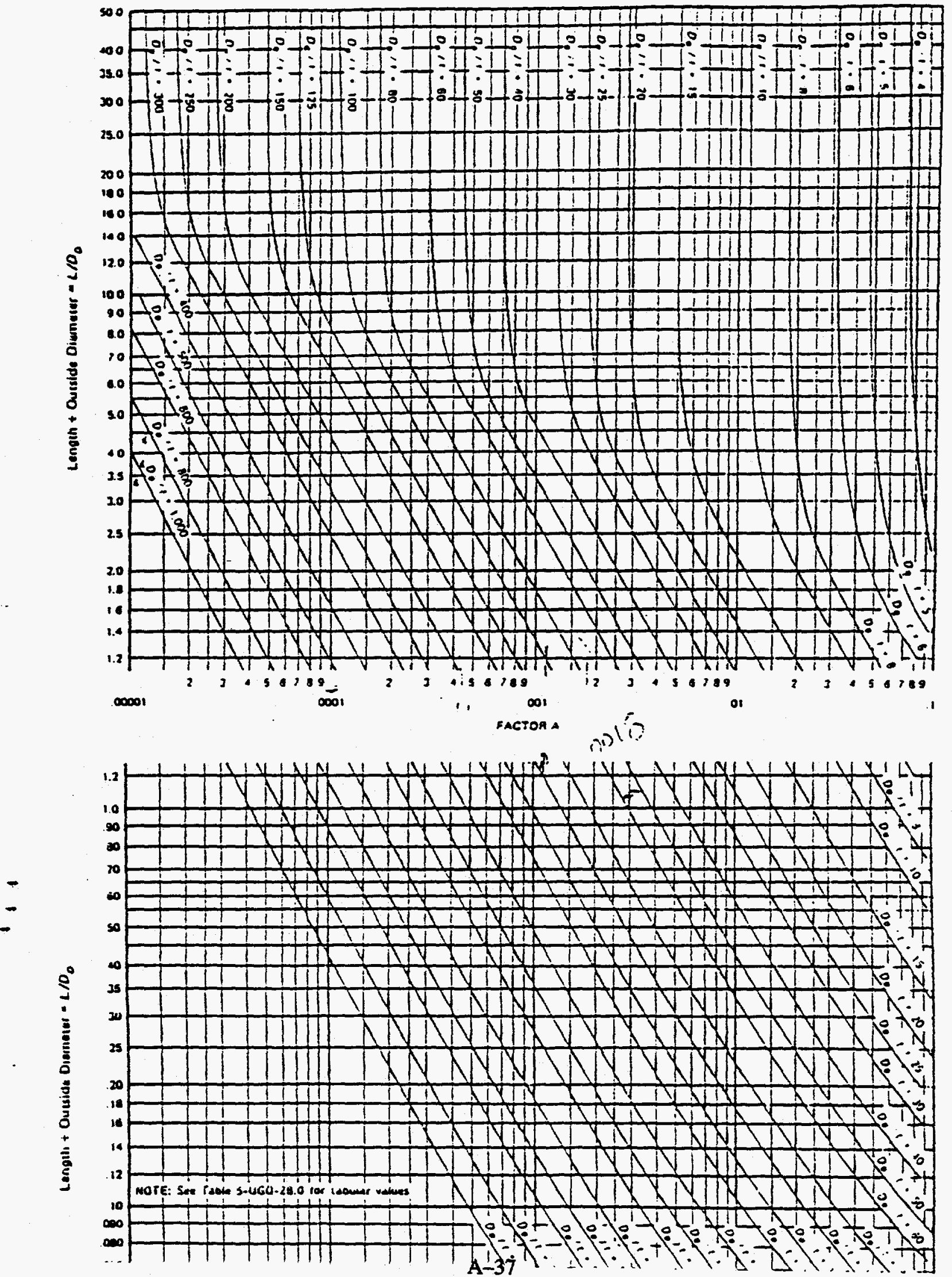


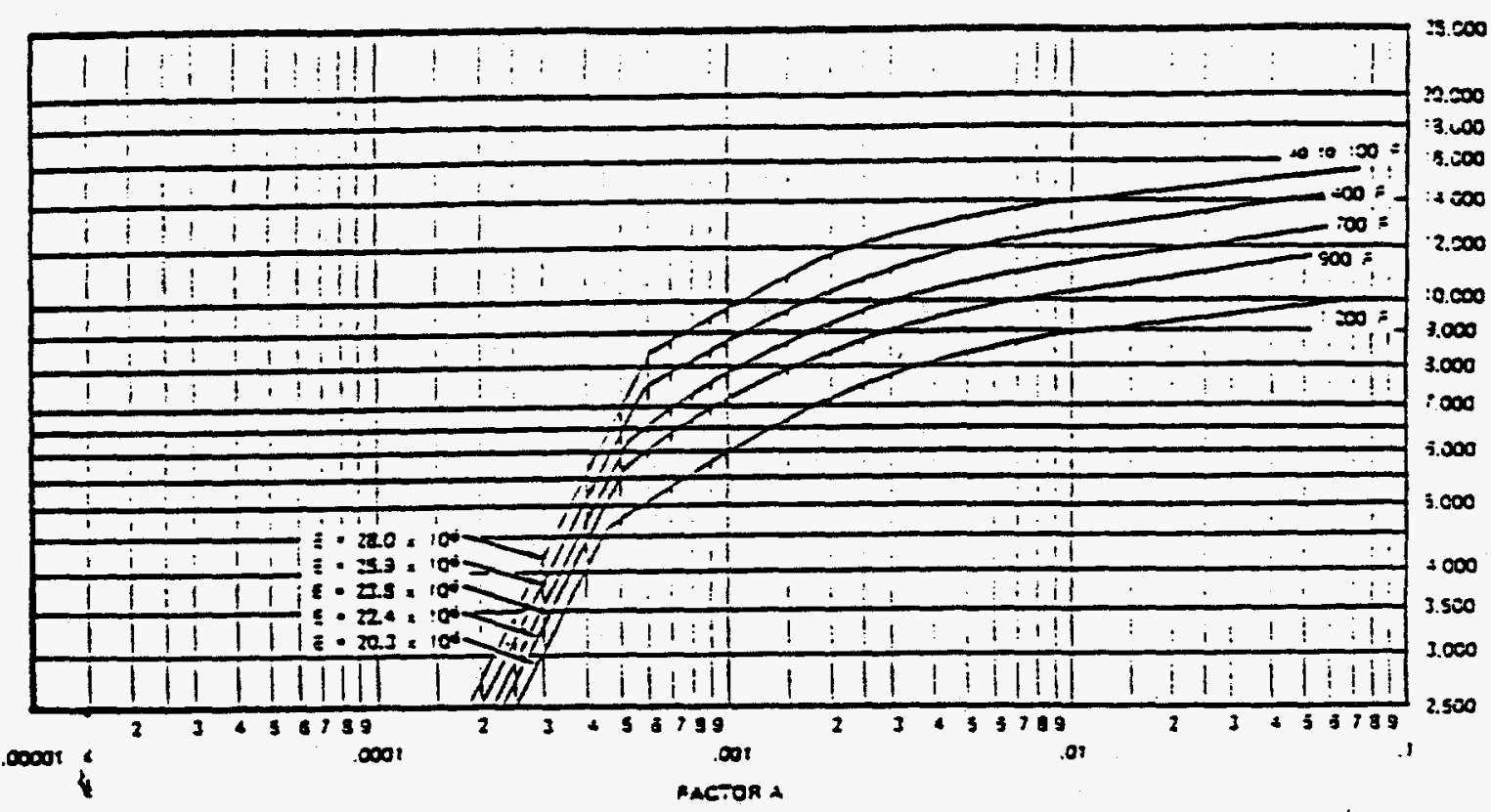

FG. 5-UHA-282 CHART FOR DETERMINING SHELL THICKNESS OF GYLNDRICAL AND SPH'ERICAL VESSELS UNDER SXTERNAL PRESSURE WHEN CONSTRUCTED OF AUSTEATIL STEE:

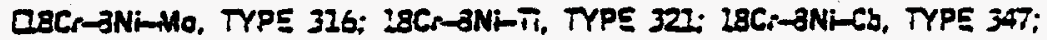
25Cr-12Ni, TYPE 309 (THROUGH IIOOF ONLY); 25Cr-20Ni, TYPE 310; AND I7C, TYPE 4308 STANMLESS STEEI THROUGH TOOF ONLY] DNOTE (8)]

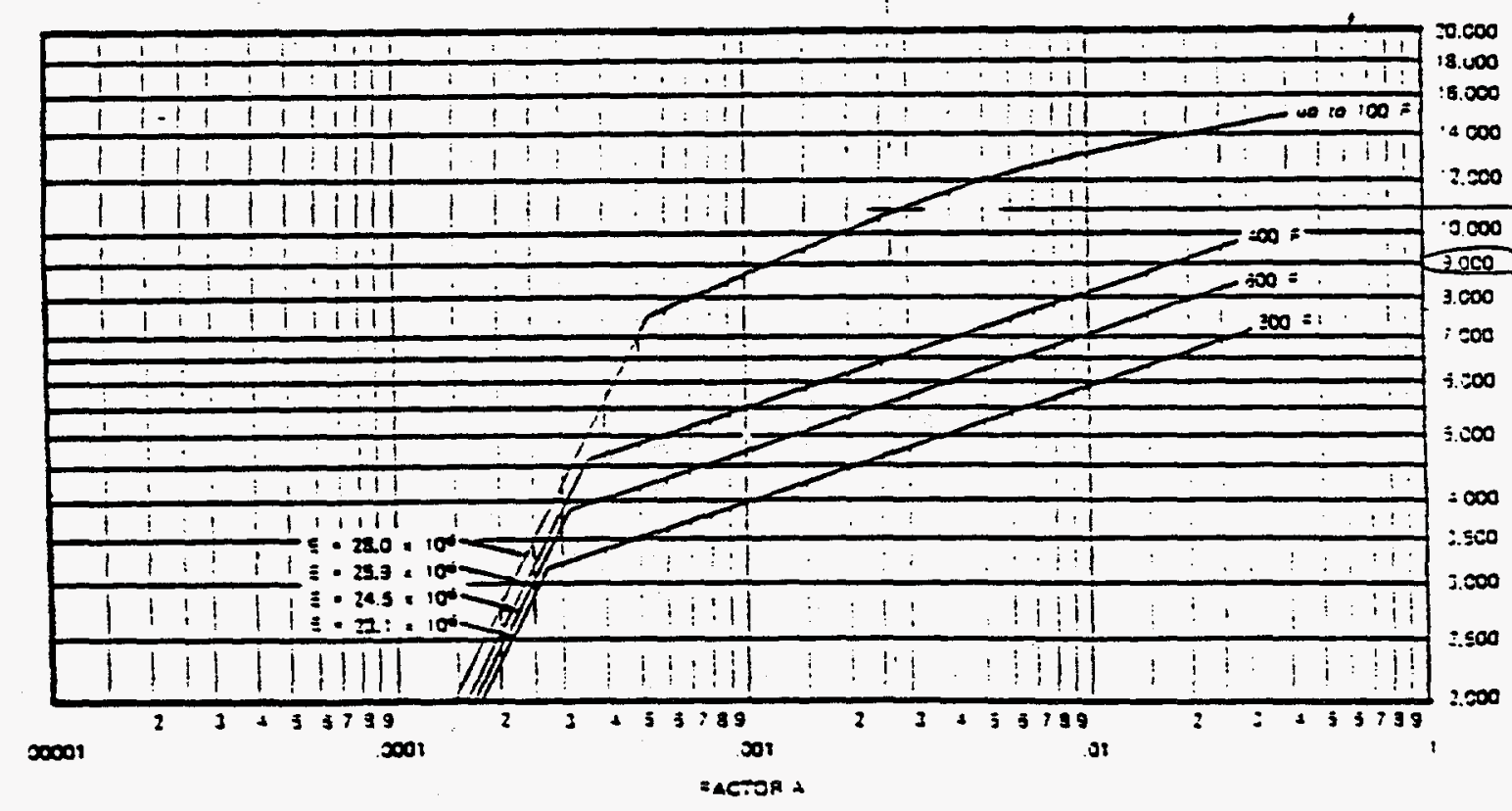

FIG. 5-UHA-283 CHART FOR DE:ERMINING SHE!- THICKNESS OF CYLNDRICAL IND SPHERICAL VESSELS UNDER DTTERNAL PRESSURE WHEN CONSTRUCTED OF AUSTENTIC STEE: (I8C.-ONi-0.03 MAXIMUM CARBON, TYPE 304L) (NOTE (8)] 


\section{VACUUM VESSEL SAFETY \\ (Formerly Fermilab Engineering Standard SD-41)}

\section{INTRODUCTION}

Vacuum vessels such as insulating vacuums on dewars and vacuum chambers under vacuum pose a potential hazard to equipment and personnel from rupture or implosion. This chapter specifies the procedure to be followed in designing, fabricating, testing, and using vacuum vessels in order to reduce hazards. This chapter applies to any vessel used at Fermilab except

a. any vacuum vessel whose inside diameter or cross section diagonal is under twelve inches with no limitation of length.

b. any portions of beam pipes buried underground.

c. any vessel with a volumetric capacity of less than 35 cubic feet.

d. any vessel under external pressure whose product $P \times V$ is less than 515 (psi) (cu. $\mathrm{ft}$ ), where $P$ is the external differential MAWP and V is the volumetric capacity. ${ }^{1}$

\section{DEFINITIONS}

The Code -ASME Section VIII Divisions 1 and 2. The revision of the Code to be applied to a given vessel is the latest revision at the time of the vessel's fabrication.

Vacuum Vessel - any vessel having atmospheric pressure outside the vessel and a pressure less than amospheric inside the vessel.

Engineering Note - a written analysis demonstrating that a given vessel satisfies the requirements of this chapter.

Volumeric Capacity - the volume of water the vessel can hold or store. (If another vessel or object is contained inside the vacuum vessel, the object's volume should be subtracted out)

\section{SPECIAL RESPONSIBILITIES}

The division/section head who controls the area of operation of the vessel is responsible for carrying out the requirements of this chapter. He shall arrange for the review of the Engineering Note by a qualified person. He shall certify vessel compliance with this chapter by signing the Engineering Note and shall maintain an open, updated file on all vacuum vessels located in his areas of operation. After certification, the Fermilab engineering standard conformance label shall be attached to the vessel. The original of the Engineering Note shall be placed into the Laboratory Vacuum Vessel master file maintained by the ES\&H Section.

The ES\&H Section shall audit the divisions and sections on their compliance to this chapter.

\footnotetext{
1 This pressure volume product is equivalent to the vessel energy requiring a pressure vessel engineering note from Lawrence Livermore National Laboratory's Health and Safety Mamual and Mechanical Engineering Design Safety Standards.
} 
provisions of this chapter. Exceptions are to be identified and submitted to the Director for review as early in the design process as possible. These exceptions shall only be allowed after the Director has assured himself that sound engineering practice will be followed during design, fabrication and test of the vessel. The ES\&H Section shall maintain copies of exceptions for the Director. An exceptional vessel is hereby defined as one which cannot meet the tenets of this chapter and therefore requires a Director's Exception.

6. A technical appendix describing procedures for an Engineering Note analysis is included. 
The Mechanical Safety Subcommittee and/or Cyogenic Safety Subcommittee shall serve the division/section heads and ES\&H Section in a consulting capacity on all vacuum vessel matters. These committees may propose appropriate modificarions to this chapter as necessary. Changes in policy and responsibility shall be recommended by the Laboratory Safery Committee after consuling with the division/section heads. Changes in procedure shall be recommended by the Mechanical Safety Subcommitze and/or Cryogenic Safery Subcommittee.

\section{PROCEDURE}

Fermilab's contract with the Deparment of Energy stipulates that Fermilab conform to the current DOE 6430.1 standard. This standard inciudes the A.S.ME. Pressure Vessel Code. The A.S.ME Code does not apply to vacuurom vessels, but nevertheless we shall adhere to it to the extent practical for vacuum vessels in a laboratory enviromment. The design criterion for vacuum vessels at Fermilab shall be a minimum collapse pressure equal to 30 psid or 4 times the maximum external differential pressure, whichever is smaller. ${ }^{2}$

\section{Implementation of Procedure}

1. Prepararion of Engineering Note: An Engineering Note shall be prepared by an engineer or designer for all existing or new operational vacuum vessels at Fermilab; whether purchased, in-house built, an experimenter's vessel, a used vessel, or located in an unmanned area. The format of the Engineering Note is shown in Exhibit A-1. Its purpose is to allow a reviewer to check the design and installation and to inform a future user of the vessel parameters. The Engineering Note shall include design calculations for in-house built vessels and experimenter built vessels, and the manufacturer's data reports for purchased vessels if available. The Note shall also include precautions and operating procedures necessary for the safe use of the vessel.

2. Review of Engineering Note: All vacuum vessel Engincering Notes shall be reviewed by an independent, qualified reviewer, other than the engineer or designer who prepared it, for concurrence to this chapter. The reviewer shall be from a group not reporting to the preparer of the Engineering Note or his supervisor.

3. Amendment of Engineering Note: Any subsequent changes in usage, operating temperanure, valving, etc., which could affect the safety of the vessel requires an amendment to the original Engineening Note. This amendment shall be reviewed in the same manner as the original Note.

4. Similar Vessels: Vacuum vessels which are similar to previousiy constructed and approved vessels need not have the full engineering analysis repeated. Adequate documentation can be provided by referencing the approved engineering analysis and noting any differences. Acceptance testing will still be required. For the purposes of this paragraph, similar vessels mean that the same kinds of materiais and construction techniques are used and similar operating parameters will be used. The geometry must be similar, however, this paragraph may be applied if geometry differences do not affect the engineering analysis or safety.

5. Director's Exception: Exceprions to the provisions of this chapter shall be allowed only with the signarure of the Laboratory Director or his designee documented in the Engineering Note. The need for such exceptions is to be minimized by adherence to the

2 The Compressed Gas Association uses the A.S.M.E. Pressure Vessel Code as a guide for designing vacuum vessels for a minimum collapsing pressure of 30 psi differential. See Pamphlet CGA-341. 

FAX

January 14,1994

TO: Dan Futton, us2000

FROM: John Harrop, John Crane Belfab

subject: Radlation Detector Bellows

Ref: $P / N$ R70-000006 R70-000007

I have gathered together as much of the information that I could find in my liles regarding the subject project and have attached what I think 18 the bast data as to our inal discussions on the application.
As I recall the anall bellows vas proposal and that we ware working on the larger bellows to make sure that the opringrate was low enough to be compatible with you drive syetem.

Please review the attached data and if you have any questions juet give me a oali.

JSH 
Date -

*BELCALX2*

Quot. No. $305-200$

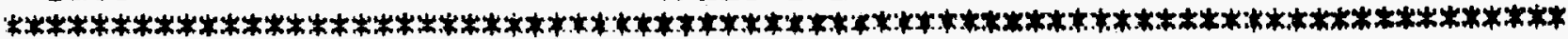
B.1 lowe 0.D.
$13.900 \mathrm{DL}+\mathrm{T}-$
19255
Thiciness (Por Ply)
Bel I ow I. D
12. 600 Material
Dt Plteh
No. of Conv's.
I.D. Flate
0.100
Rlpple Depth

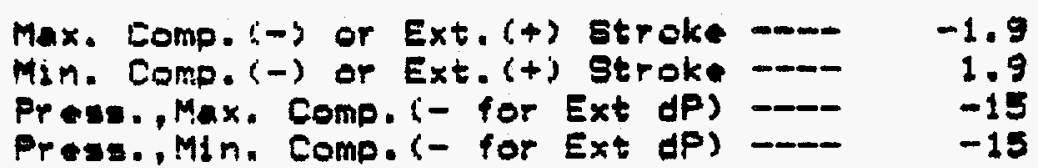

0.005

0.12

50

0.014

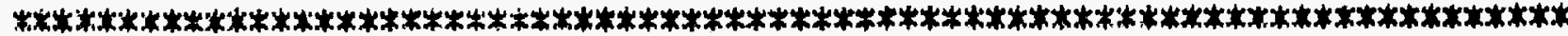
"FUNETIONAL DATAN

SPRIMG RATE

13.990

EFFECTIVE AREA -

FREE LENETH - 7.000

BQLID HEIGHT (3.Znt) - - - 1.600

STRAKE/PSI -- -

BQUIRM PREgBURE Q F.L.--- 11.726

EELLDWE WEIEHT (BTN GTL) -- 7.945

TWIET (ARC-BEC / IN-OZ) - 0.002

SHEAR. STRERE (PSI / IN-LB)- 0.802

MAX LATERAL DFFEET -

LATERAL BPRING RATE - -

NATURAL FREQUENCY -

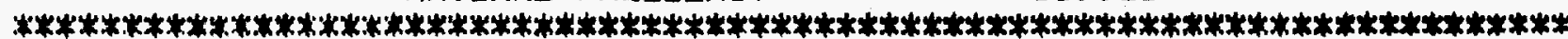
*GTRESEET:

*DEFLECTION*

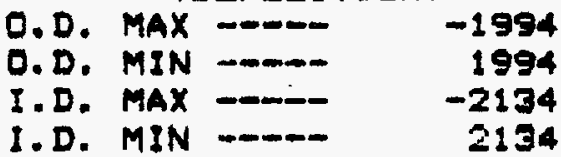

*COMBINED*

D.D. MAX $-m-\infty-27521$

0.D. MIN - ---23532

1. D. MAX m-m- 50574

I.D. MIN - $--\quad 58912$
*PREQEURE*

$\begin{array}{lr}\text { Q.D. MAX - } & -25527 \\ \text { O.D. MIN - } & -25527 \\ \text { I.D. MAX }-0-\infty & 27321 \\ \text { I.D. MIN }--\infty & 27321\end{array}$

*CYCLICX

Q. D. MEAN - - - -25527

0.D. ALT - - -

I.D. MEAN - -m $\quad 54643$

I.D. ALT $\rightarrow-\infty-4269$ 
Bellows O.D. - - - -

Bellows 1.0,--..--

O.D. Flats - - - - -

1.D. Flats
7.625

6.625

0.045

0.045
Thlckness - - - -

Die Piteh $---\infty---$

No. of Conv's, - - -

Flpple Depth - - - -
0.006

0.08

60

Max. Comp.(-) or Ext. (+) Stroke - - -

Min. Comp.(-) or Ext. (+) Btroke - - -

Prese, Max. Comp. (- for Ext dP) - - -

Preas, MIn. Comp. (- for Ext UP) - - -

1.75

$-15$

$-15$

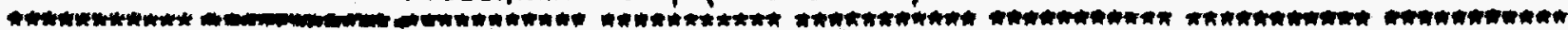
*FUNCTIONAL DATA*

SPRING RATE 18.01580

EFFECTIVE AREA 39.89118

FREE LENGTH 4.650 SOLID HEICHT (3.2nt) 0.96

STROKEIPSI -

SQUIAM PREBSURE @ F.L.

2.141322

BELLOWS WEIGHT (STN STL) - -

22.64813

TWST (ARC-SEC / IN-OZ) - -

SHEAR STRESS (PSI / IN-LB)-

1,947262

0.006428

MAX LATERAL OFFSET _- _. _.. 1.180979

LATERAL SPRING RATE - - - -

NATURAL FREQUENCY - $\ldots$

$67.48912 \leftarrow$ deaione ley 30.30035

0.025

\section{"DEFLECTION*}
O.D. MAX
O.D. MIN
$-6540$
6540
$-7308$
I.D. MAX
- - - -
I.D. MIN $-\cdots--$
7338

"COMBINED"
O.D. MAX - - - -
$-80509$
O.D. MIN - - - -
$-17280$
I.D. MAX -----
38889
1.D. MIN - - - -
68020

*STRESSES*

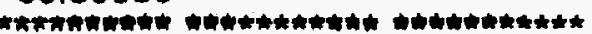

WPRESSURE*
O.D. MAX
O.D. MIN
$-23769$
I.D. MAX
$-23769$
26872
I.D. MIN - - - -
26672

*CYCLIC"
O.D. MEAN - - -
O.D. ALT - - -
$-20709$
I.D. MEAN - - -
I.D. ALT - - -
$-6540$
53344
$-14678$ 


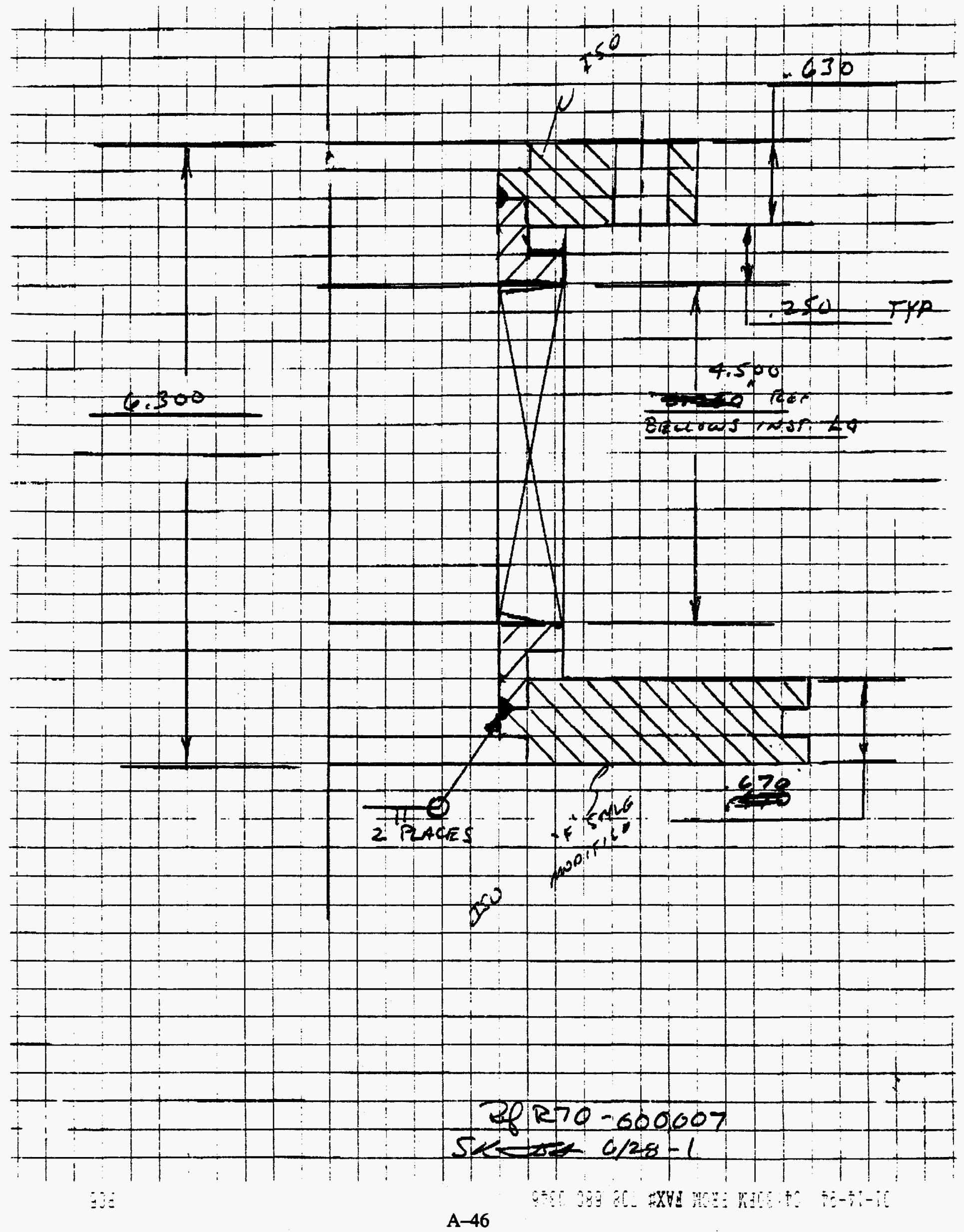


FAX TRANSMITTAL SHEET

JOAN CRANE BLAB

CENTRAL REGIONAL OFFICE

262 Hawthorn Commons, suite 325

Vernon H1118, IL 60061

PAX: $708-680-0346$

PH: $708-2848389$

PAGE 1 of 2

To: DAN HUTTON

DATE: $9 / 7 / 93$

$$
\text { MS } 2000
$$

SSCL Patsies Res Div.

Danes $t x$

$$
214-708 \cdot 6354
$$

REVISED DESILN For LAREL BRLLOWS A Trento. WE HAVE a UW SIZE DIE $12.6 " \times 13.9 \%$ WELL USE ZPLY.005

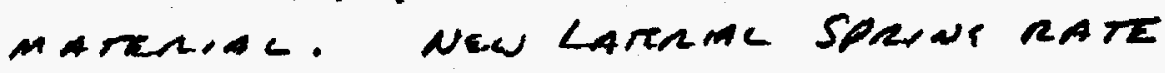
$75 \mathrm{lb} / \mathrm{i}$ WE ⿺ with TS DESILN IS NORE W LIN wire Your onelewilc sizes.

- wis Hate Back pork pries For you stontzy,

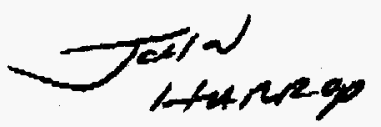

32

拝

A -47 


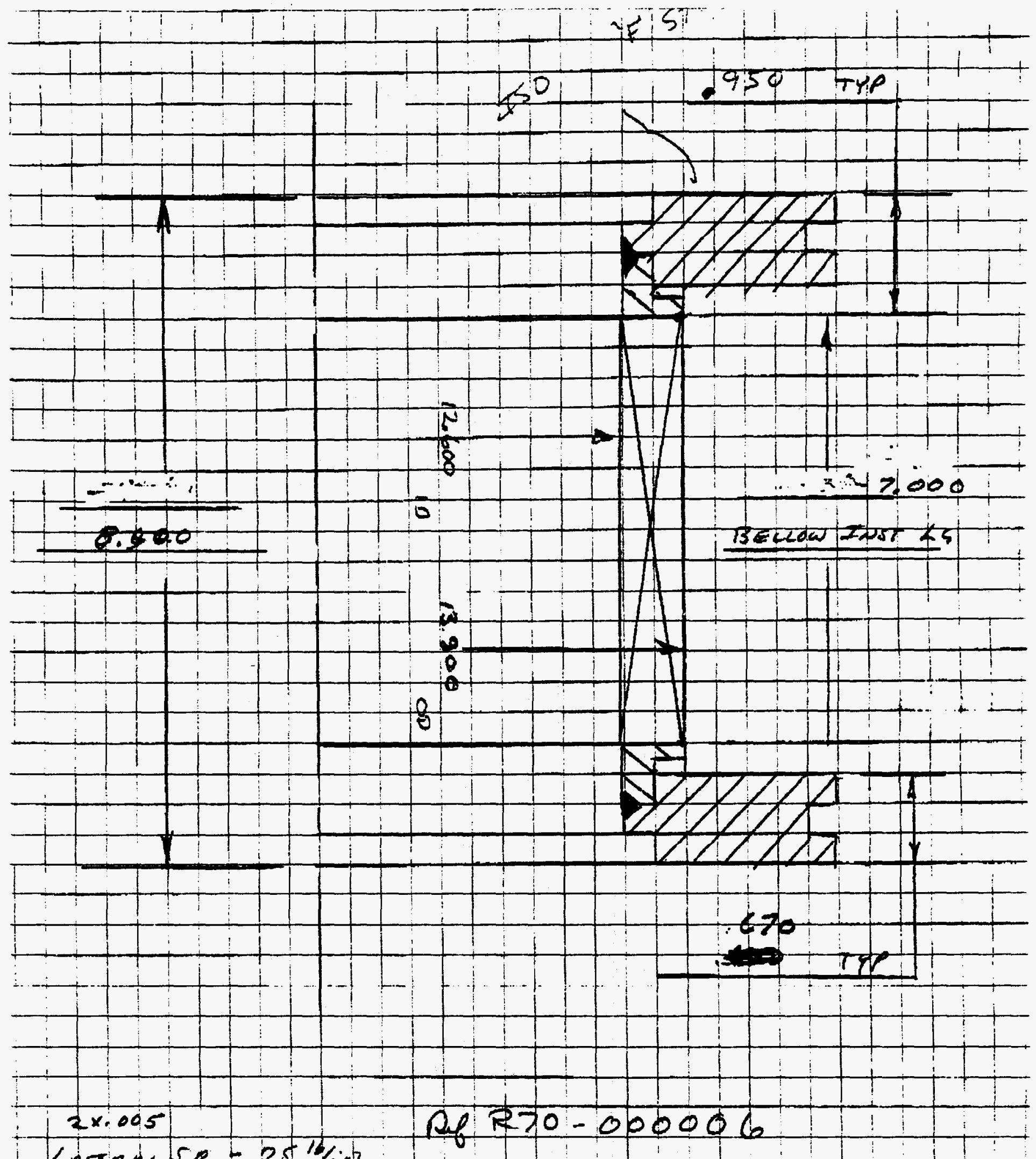

farencisetp5tint

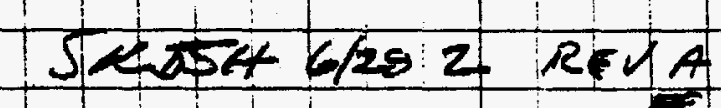

$$
\begin{aligned}
& \text { A }-48
\end{aligned}
$$




\section{SYNCHROTRON RADIATION DETECTOR}

Directory Location - /home/nova/prd/kelly/vacuum

\section{File}

R70 000006
R70-000007
R70-000008
R70-000009
R70-000010
R70-000011
R70-000012
R70-000013
R70-000014
R70-000015
R70-000016
R70-000017
R70-000018
R70-000019
R70-000020
R70-000021
R70-000022
R70-000023
R70-000024
R70-000025
R70-000026
R70-000027
R70-000028
R70-000029
R70-000030
R70-000031

Description

Bellows Flange Assembly Bellows Flange Assembly

Vessel Tee Weldment

Flange, Reducing

Flange, PMT, Modification

Bracket, SRD Crystal

Bracket, Scintillator

Flange, PMT

NAI Crystal Assembly

Scintillator Crystal Assembly

Detector Sub-Assembly

Synchrotron Radiation Detector

Base WeIdment

Flange, ISO200, Modified

Vessel Weldment Sub-Assembly.

Scintillator Plastic

Crystal, NaI

Light Pipe Transition, Scintillator

Light Pipe Transition, SRD

Flange, PMT Weldment

Leveling Bolt, Internal Wrenching

Plate, Leveling Table

Clevis, Actuator

Base Support, Weldment

Spacer, Drive Motor

Plate, Leveling

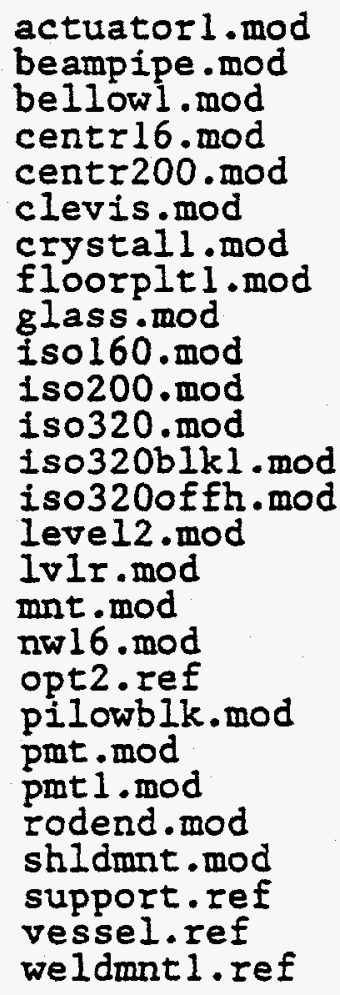

actuator $1 \cdot \bmod$

beampipe.mod

bellowl.mod

centr $16 . \bmod$

centr200.mod

clevis.mod

crystall.mod

floorplt l.mod

glass.mod

iso160.mod

is $0200 \cdot \bmod$

iso320.mod

iso320b1kl.mod

iso320offh.mod

level2.mod

IVII.mod

$\operatorname{mnt} \cdot \bmod$

nw16.mod

opt2.ref

pilowblk.mod

pmt.mod

pmt 1.mod

rodend.mod

shldmnt.mod

support.ref

vessel.ref

weldmnt 1.ref

basewld.mod

bellow.mod

bolt.mod

centr $160 . \bmod$

centr320.mod

crystal.mod*

flgclmp.mod

floorvrt.mod*

glass1.mod*

iso160b1k.mod

iso200blk. mod

iso $320 \mathrm{~b} 1 \mathrm{k}$.mod

iso $320 \mathrm{~h} \cdot \bmod$

level.mod

levelassy.ref

Ivlrplt.mod

$\operatorname{mnt} 1 \cdot \bmod$

optl.ref

oring.mod

pipe.mod

pmt.ref

pmt 1. Ief

shield.mod

subassy. Ief

tassem. ref

vesse12.mod*

weldmnt2. ref 


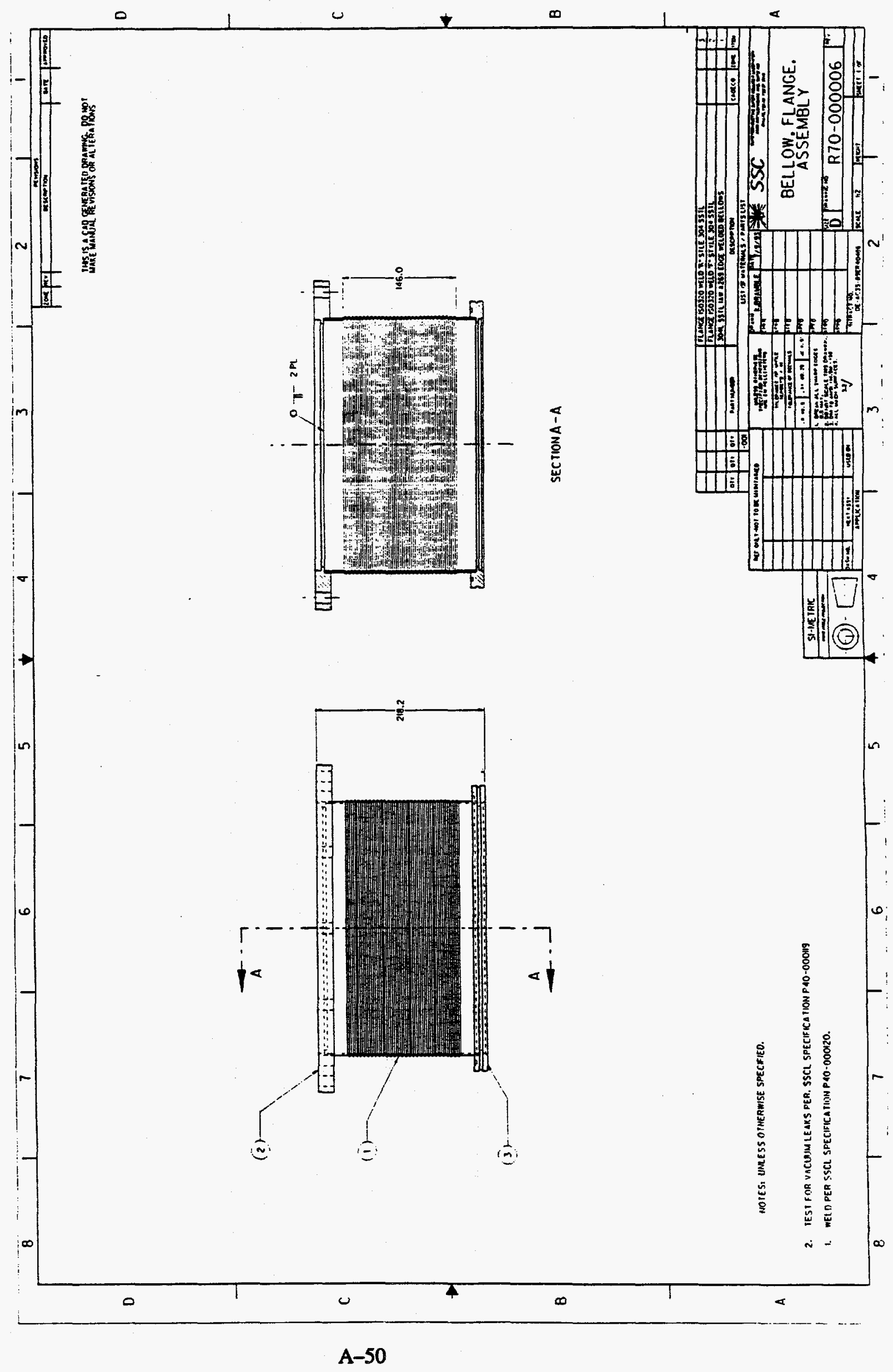




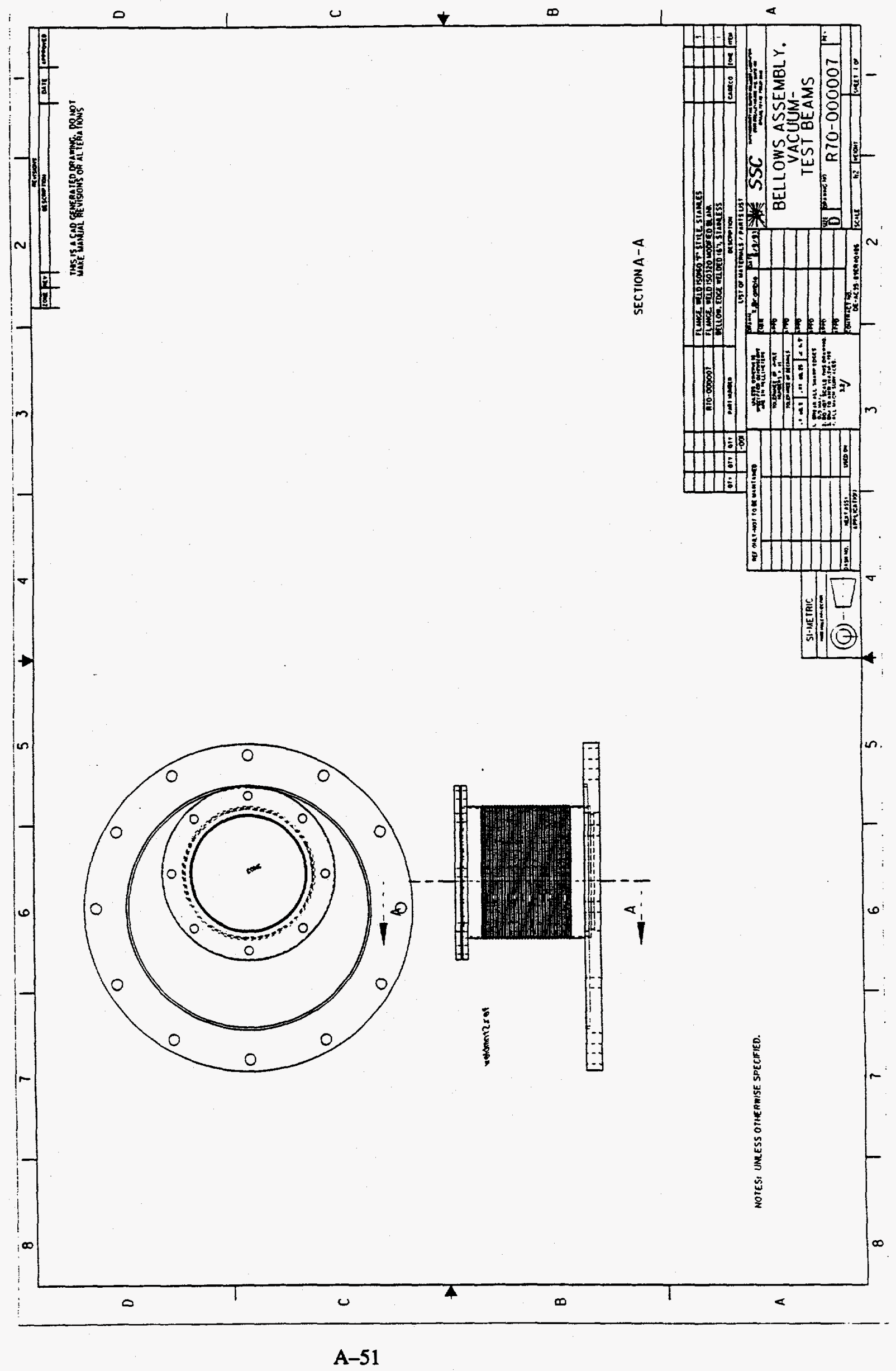




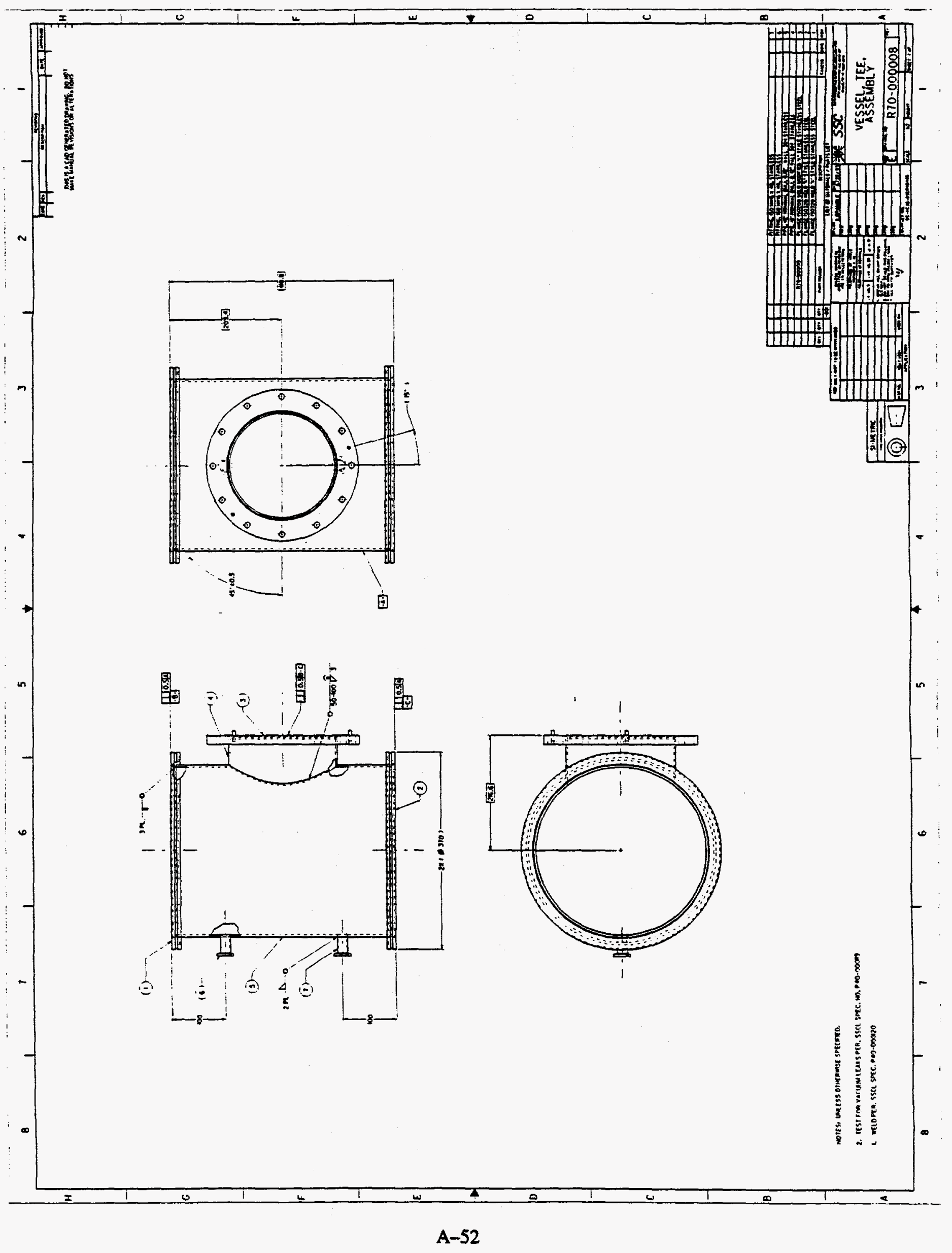




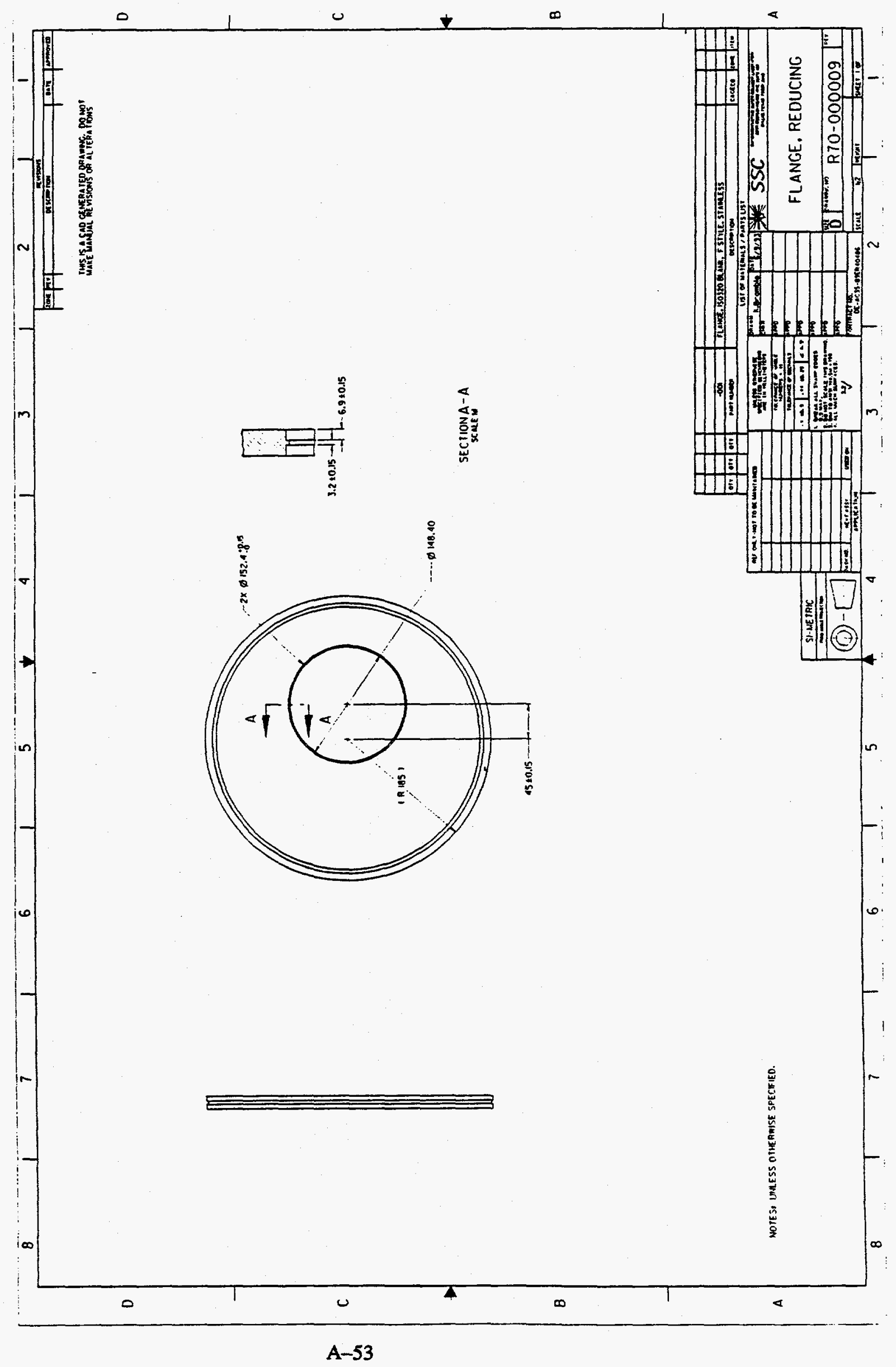




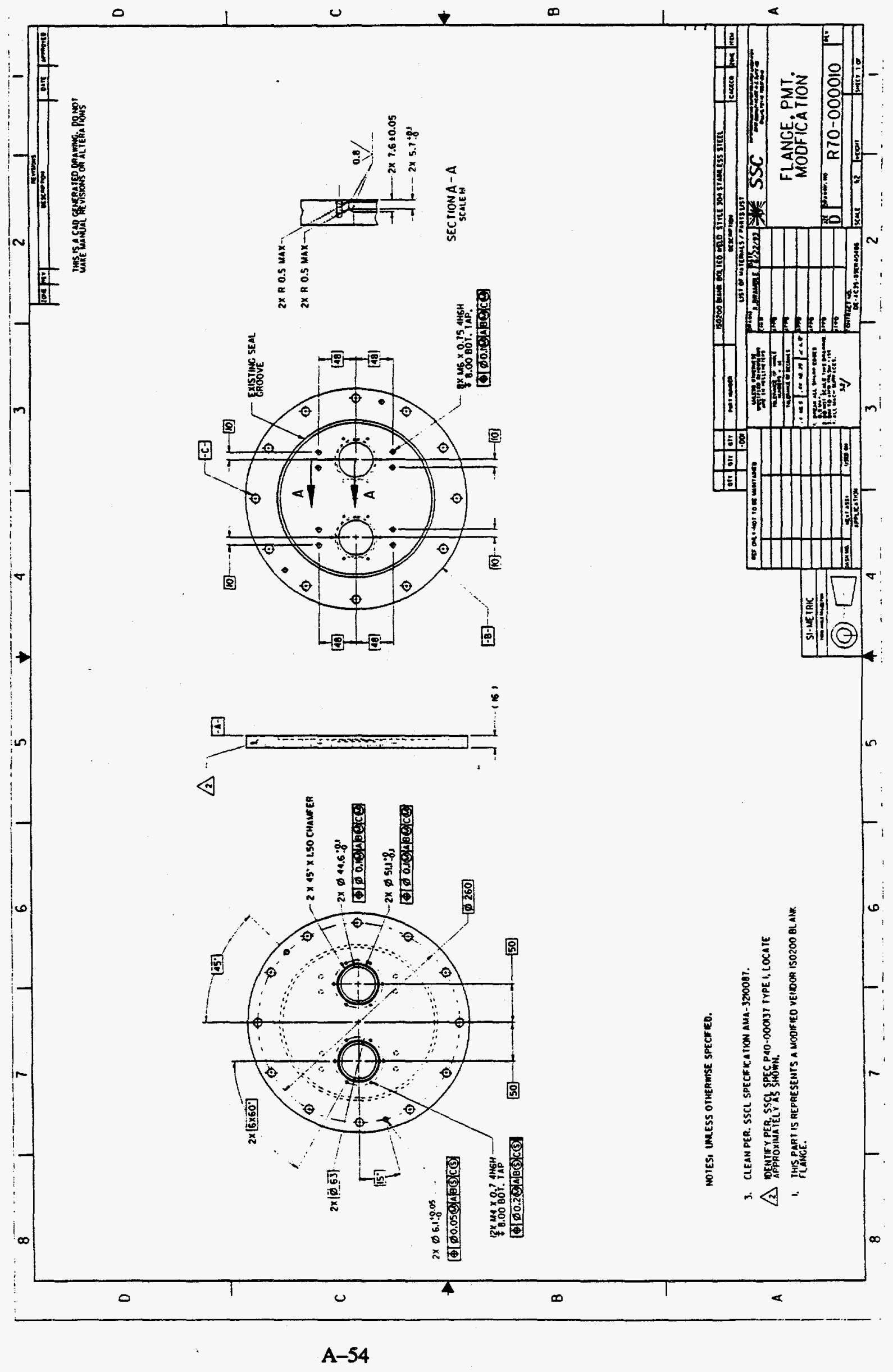




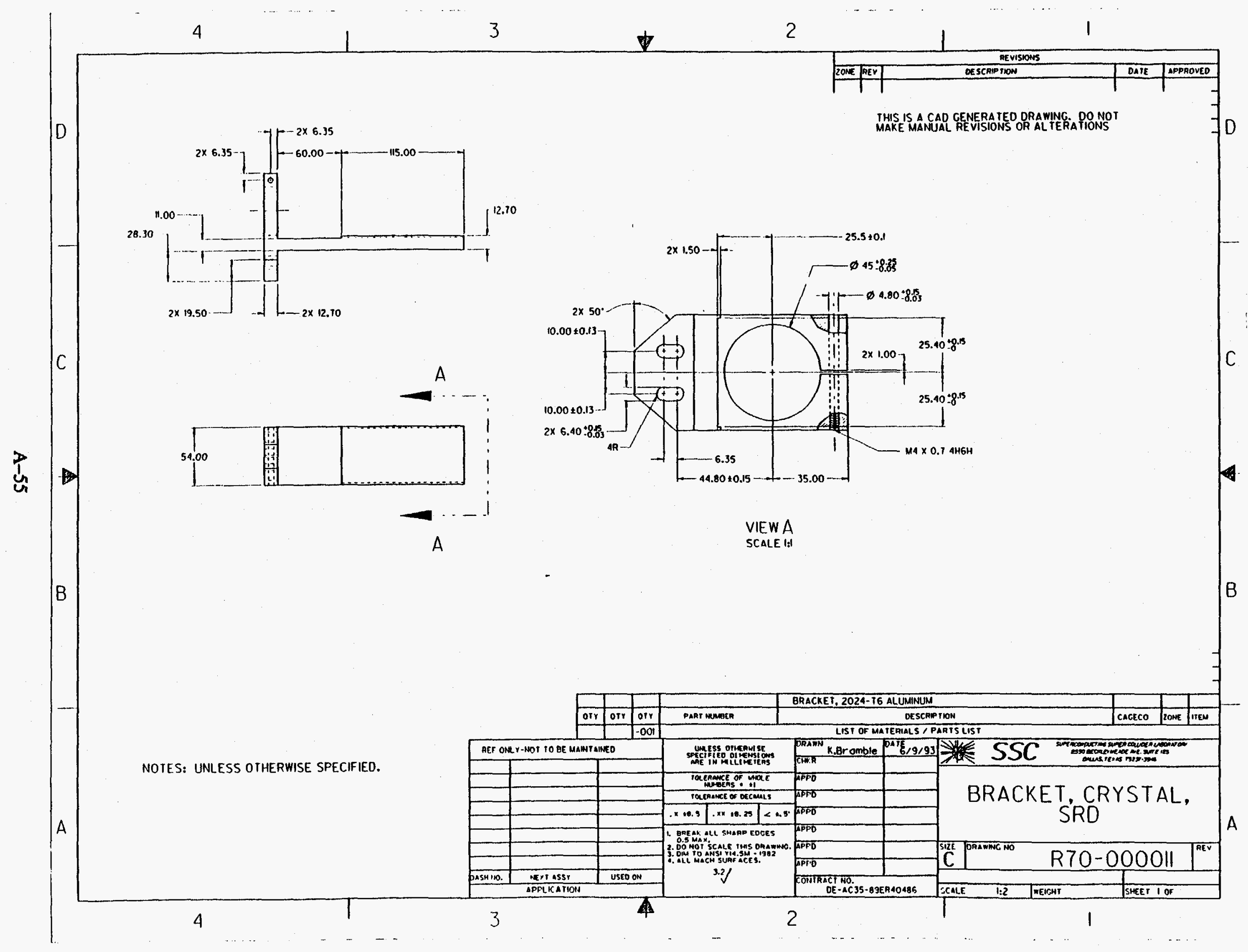




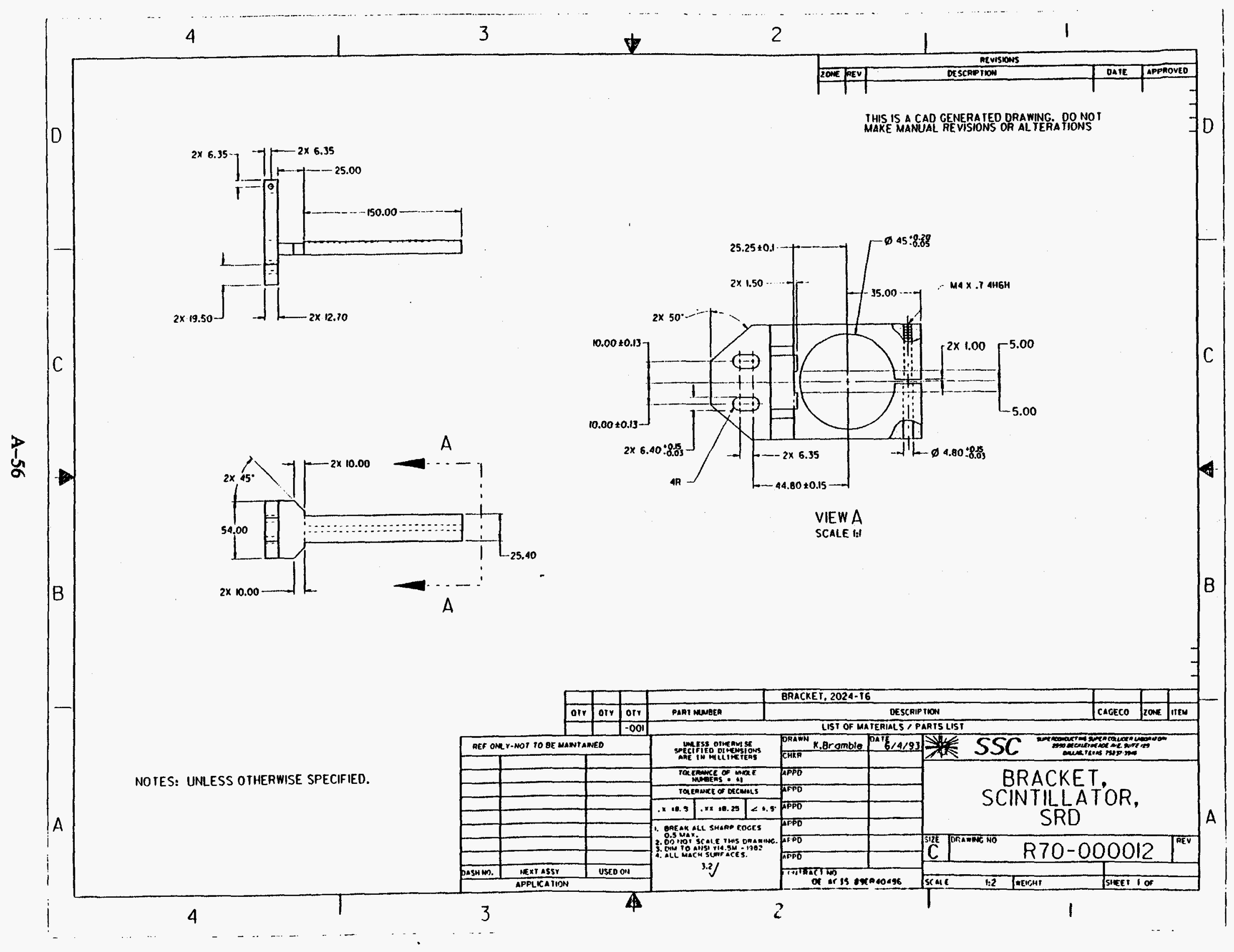




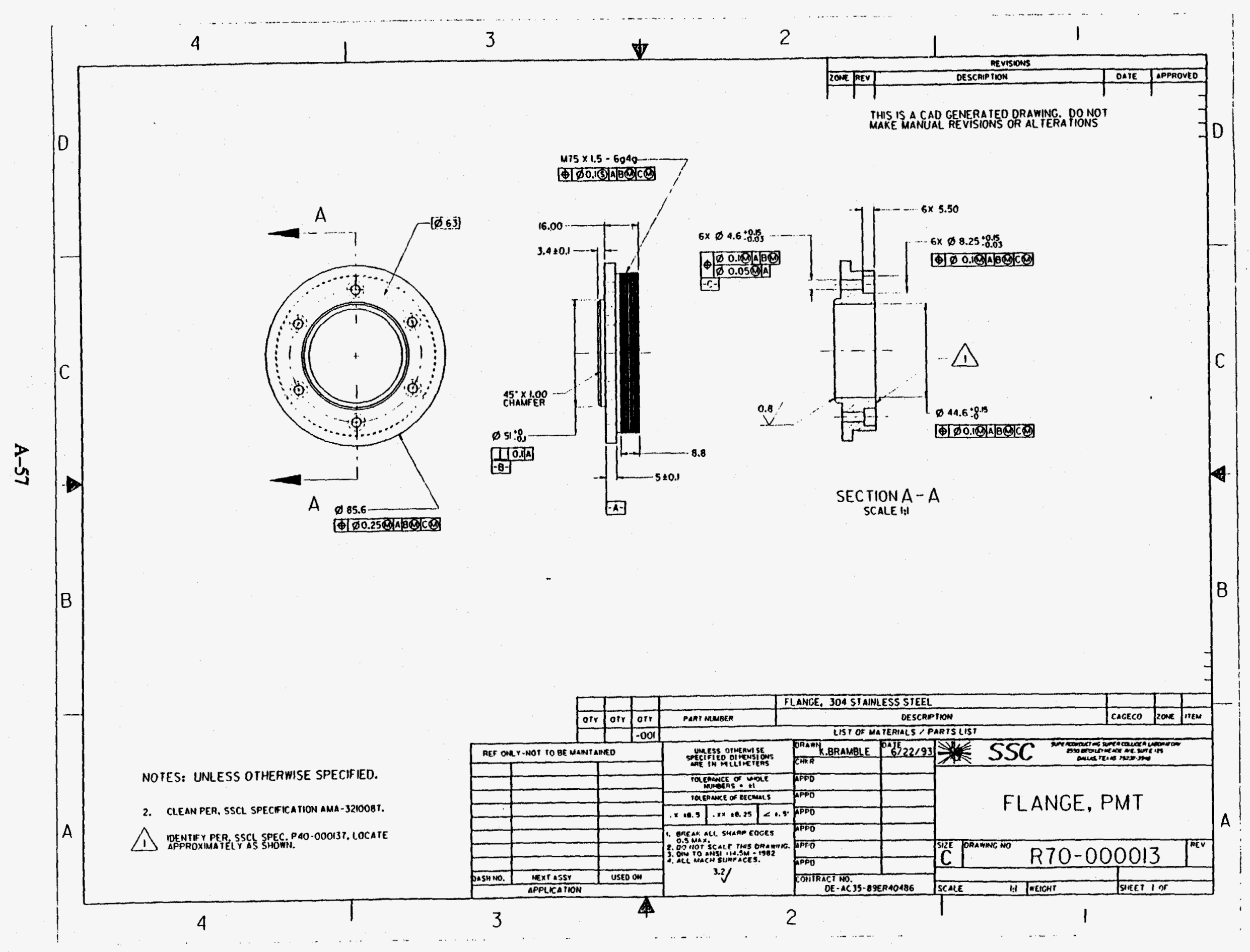




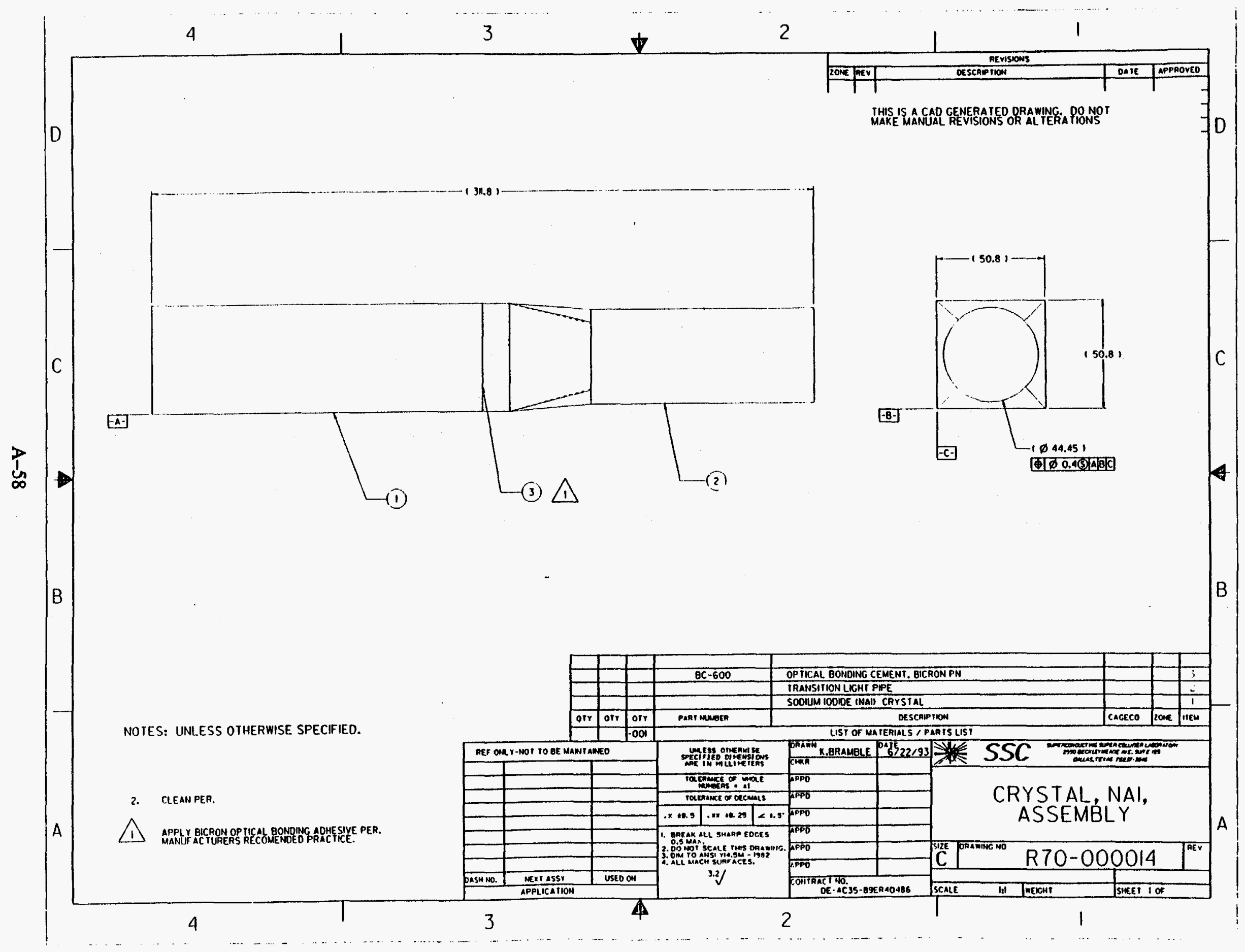




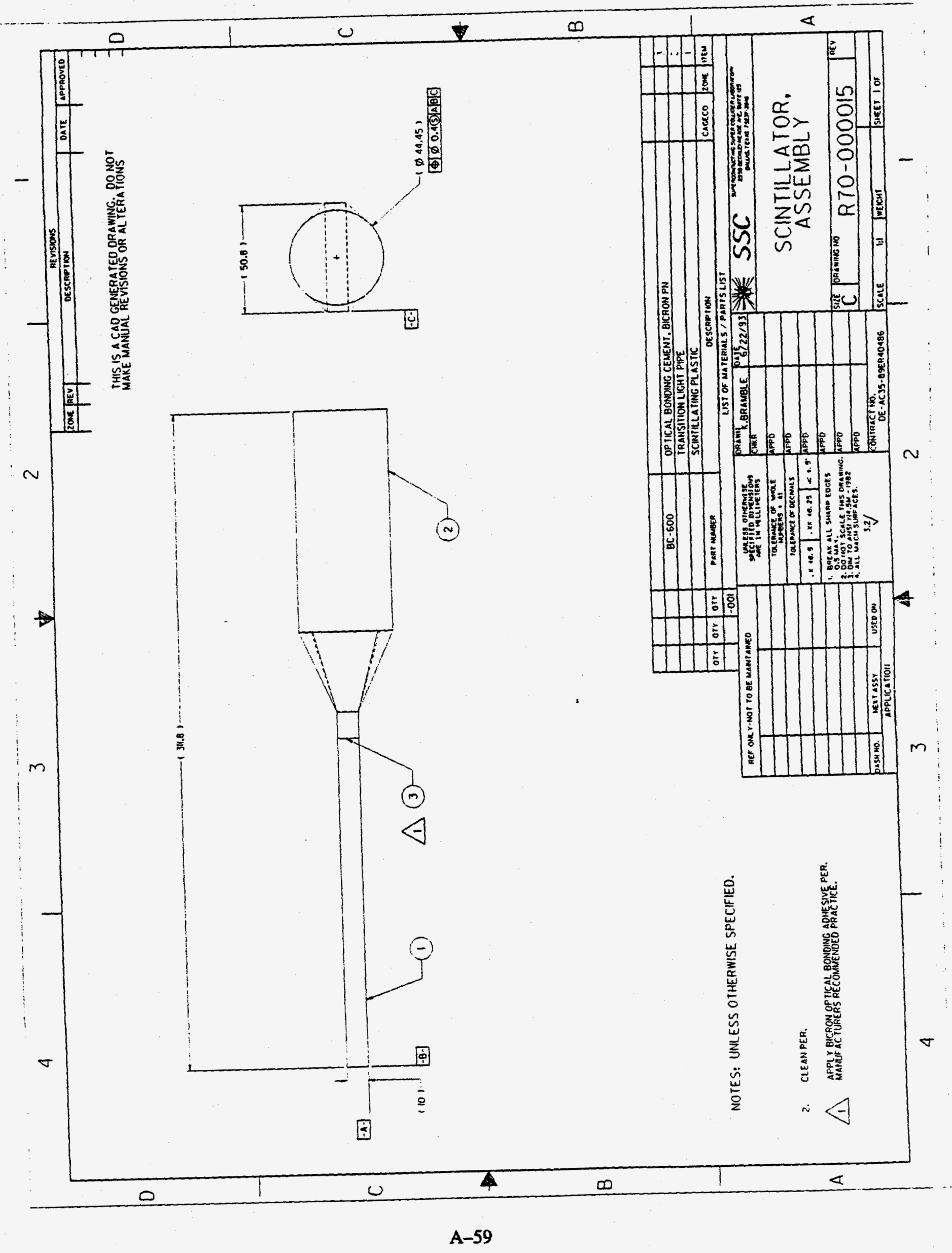




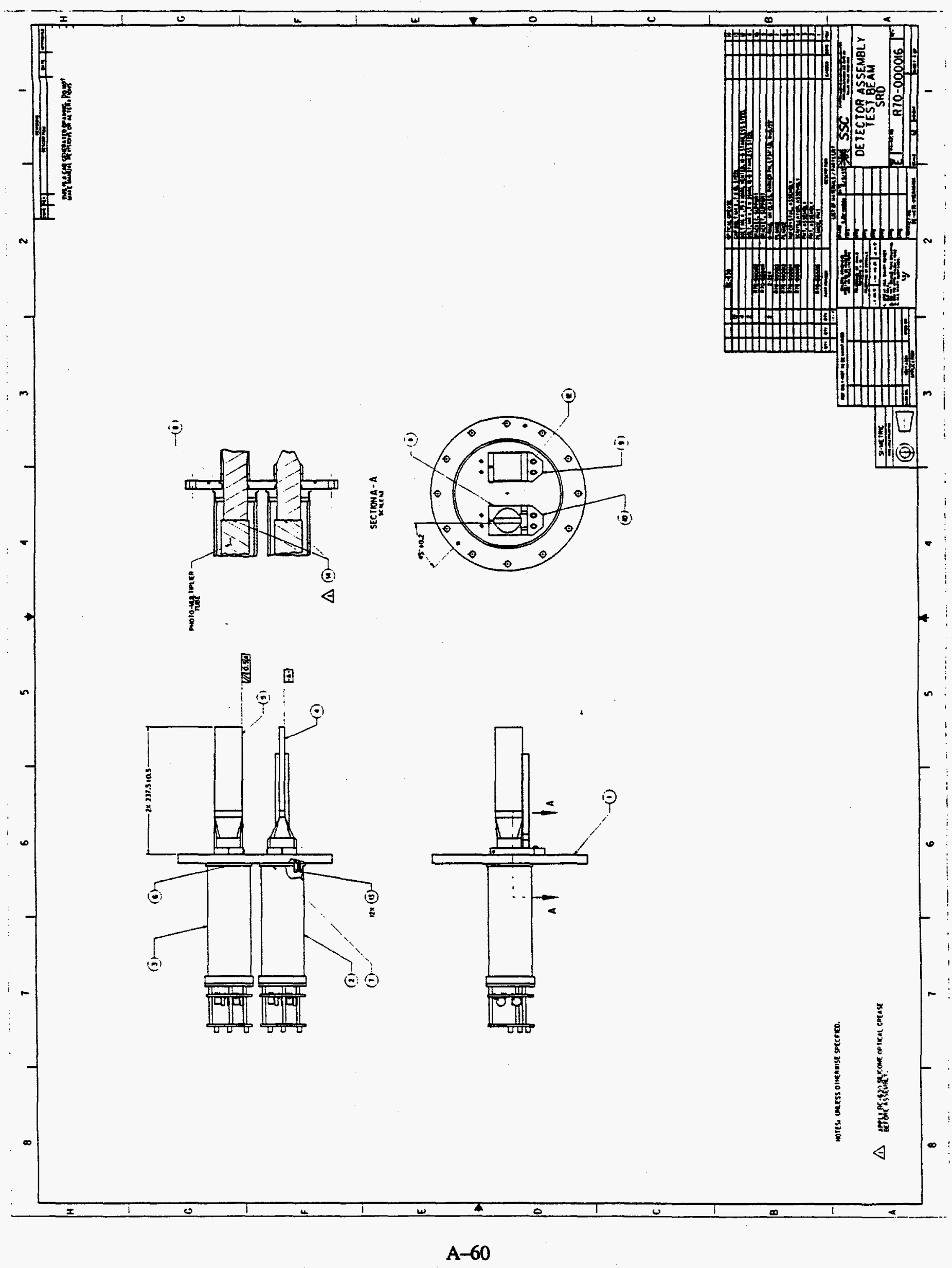




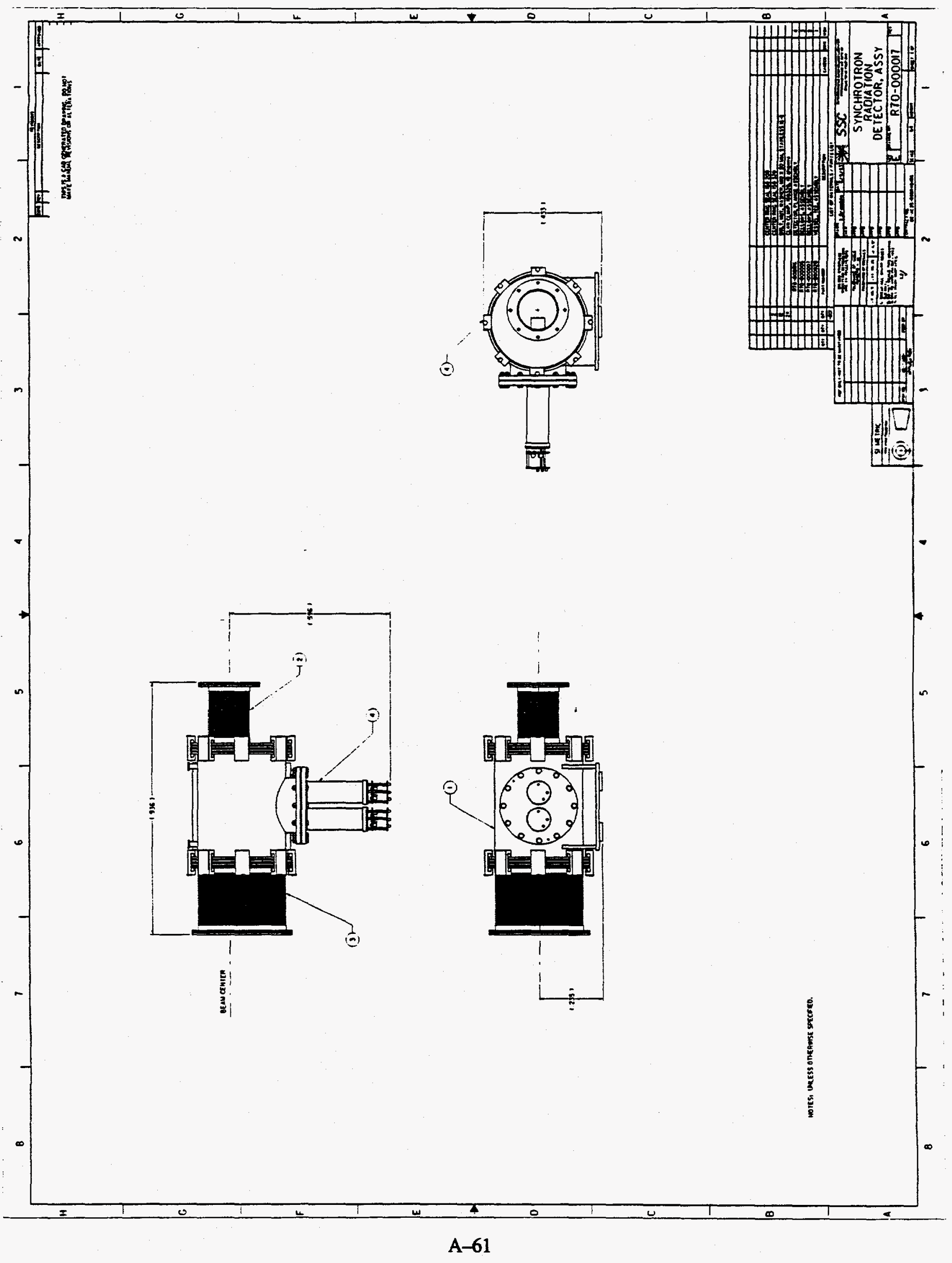




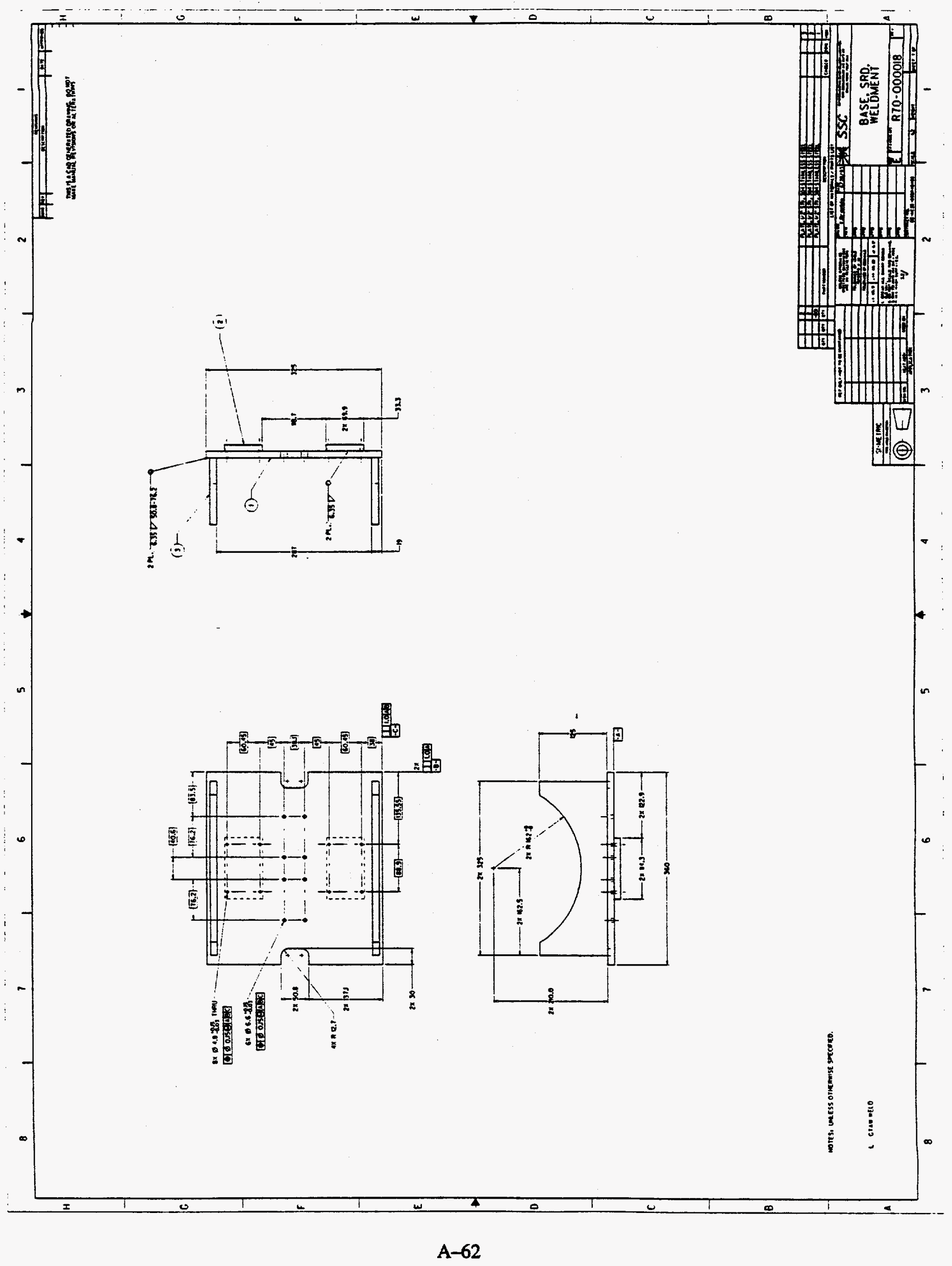




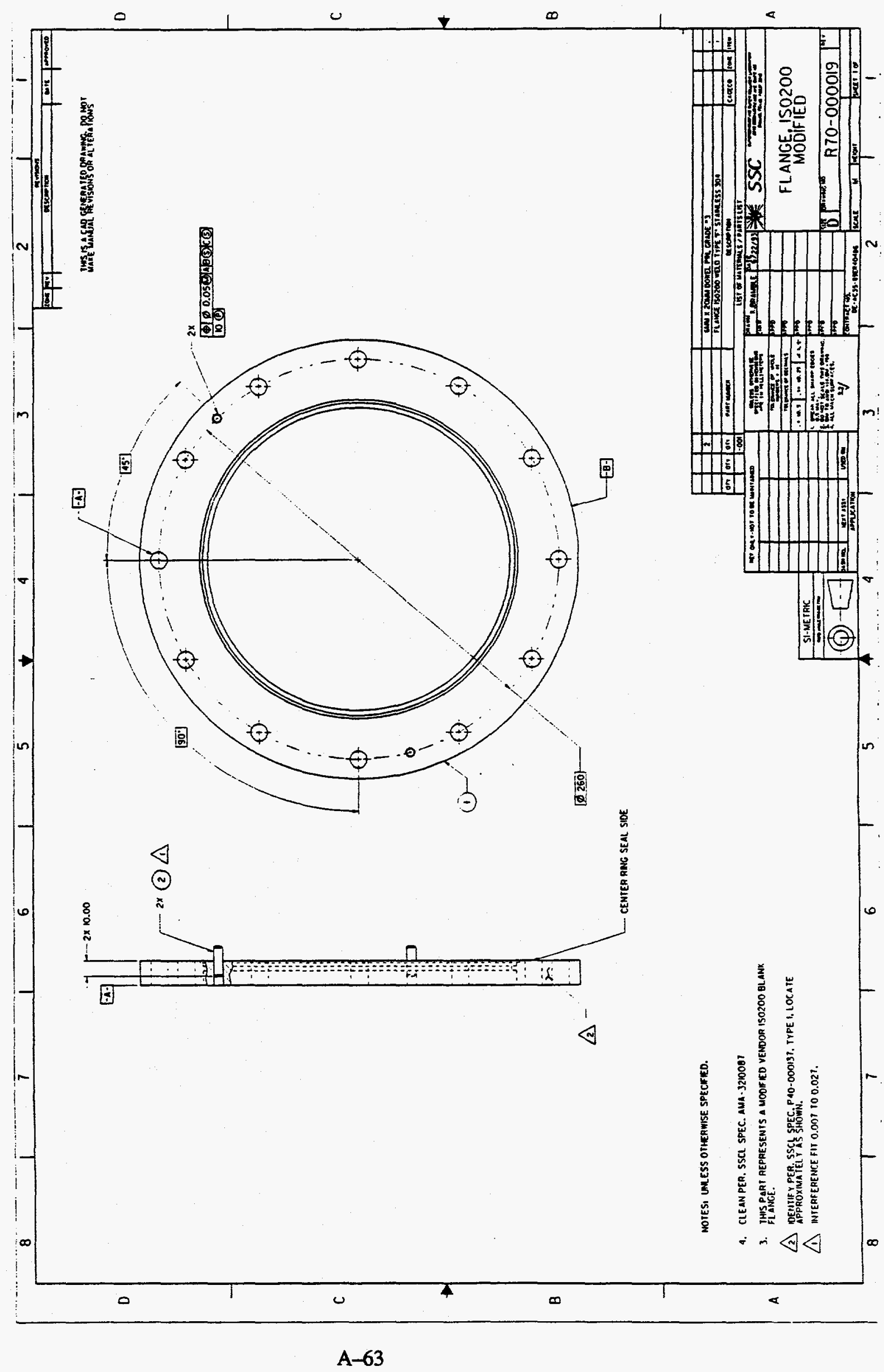




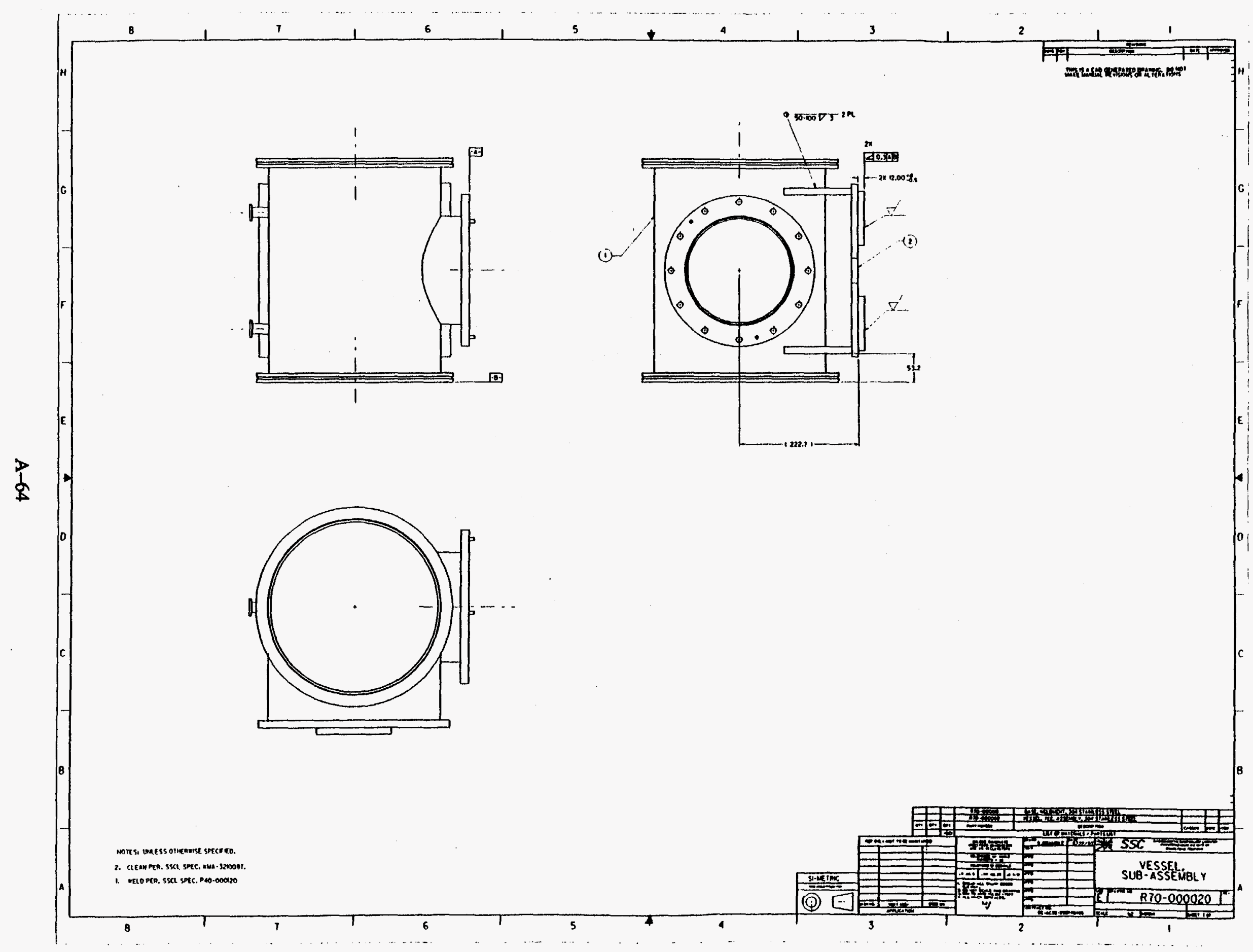




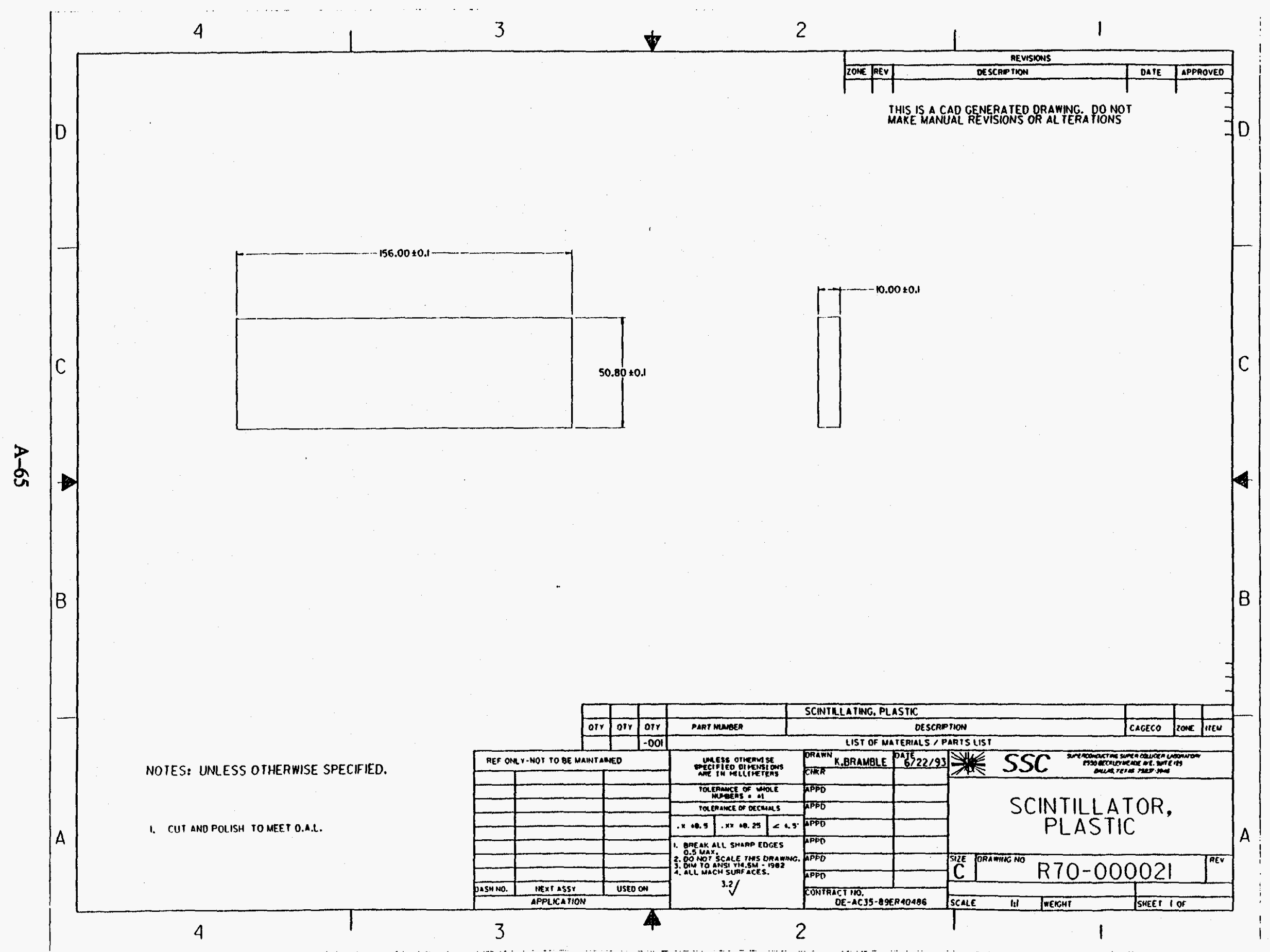




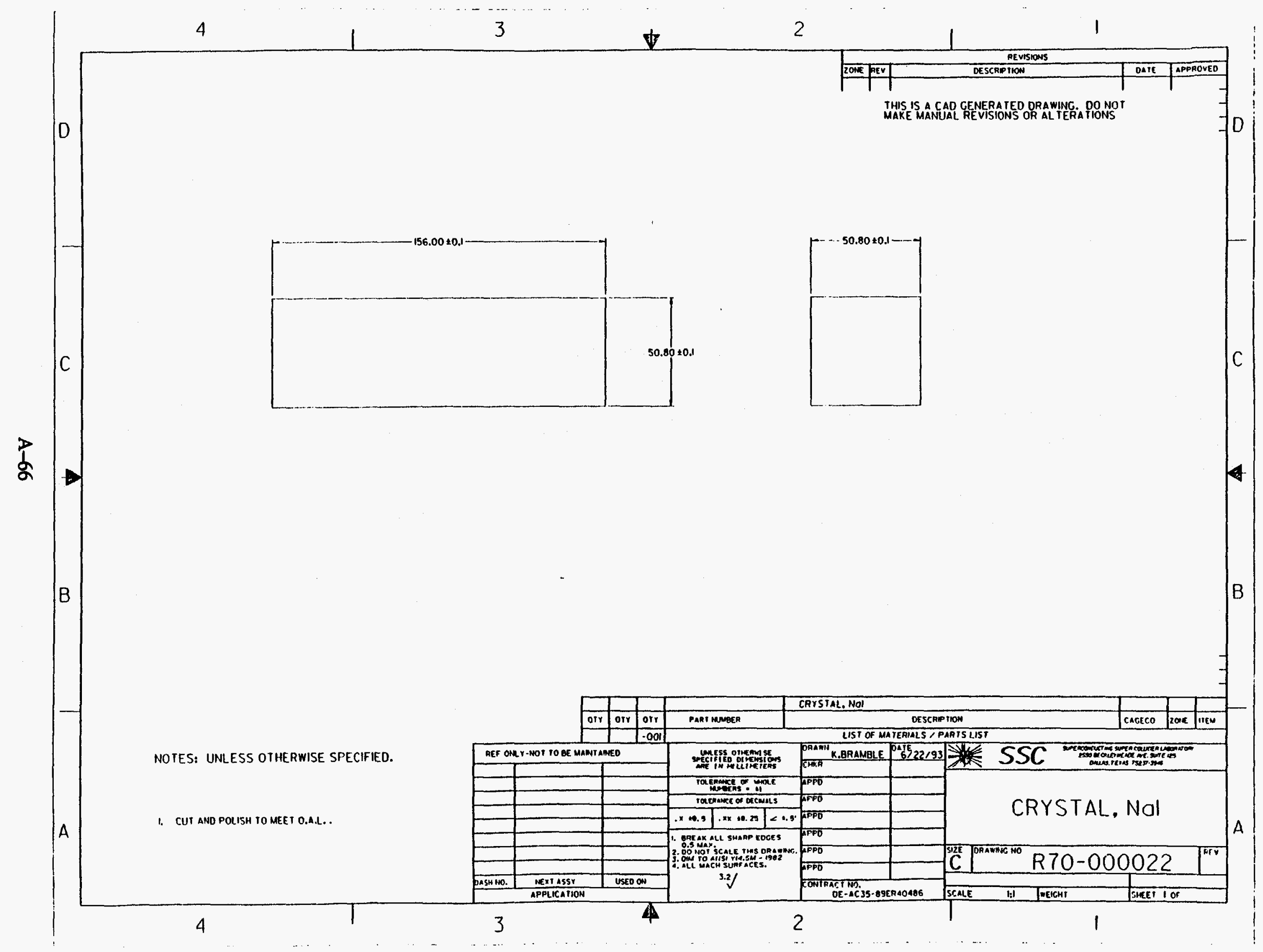




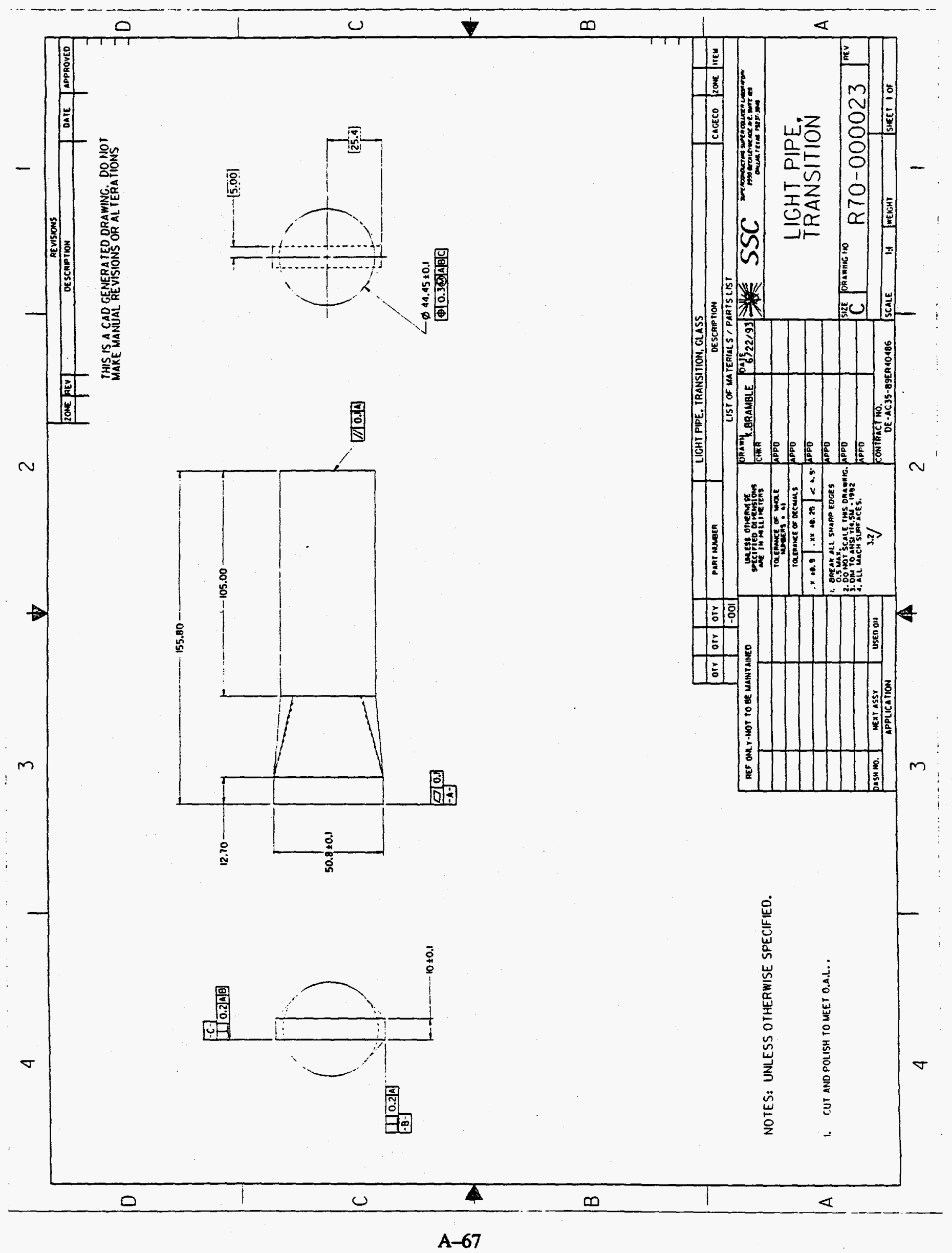




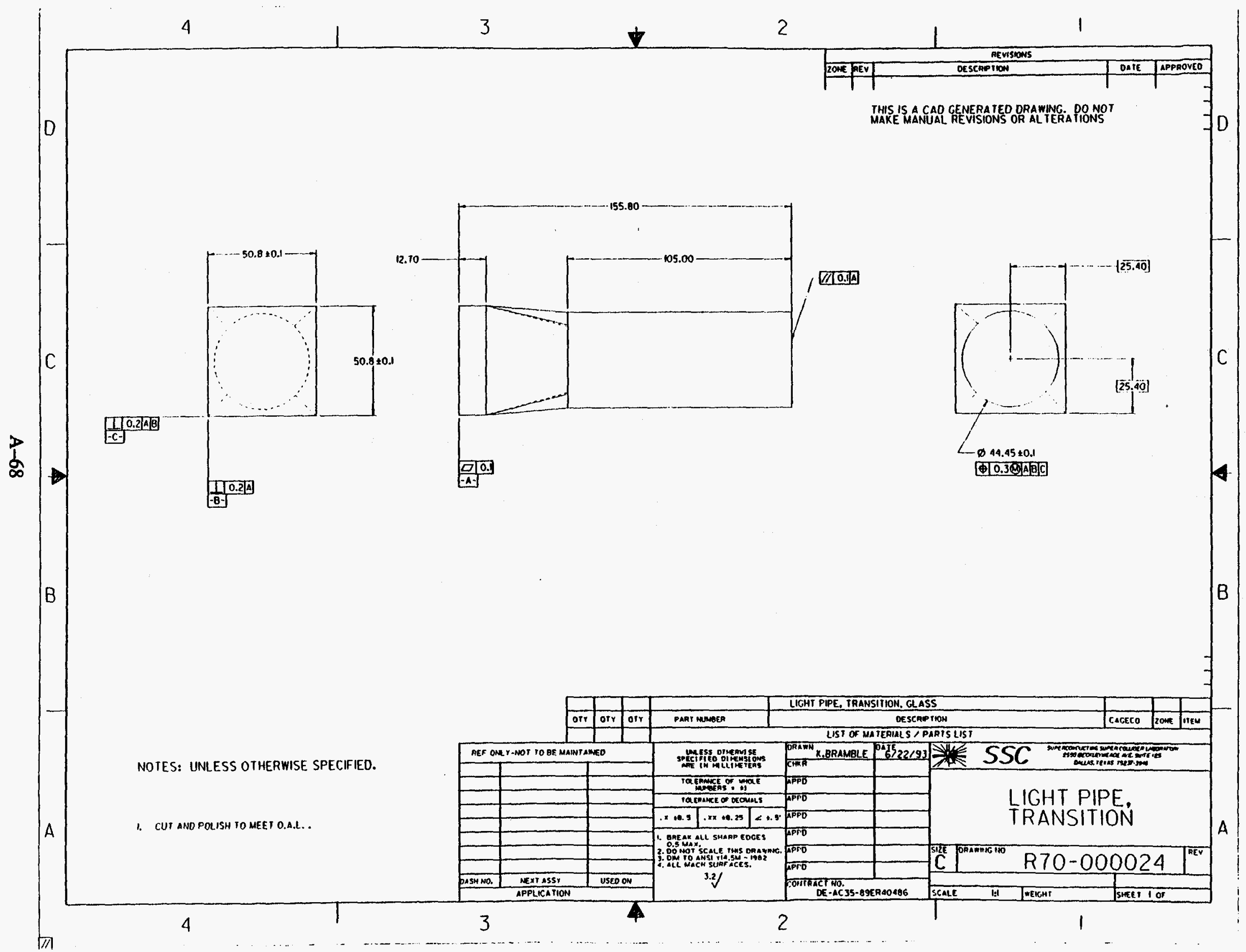




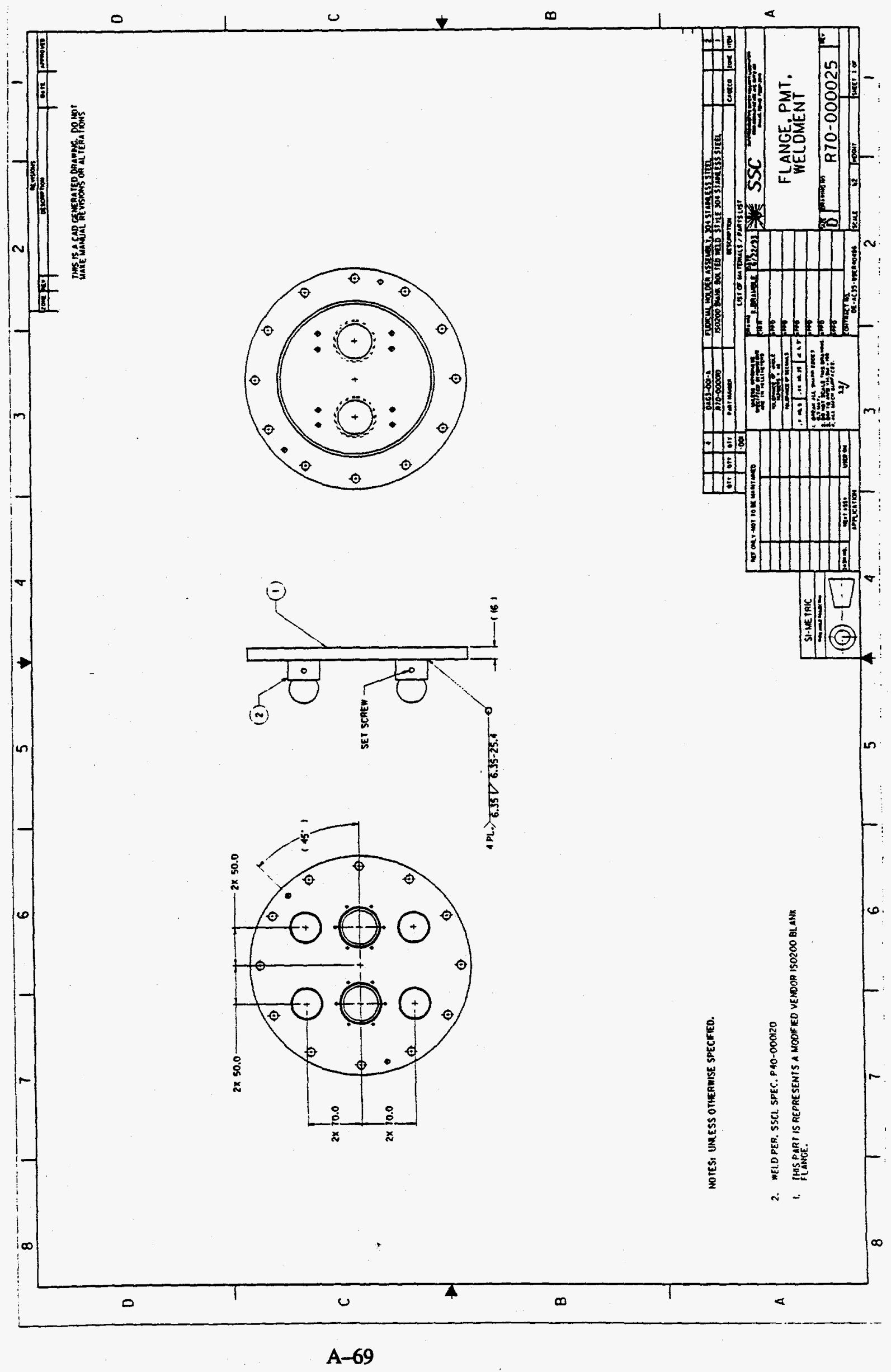




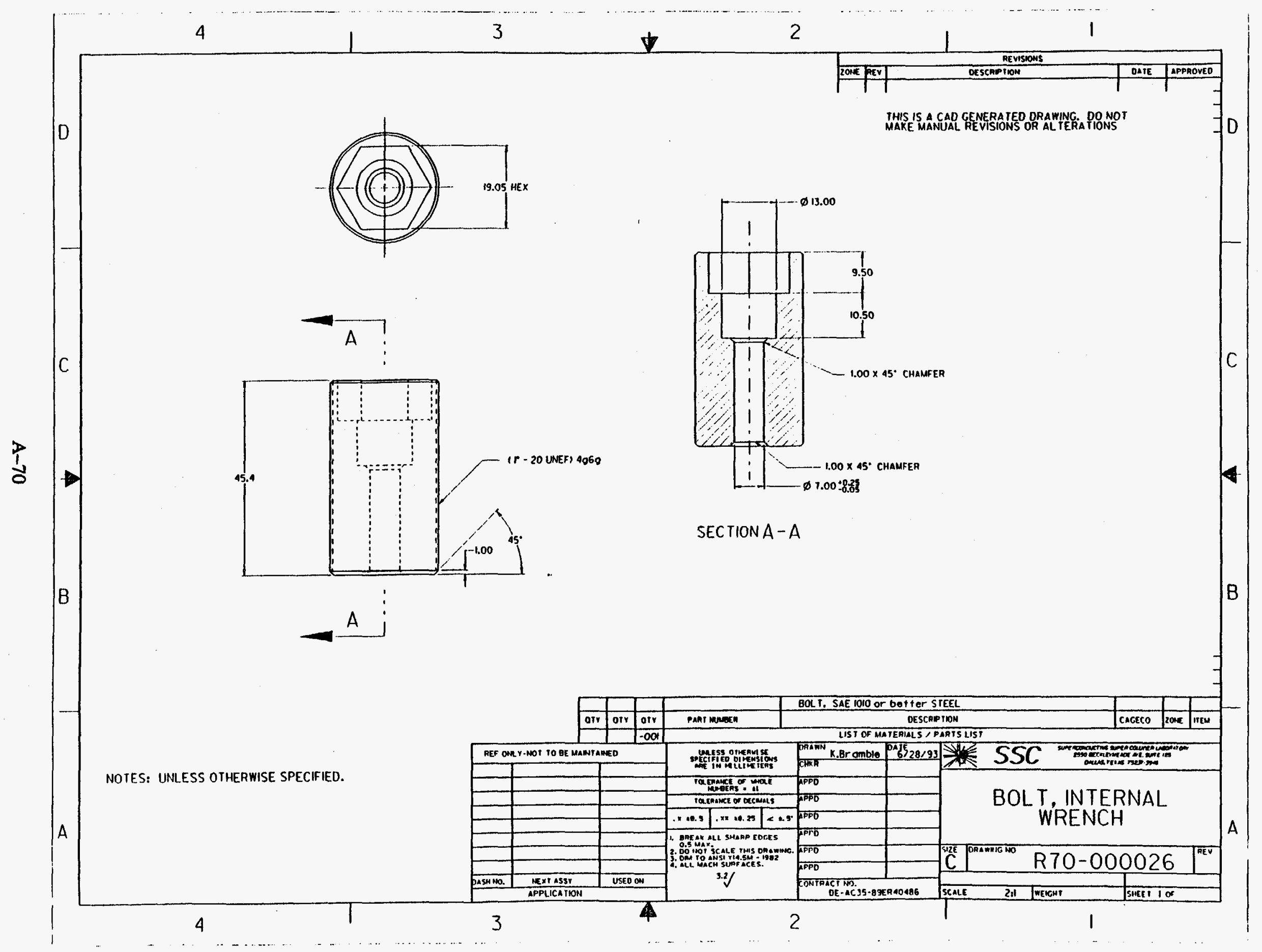




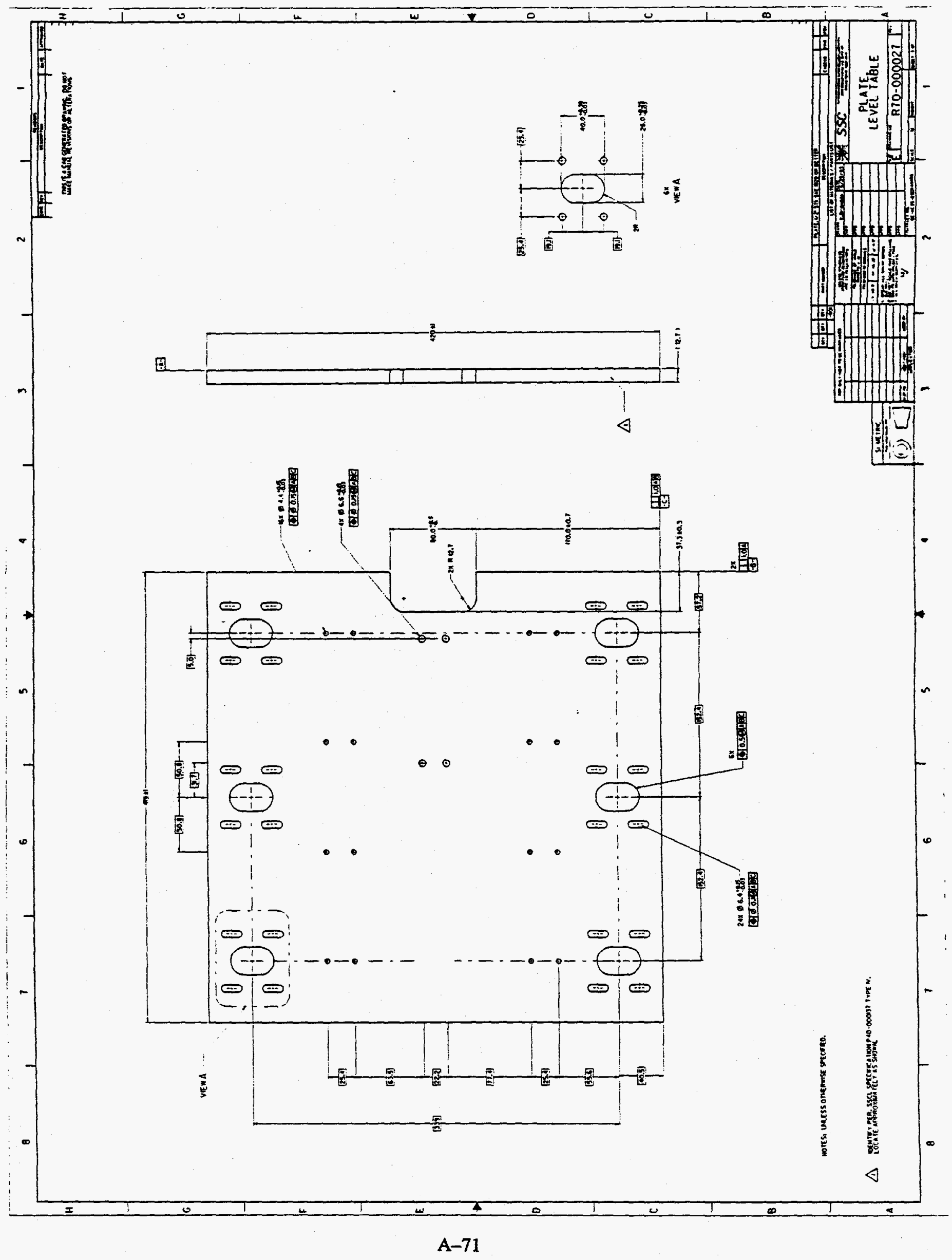




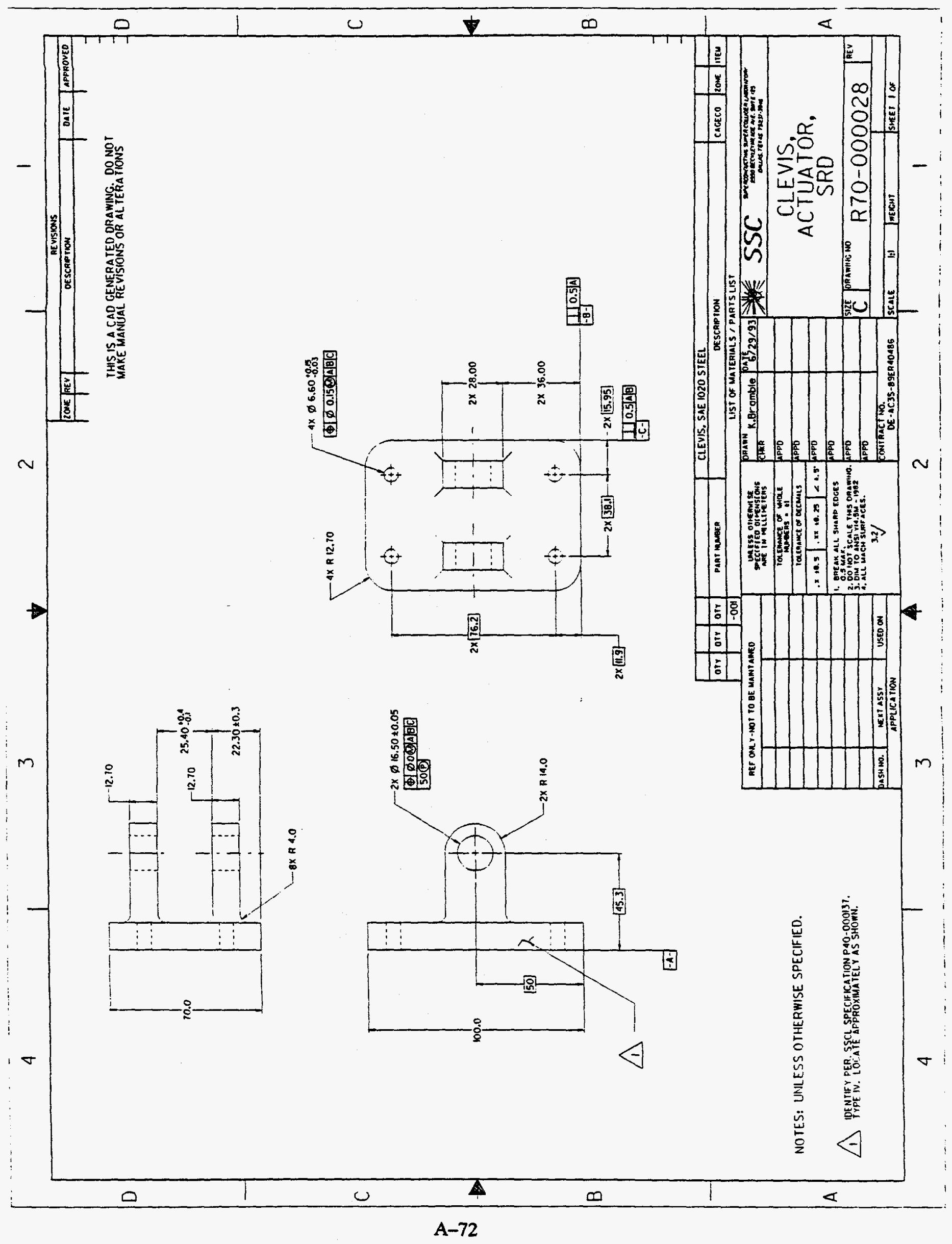




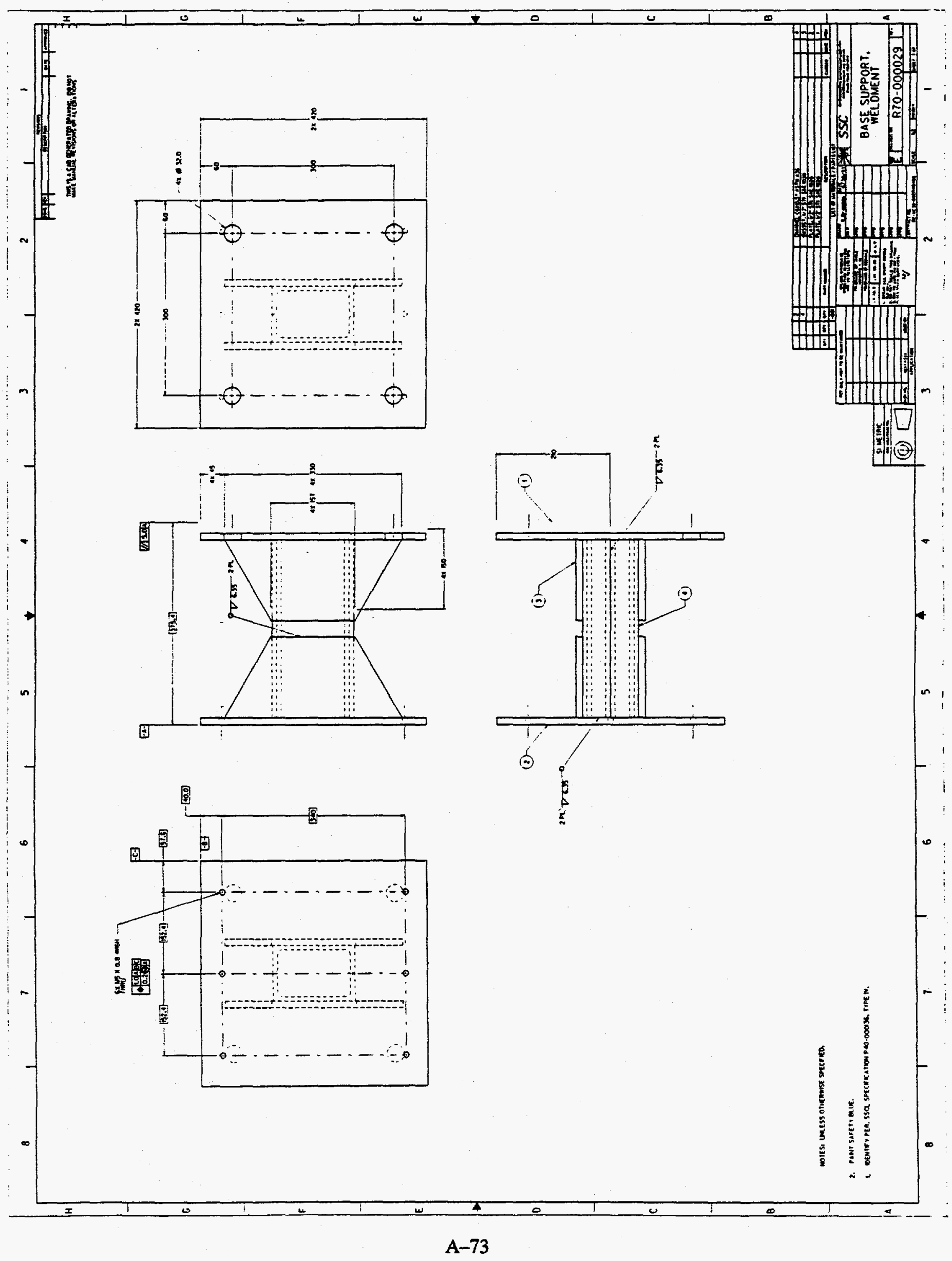




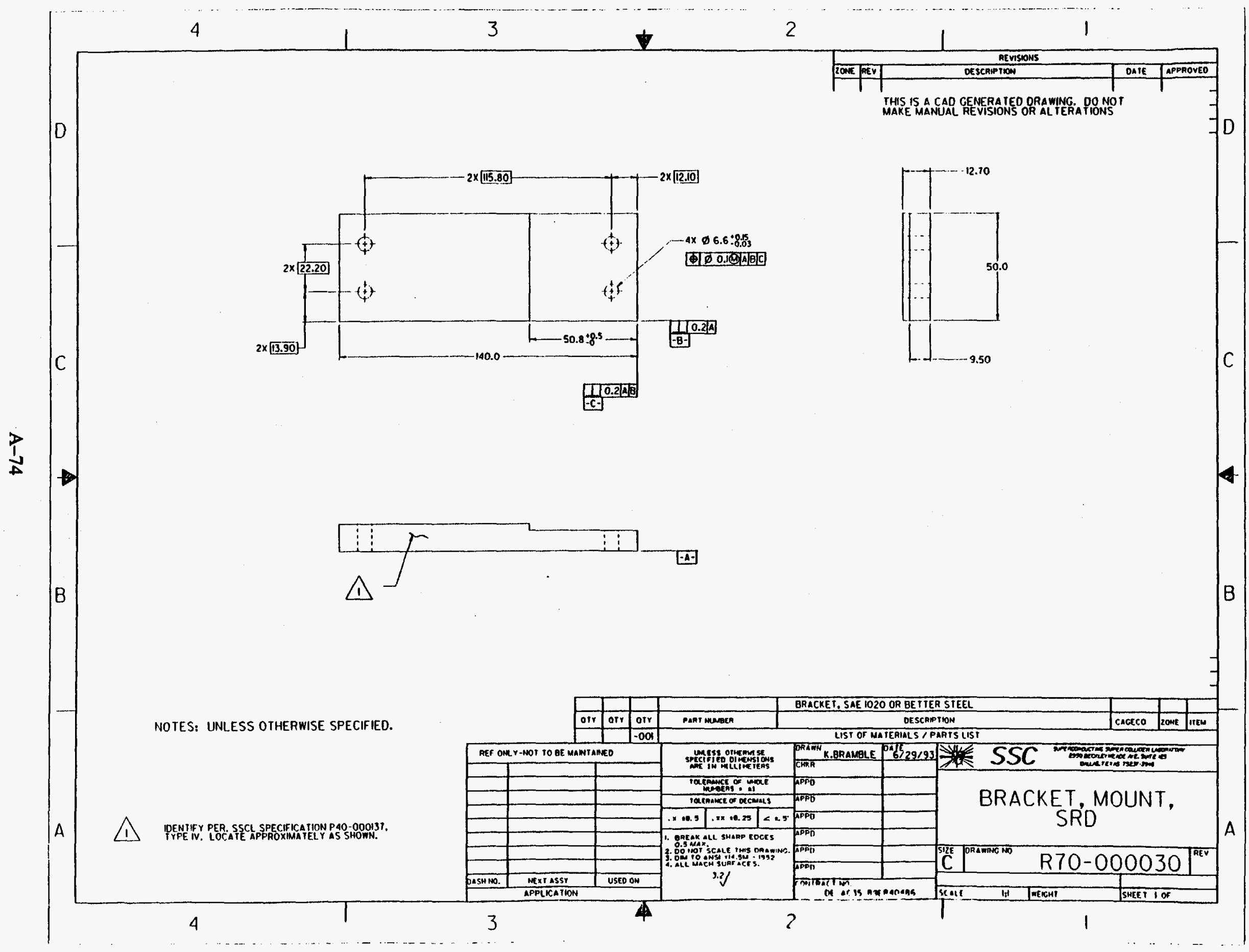




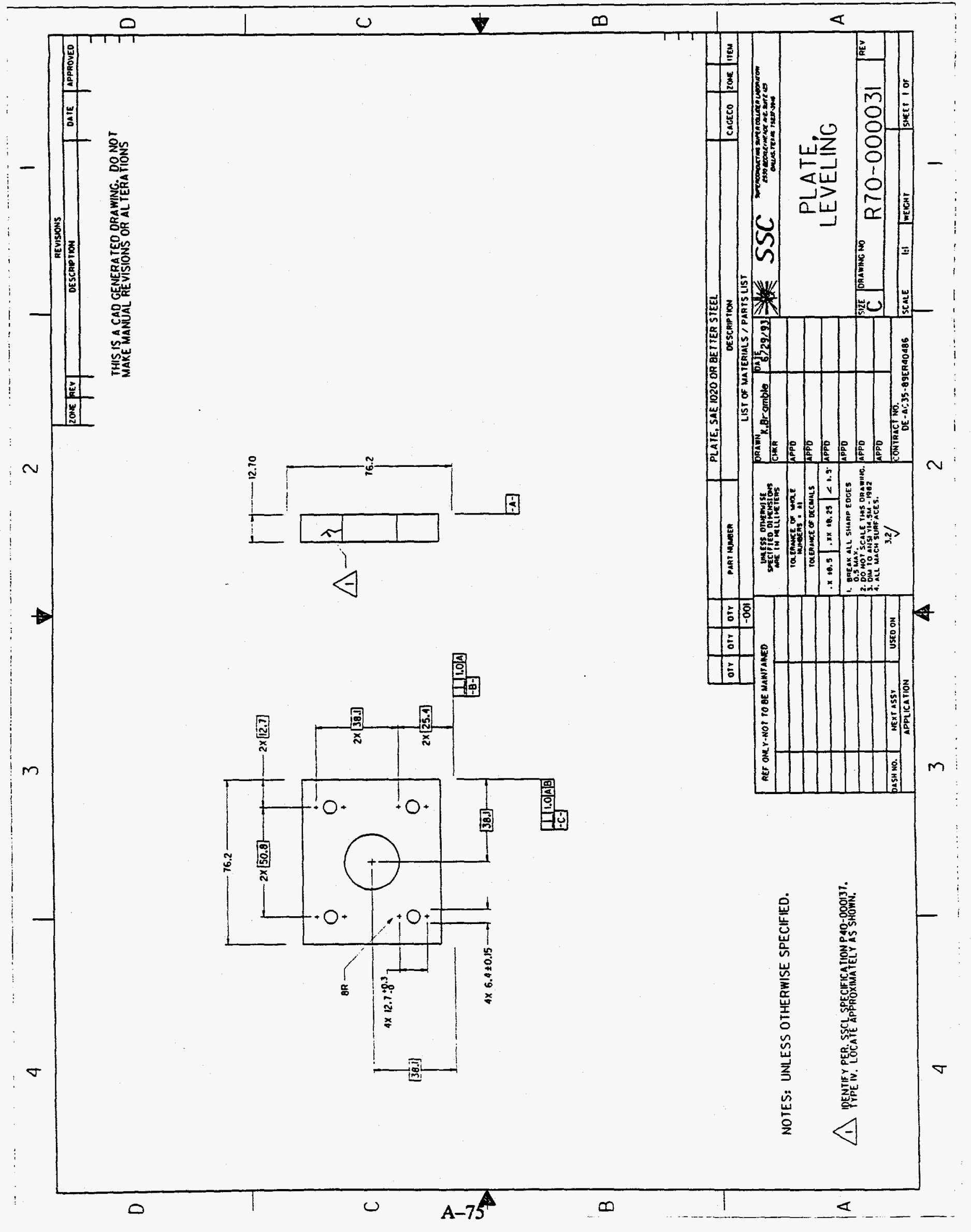





\section{Test Plan for SRD Chamber/Light Pipe Seal}

I. Scope

This test is to determine the effectiveness of an unlubricated $O$-ring crush seal used against an acrylic light pipe to be used in the Synchrotron Radiation Detector of the test beam region of the SSCL. The test sequence will examine three areas of concern: a) the leak tightness of the seal design itself, b) the frictional load capacity of the O-ring seal to hold the light pipe in position against the forces of atmospheric pressure, c) any damage of the light pipe from the crush seal, specifically mechanical deformation or chemical crazing.

II. Supporting Documentation

A. Copy of the test part drawings: VAC-0001 rev. A, $-0002,-0003,-0004,-0005$ rev. A, and -0006 .

III. Preparation

A. Inspection

Inspect all parts prior to assembly for burrs, nicks and scratches that could affect the sealing surfaces. Correct as necessary.

B. Cleaning

All parts should be cleaned prior to assembly using isopropyl alcohol and chem wipes to degrease all surfaces. Blow clean with dry nitrogen. Use gloves to prevent touching surfaces with hands after cleaning.

C. Assembly

Use gloves during assembly of $\mathrm{O}$-rings and light pipe to prevent contamination of surfaces.

1. Slip O-ring over light pipe and insert into seal plate (VAC-0004) such that the end of the light pipe is below the surface of the seal plate as shown in VAC-0001. Make certain that the $\mathrm{O}$-ring does not roll and is not twisted about its circumferential axis.

2. Install the PMT fiange (VAC-0003) over the light pipe and tighten the screws in a star pattern in increasing steps of torque. Check the position of the light pipe recess to the seal plate as the screws are tightened and note if the light pipe moved. Final torque on the screws is to be $4.5 \mathrm{~N}-\mathrm{m}$ ( $40 \mathrm{in}-\mathrm{lbs}$ ). 
3. Lubricate $\mathrm{O}$-ring for back plate (VAC-0005) with silicone high vacuum grease and install. Assemble to seal plate and tighten screws in star pattern as before with final torque of $4.5 \mathrm{~N}-\mathrm{m}$ ( $40 \mathrm{in}-\mathrm{lbs})$.

4. Record the dimension from the end of the light pipe to the parallel surface of the PMT flange. Record the date and time.

IV. Testing

A. Leak Check

1. Connect the test fixture to the leak detector: ALCTEL ASM 110 TURBO CL in the EFD vacuum lab.

2. Pump down the system to $5 * 10$ e-4 Torr.

3. Check the leak tightness of the assembly to helium and record the leak rate.

4. Compare the experimental data with the theoretical calculations.

B. Load Test

1. Check the dimension from the end of the light pipe to the parallel surface of the PMT flange to make certain the light pipe has not moved during the leak check test. If it has moved, note this and go to section $\mathrm{C}$.

2. Place assembly in the compression testing machine with the light pipe facing up. Support the assembly such that it will be stable as compressive load is applied to the light pipe.

3. Place a 2 inch diameter, $1 / 8$ inch thick aluminum bearing disk on the end of the light pipe. The disk should have at least a 16 mirco-inch rms finish on the side next to the light pipe.

4. Bring the head of the test machine down within 0.020 " of aluminum disk. Start the test cycle and record the load at which the light pipe begins to move.

C. Damage Test--Short Term

1. Immediately after the load test above, remove the PMT flange and the light pipe from the assembly. Note the date and time.

2. Visually inspect the light pipe for signs of indentation or crazing of the light pipe and record observations. 
D. Repeat Testing in sections A and B on Sample 2

1. Disassemble and clean vacuum grease from the fixture. Reassemble fixture as detailed in section III above.

2. Repeat the tests of subsections $A$ and $B$ as detailed in this section. DO NOT repeat subsection $C$, but instead proceed to subsection $E$ below.

E. Damage Test--Long Term

1. After second load test allow fixture to sit at room temperature for a period of 6 weeks under vacuum before disassembling.

2. After the settling period has expired, remove the PMT flange and the light pipe from the assembly. Note the date and time.

3. Visually inspect the light pipe for signs of indentation or crazing and record observations. 



\title{
LEAK TEST THE OF O-RING CRUSH SEAL DESIGN FOR SRD CHAMBER/LIGHT PIPE
}

\author{
Sanyi Zheng \\ Physics Research Division \\ EFD Vacuum Group \\ September 21, 1993
}

\section{SCOPE}

This test is a part of an experiment to determine the effectiveness of an un-lubricated O-ring crush seal used in conjunction with an acrylic light pipe. The light pipe is a part of a subassembly of the Synchrotron Radiation Detector to be installed in the test beam region of the SSCL. The purpose of the test is to check the leak tightness of O-ring seal design.

\section{SUPPORTING DOCUMENTATION}

Copy of the test part drawings: VAC-0001 rev.A, $-0002,-0003,-0004,-0005$ rev.A, and -0006 .

\section{PREPARATION}

Powder free vinyl gloves were used during inspection, cleaning, and assembly to prevent contamination of the parts.

1 Inspection

Before assembly, all parts were inspected. There were no visible scratches, nicks, and burrs that affected the sealing surfaces.

$2 \quad$ Cleaning

All parts were chemically cleaned by using isopropyl alcohol prior to assembly. After blowing with dry nitrogen, a visual inspection was made on each part especially sealing surfaces. Any piece showing water marks, stains, or chemical residue was recleaned.

\section{Assembly}

a) An O-ring was slipped over the light pipe and inserted into the seal plate (VAC0004) such that the end of the light was below the surface of the seal plate as shown in VAC-0001. The O-ring did not roll and was not twisted about its axis.

b) The PMT flange (VAC-0003) was installed over the light pipe and the screws were tightened in a cross pattern in increasing steps of torque. Checked the position of the light pipe recess to the seal plate as the screws were tightened and noted if the light pipe moved. Final torque on the screws was $4.5 \mathrm{~N}-\mathrm{m}$ (40 in-lbs).

c) Lubricated O-ring for back plate (VAC-0005) with silicone high vacuum grease and installed. Assembled to seal plate and tightened screws in a cross pattern as before with a final torque of $4.5 \mathrm{~N}-\mathrm{m}(40 \mathrm{in}-\mathrm{lbs})$. 


\section{LEAK CHECK}

\section{Equipment}

\section{ALCTEL ASM 110 TURBO CL Helium Leak Detector}

\section{Procedure}

a) Connected the test fixture to the leak detector in the EFD Vacuum Lab (clean room environment)

b) Pumped system down to below $5 \times 10^{-4}$ Torr.

c) During the leak test, the helium nozzle was directed at the gap between light pipe (VAC-0002) and PMT flange (VAC-0003), allowing helium gas to enter the gap and reach the O-ring seal.

d) Set the Helium sensitivity selector range on $3 \times 10^{-8} \mathrm{Atm}-\mathrm{cc} / \mathrm{sec}$.

e) The test piece was sprayed with helium for 15 seconds. A positive deflection of less than 0.4 was noted on the leak detector with the range set at $10^{-8} \mathrm{Atm}-\mathrm{cc} / \mathrm{sec}$. The test piece is found to be leak tight

f) Disassembled and cleaned vacuum grease from the fixture. Reassembled fixture as detailed in section III above by using a new O-ring.

g) Repeated the test described in this subsection from a) through $\mathrm{f}$ ). 


\section{SUMMARY \\ $1 \quad$ TEST \#1}

Time:

Performed By:

Participant:

Equipment:

Vacuum:

Leak Sensitivity

Selector Range:

Background Reading

from the Meter.

The Reading after one minute:

Deflection:

Conclusion:
13:30, September 8, 1993

Sanyi Zheng, Kim Chapman

Kelly Bramble, Howard Fender, and Ken Schlindwein

AICTEL ASM 110 TURBO CL Helium Leak Detector

$<1 \times 10^{-4}$ Torr

$3 \times 10^{-8}$ Atm-cc/sec

$0.8 \times 10^{-8} \mathrm{Atm}-\mathrm{cc} / \mathrm{sec}$

$1.0 \times 10^{-8} \mathrm{Atm}-\mathrm{cc} / \mathrm{sec}$

$(1.0-0.8) \times 10^{-8} \mathrm{Atm}-\mathrm{cc} / \mathrm{sec}$ $=0.2 \times 10^{-8} \mathrm{Atm}-\mathrm{cc} / \mathrm{sec}<0.4 \times 10^{-8} \mathrm{Atm}-\mathrm{cc} / \mathrm{sec}$

THE LEAK TIGHTENESS IS APPROVED 
2 TEST \#2

Time:

08:20, September 13, 1993

Performed By:

Sanyi Zheng, Kim Chapman

Participant:

None

Equipment:

ALCTEL ASM 110 TURBO CL Helium Leak Detector

Vacuum:

$<1 \times 10^{-4}$ Torr

Leak Sensitivity

Selector Range:

$3 \times 10^{-8} \mathrm{Atm}-\mathrm{cc} / \mathrm{sec}$

Background Reading

from the Meter.

$0.1 \times 10^{-8} \mathrm{Atm}-\mathrm{cc} / \mathrm{sec}$

The Reading after

One Minute:

$0.3 \times 10^{-8} \mathrm{Atm}-\mathrm{cc} / \mathrm{sec}$

Deflection:

$(0.3-0.1) \times 10^{-8} \mathrm{Atm}-\mathrm{cc} / \mathrm{sec}$

$=0.2 \times 10^{-8} \mathrm{Atm}-\mathrm{cc} / \mathrm{sec}<0.4 \times 10^{-8} \mathrm{Atm}-\mathrm{cc} / \mathrm{sec}$

Conclusion:

THE LEAK TIGHTNESS IS APPROVED 


\title{
Load and Damage Test Results for SRD Light Pipe Seal
}

\author{
B. Load Test
}

1. Verification

The dimensions from the end of the light pipe to the parallel surface of the PMT flange were re-measured and no movement of the light pipe was measured due to the vacuum loading during the leak test.

2. Setup

The light pipe assembly was placed between the compression test platens of the Instron machine of the Magnet Systems Division's Test Department. The surface finish of the platens was acceptable such that a bearing disk was not needed.

The platen was lowered and a series of compression tests were run on each sample. The load rate of the first sample was about $8.9 \mathrm{lbs} / \mathrm{min}$ up to a maximum of $300 \mathrm{lbs}$ with a maximum platen travel speed of $0.020 \mathrm{in} / \mathrm{min}$. The load rate of the second sample was increased to $20 \mathrm{lbs} / \mathrm{min}$ up to the maximum of $300 \mathrm{lbs}$ and a platen speed maximum of $0.080 \mathrm{in} / \mathrm{min}$

3. Results

\section{a. Sample 1}

On the first run, the load/deflection curve showed a steady compression of the $\mathrm{O}$-ring up to $35 \mathrm{lbs}$ at which there was a gross $0.015 \mathrm{in}$. movement under very little load. This is believed to be rolling of the $\mathrm{O}$-ring in the groove and the deformation curves of all runs were consistent in this feature. Once the gross deflection had settled the load increased nearly linearly up to $80 \mathrm{lbs}$. at which point the test was suspended to check for permanent movement.

The second run showed a $0.005^{\prime \prime}$ permanent set which might have relaxed back over time. The load in this run was steadily increased until stick-slip movement of the light pipe began to take place. Stick-slip started at $115 \mathrm{lbs}$ and became very prominent at the $150 \mathrm{lb}$. level.

The third run started with a 0.015 in. permanent set from the previous stickslip motion. Stick-slip motion did not commence until 175 lbs. 


\section{b. Sample 2}

On the first run the characteristic plateau of the rolling of the O-ring occurred at the same load as did sample 1. The load on this sample was increased up to $200 \mathrm{lbs}$. at which point the test was suspended to check for permanent deflection. A 0.030 in. permanent deflection was found. Since no stick-slip motion was detected during the test it is assumed that the load rate and platen travel speed were sufficiently high enough to keep the load increasing even though slippage was occurring.

The load/deflection curve was identical on the second run with the maximum load of $300 \mathrm{lbs}$. being achieved. Again a large permanent set was found upon relaxation of the load. A 0.025 in. deflection was measured.

The third run was used only to find the amount of permanent deflection incurred during the second run.

c. Conclusions of the Load Test

The load carrying capacity of the of O-ring seal agrees with the calculated estimates. It is certain to provide the capability of preventing the lightpipe from being sucked into the vacuum chamber and causing a catastrophic failure. It does not however, provide the rigidity required for precision registration of the NaI crystal or the scintillating plastic. This requires the addition of a load carrying clamp to secure the light pipe in a position whose integrity can be insured regardless of load conditions. The O-ring will undoubtedly perform its primary duty of providing a vacuum seal and will serve as a backup load carrying member should the clamp system fail.

\section{Damage Test--Results--Short Term: Sample 1}

1. Shortly after the load test above, the PMT flange and the light pipe were disassembled. The assembly had been together for 71 hours.

2. A visual inspection of the light pipe showed a slight signature of the location of the O-ring. The O-ring appeared to have brinnelled the surface asperities where it was installed which resulted in a better surface finish or a highly polished line where contact was made. No indentation nor any chemical crazing was observed at the O-ring location. Therefore, no short term damage was found.

D. Repeat Testing on A and B on Sample 2

1. The test fixture was disassembled and cleaned. It was reassembled per section II 
above.

2. The vacuum test and load test were repeated on sample 2. The results are contained in those sections for continuity of discussion.

\section{E. Damage Test--Results--Long Term}

1. The fixture was attached to the mechanical vacuum pump in the Experimental Physics and kept under vacuum for 6 weeks and two days. During that time the SSC project was canceled (Bastards) and the fixture has set idle at room conditions for just over two and a half months.

2. Disassembly of the fixture revealed that the $\mathrm{O}$-ring had adhered to the light pipe at the "foot print" of the contact area. It required very light pressure to break to the bond which revealed a bright, shinny surface similar or slightly better in finish than the original finish. On either side of the O-ring however, the surface had crazed substantially up to the points where the aluminum surfaces stopped. The crazing was heaviest adjacent to the shinny line and lessened as the edges of the aluminum were reached.

3. The vacuum side showed very little difference from the atmosphere side. The vacuum grease may have provided a surface coating that prevented crazing under the O-ring. A test of multiple O-ring compounds is in order. Sandwiching several $O$-rings between to acrylic plates should provide a comparison on the crazing of their inner volumes and give a suitable compound.

4. The surface of the light pipe was not indented and therefore mechanical damage of the light pipe is not an issue. The seal is successful pending an acceptable $\mathrm{O}$ ring compound. This $\mathrm{O}$-ring was a 75 durometer hardness and an 0-ring of 60 to 80 durometer should be mechanical adequate. 
SAMPLE 1

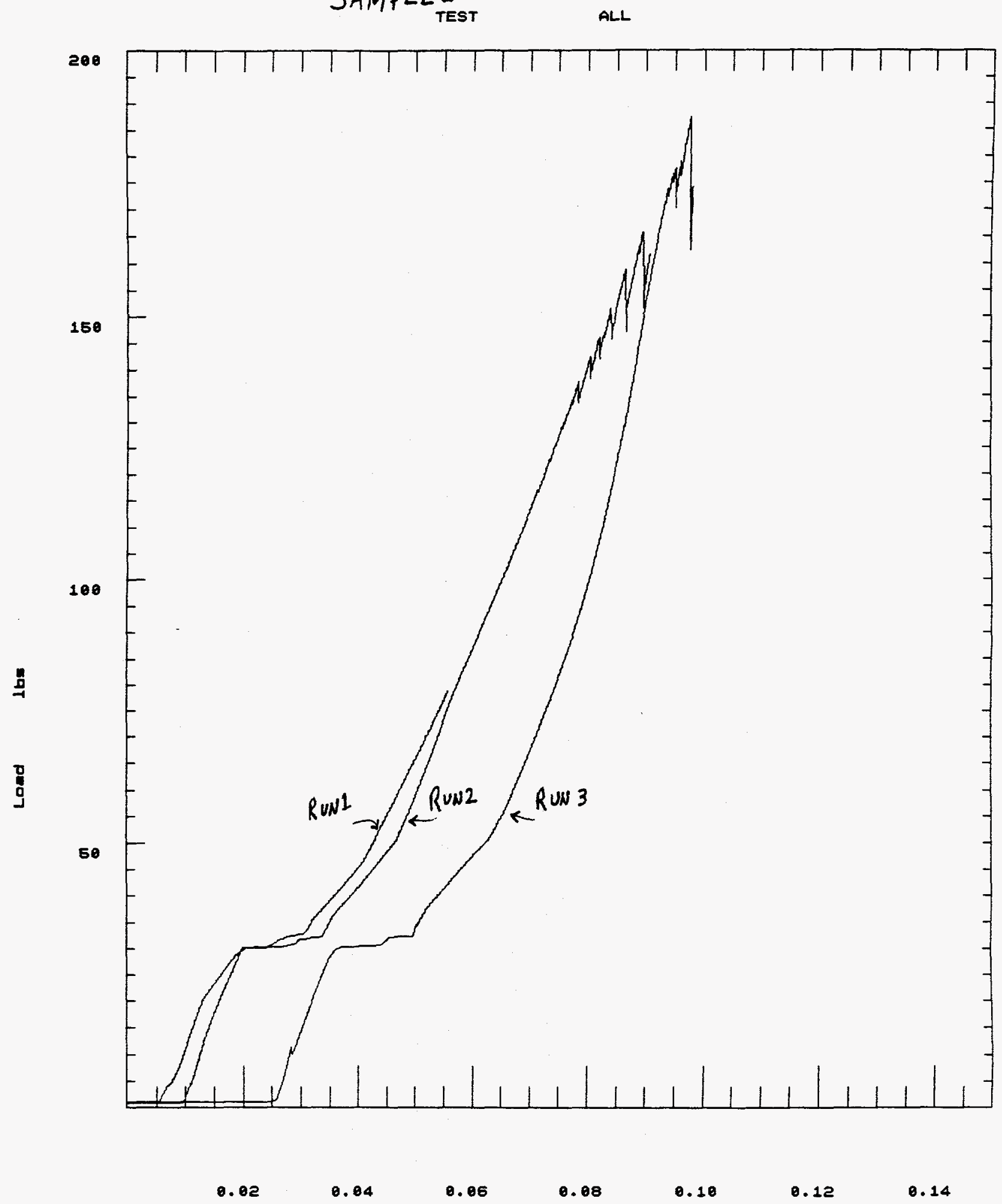

Displacement (in) 


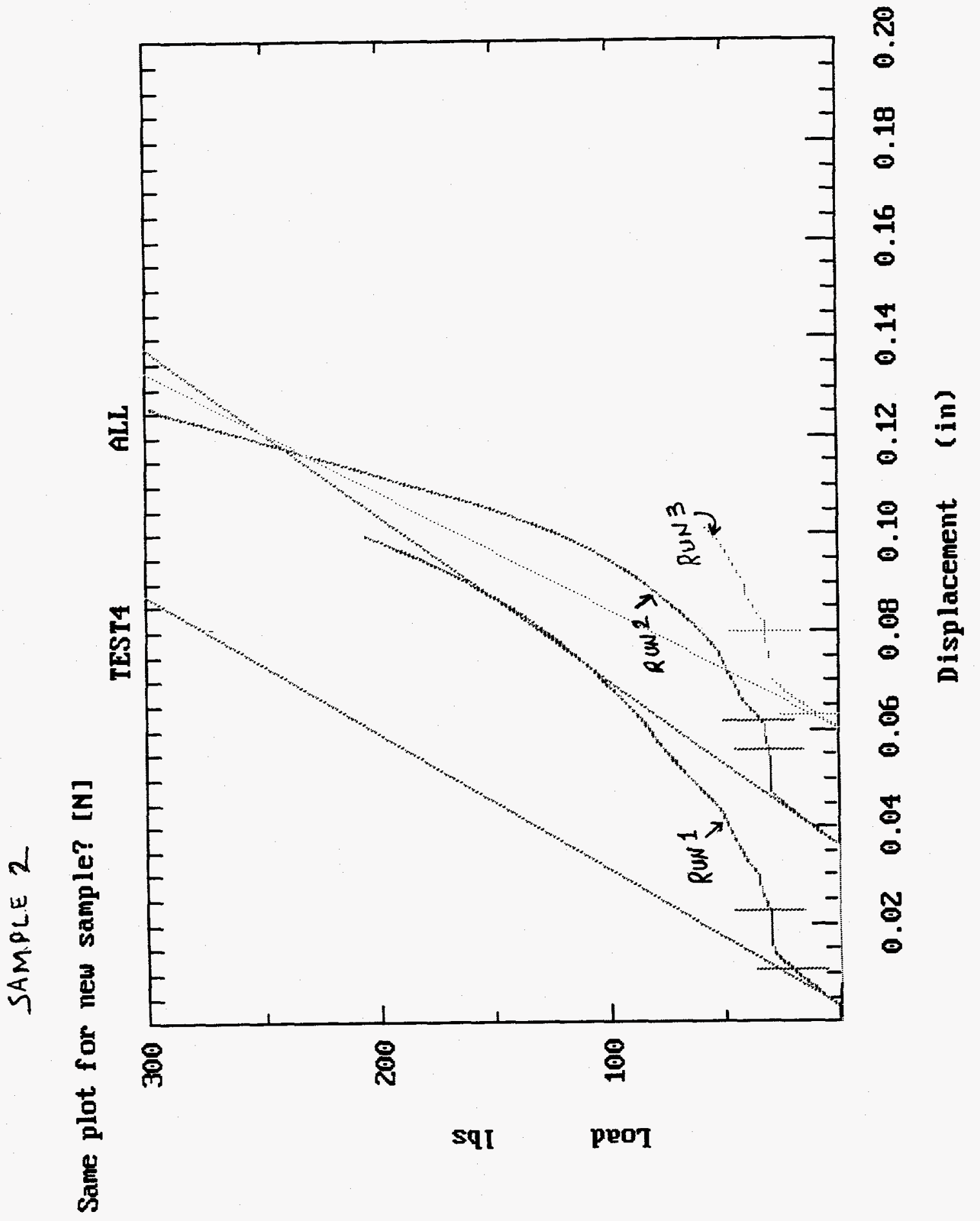



SYNCHROTRON RADIATION DETECTOR

Test Apparatus Lightpipe Seal

Directory Location - /home/nova/prd/kelly/vacuum/test

Files--

File

test.mod

vac0001

vac0002

vac0003

vac0004

vac0005

\section{Description}

Solid Model Assembly

Test Fxture Assembly

Glass Light Pipe

Flange, PMT

Plate, Seal

Plate, back 


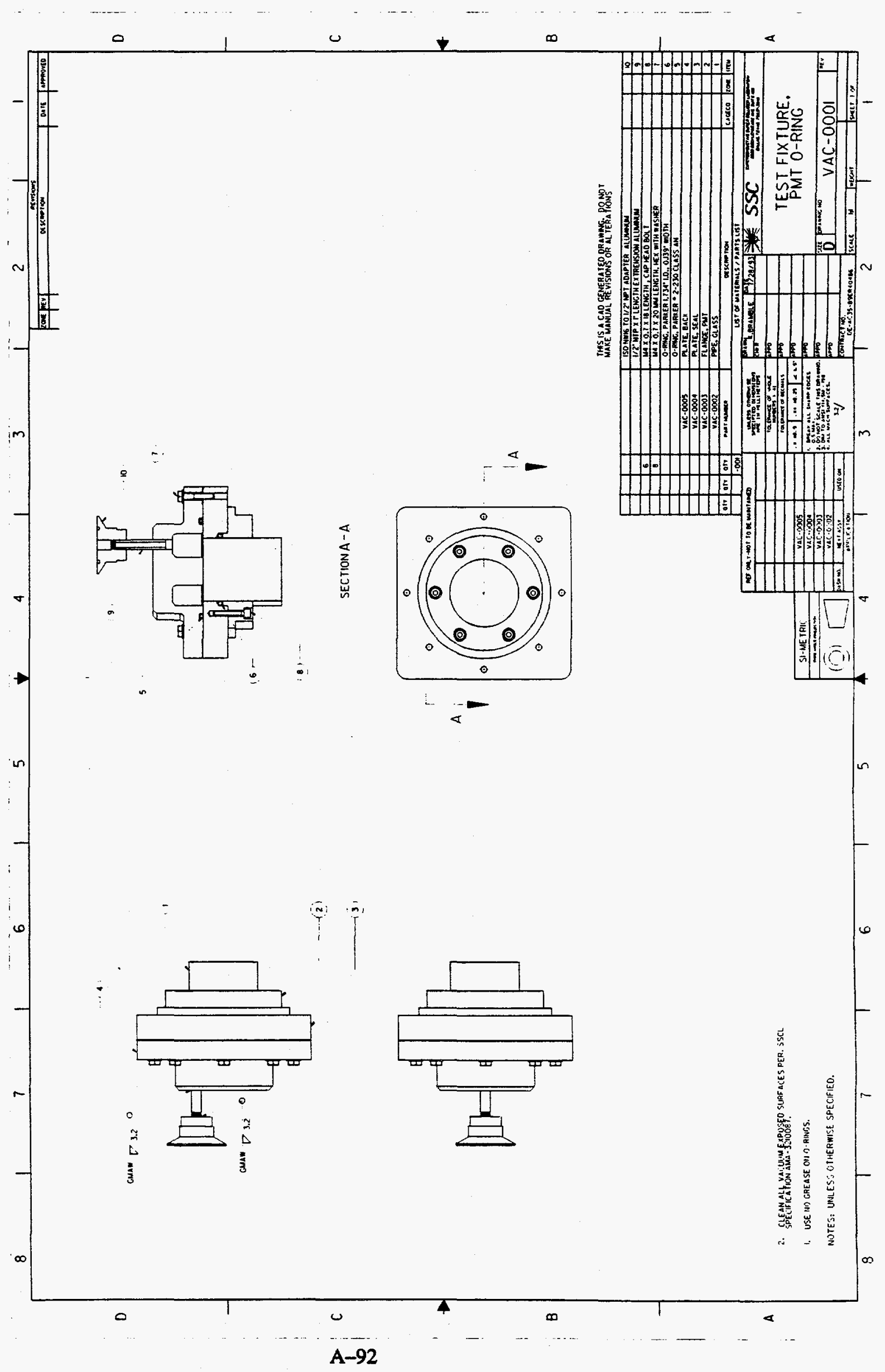




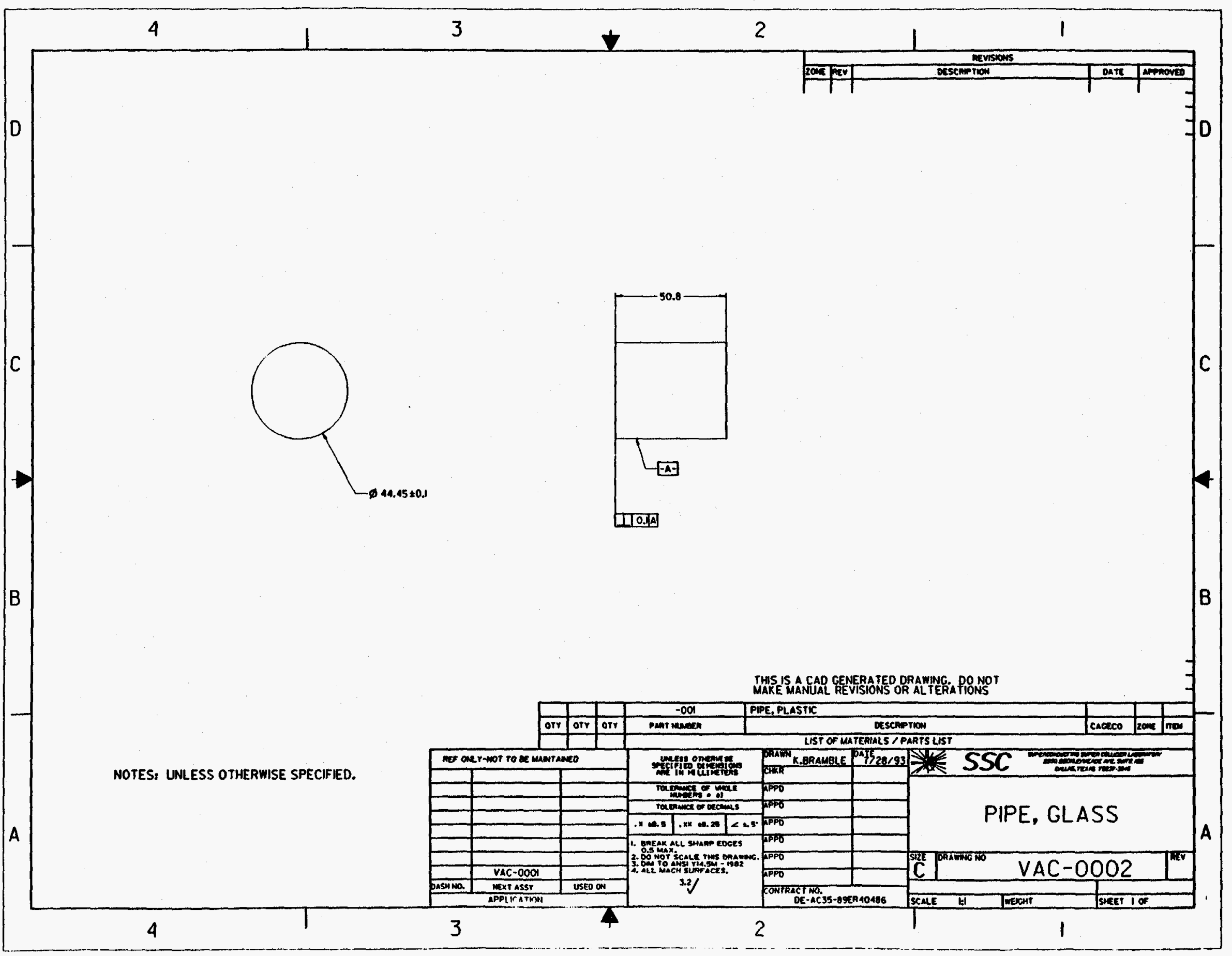




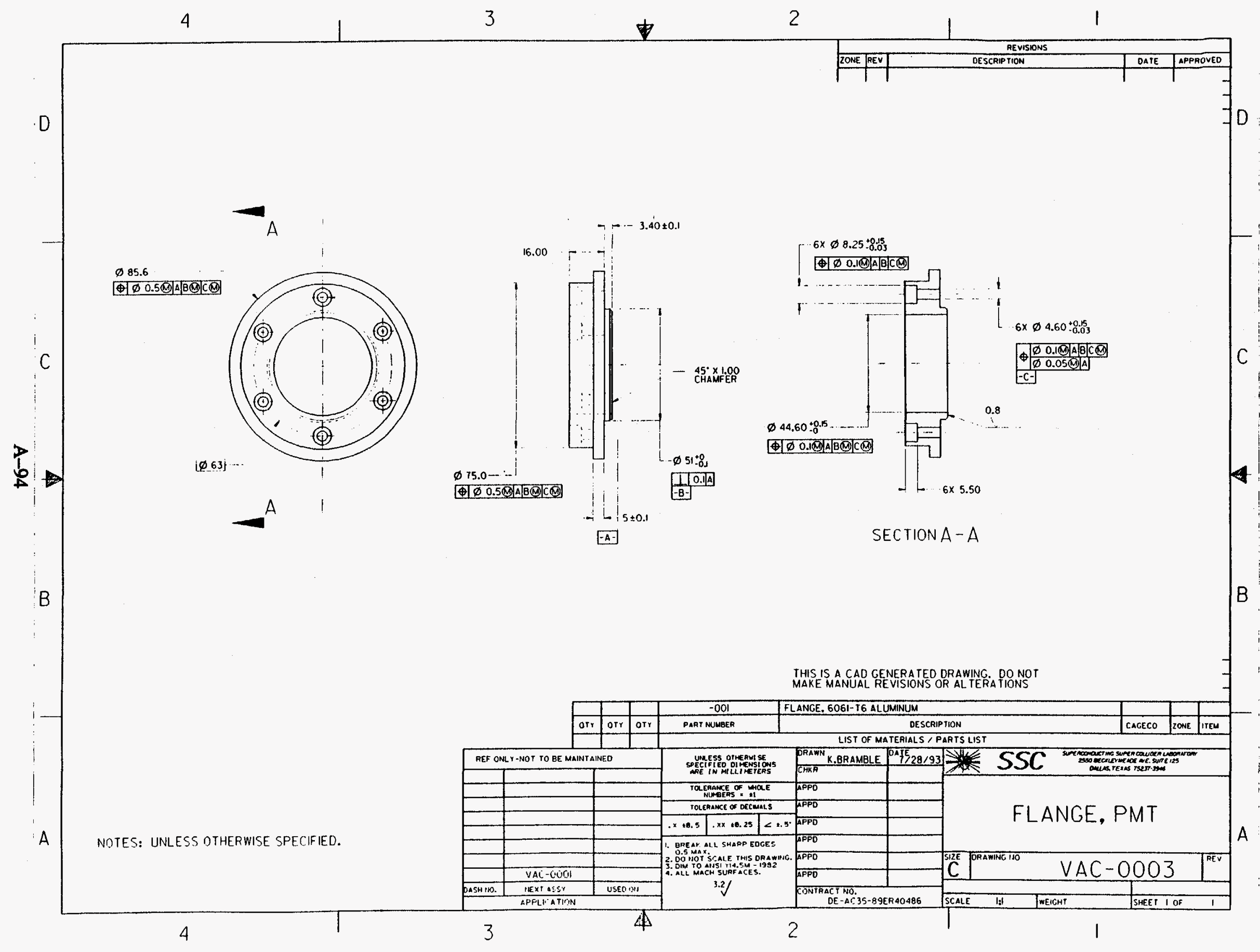




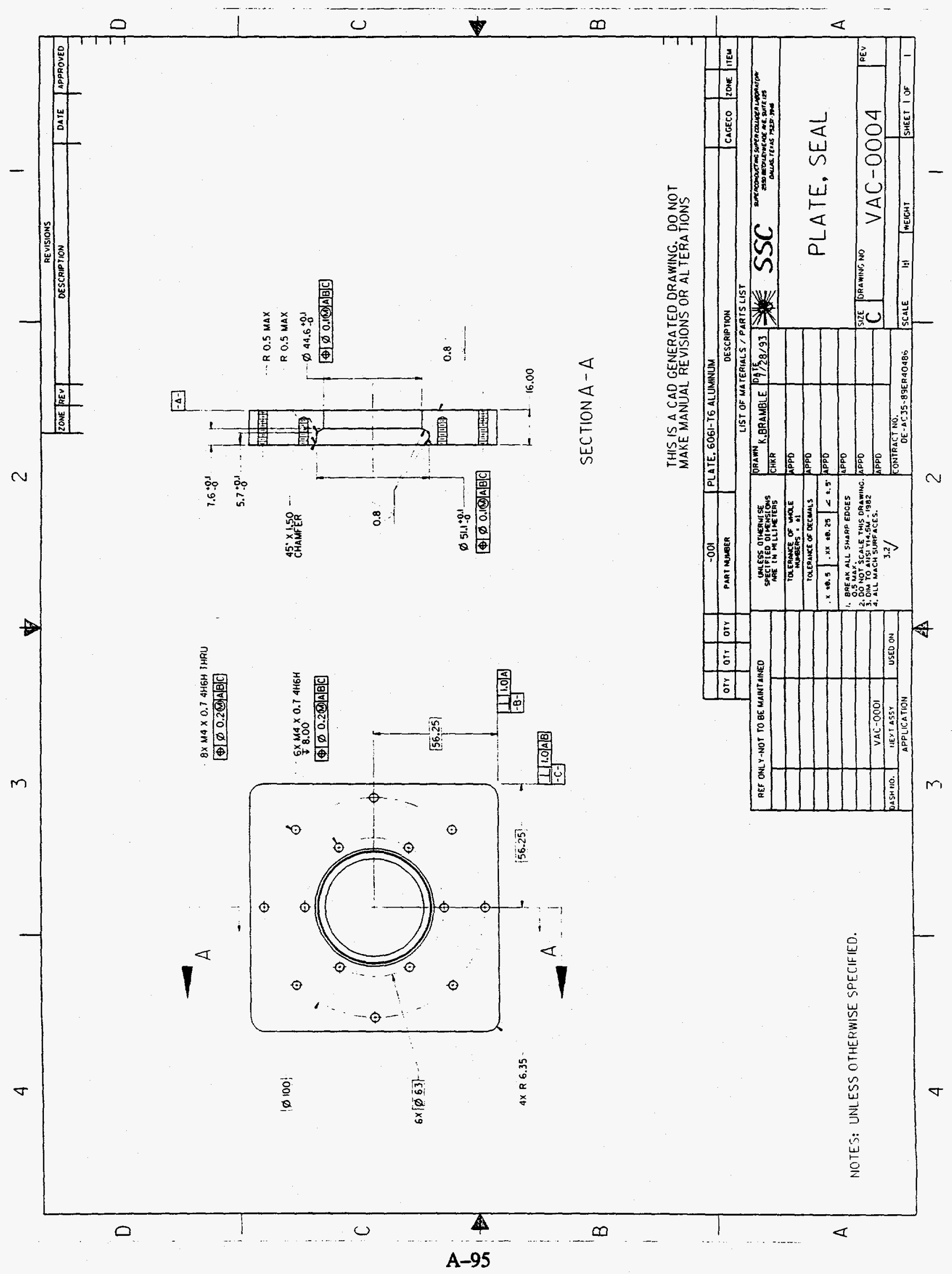




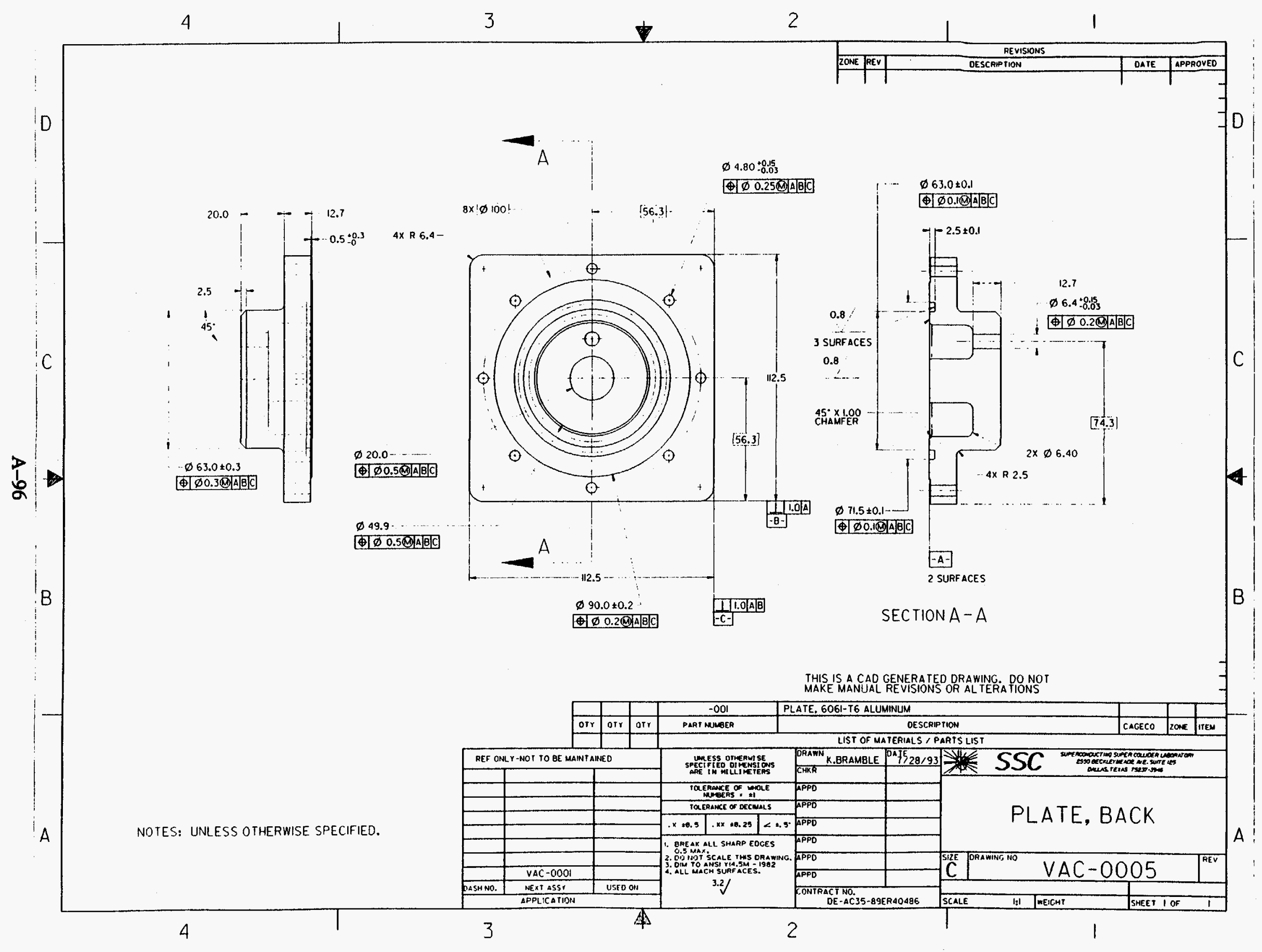

